University of Michigan Law School University of Michigan Law School Scholarship Repository

2019

\title{
Alpha Duties: The Search For Excess Returns and Appropriate Fiduciary Duties
}

Ian Ayres

YaleLawSchool, ian.ayres@yale.edu

Edward Fox

University of Michigan Law School, edfox@umich.edu

Available at: https://repository.law.umich.edu/articles/2033

Follow this and additional works at: https://repository.law.umich.edu/articles

Part of the Estates and Trusts Commons, and the Securities Law Commons

\section{Recommended Citation}

Ayres, Ian. "Alpha Duties: The Search For Excess Returns and Appropriate Fiduciary Duties." Edward Fox, co-author. Tex. L. Rev. 97, no. 3 (2019): 445-515.

This Article is brought to you for free and open access by the Faculty Scholarship at University of Michigan Law School Scholarship Repository. It has been accepted for inclusion in Articles by an authorized administrator of University of Michigan Law School Scholarship Repository. For more information, please contact mlaw.repository@umich.edu. 


\title{
Alpha Duties: The Search for Excess Returns and Appropriate Fiduciary Duties
}

\author{
Ian Ayres* and Edward Fox ${ }^{* *}$
}

Modern finance theory and investment practice have shifted toward "passive investing." The current consensus is that most savers should invest in mutual funds or ETFs that are (i) well-diversified, (ii) low-cost, and (iii) expose their portfolios to age-appropriate stock market risk. The law governing trustees, investment advisers, broker-dealers, 401 $(k)$ plan managers, and other investment fiduciaries has evolved to push them gently toward this consensus. But these laws still provide broad scope for fiduciaries to recommend that clients invest instead in specific assets that they believe will produce "alpha" by outperforming the market. Seeking alpha comes at a cost, however, in giving up some of the benefits of the well-diversified, low-cost, appropriate-risk baseline. Too little attention has been given in fiduciary law to this tradeoff and, thus, to when seeking alpha is prudent and beneficial for savers, and when it is not.

This Article begins to fill that gap by making two contributions. First, we provide the first benchmark estimates of how much alpha is required before ordinary investors would be better off departing from the consensus. For example, we estimate that a person of average risk aversion would annually need to beat the market by (i.e., obtain alpha of) between $6 \%$ and $15 \%$ before being willing to entirely forego the benefits of diversification and hold an individual stock (and that during a financial crisis such a person would need an annual alpha between $9 \%$ and 18\%). Second, we consider the implications of our results for the various branches of law governing investment fiduciaries. We propose generally that fiduciaries should prudently weigh these alpha tradeoffs, and then should explain them to their clients before recommending (or executing) investments that deviate from the low-cost, well-diversified, age-appropriate exposure standard. We argue that through new technology, this kind of

*William K. Townsend Professor, Yale Law School, ian.ayres@yale.edu.

** Assistant Professor, University of Michigan Law School, edfox@umich.edu.

The authors thank Greg Conyers, Samuel Dong, and Amen Jalal for excellent assistance. The authors also thank Ezra Friedman, John Langbein, Josh Mitts, Adam Pritchard, Roberta Romano, Max Schanzenbach, James Spindler, and workshop participants at the ALEA Conference, Yale, Michigan, Hebrew University, University of Texas, and Northwestern University for their helpful comments and suggestions. Finally, the authors thank the editors at the Texas Law Review for their hard work throughout the process.

Disclaimer: This Article discusses at various points "robo-advising." Neither author has received any support from any of the robo-advising firms, nor does either have any interest in such firms. Professor Ayres has, however, collaborated with a robo-advising site about the possibility of being compensated for helping the site add the "leveraged lifecycle" strategy he has advocated for elsewhere, see infra note 24. But Ayres has not received and currently has no plan of receiving any prospective remuneration for such work. 
information can be given to retirement savers and others at quite low cost. Our results also have a variety of more specific applications. For example, our work shows that the value of diversification increases during periods of market upheaval, and therefore the duty of trustees to diversify personal trusts and employee retirement plans should likewise strengthen during such periods. 


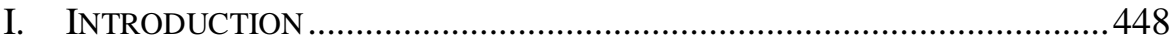

II. DisTINGUISHING BETWEEN MISTAKES AND TRADEOFFS ...................453

A. The Three Central Investment Mistakes..................................453

B. Three Alpha Investing Tradeoffs............................................459

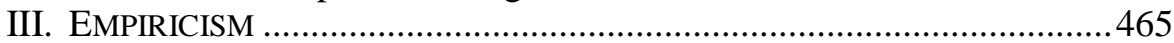

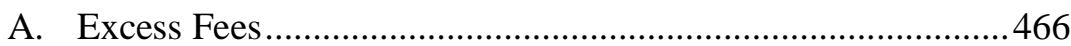

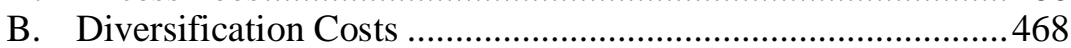

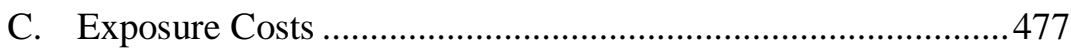

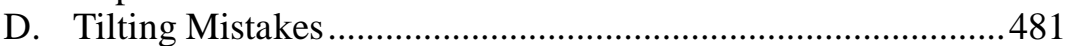

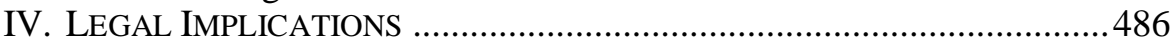

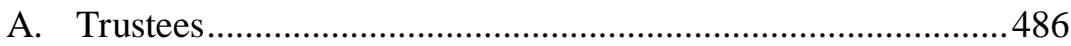

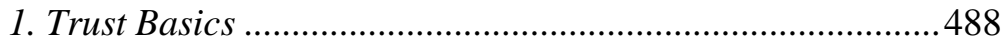

2. The Trustee's Fiduciary Duties ...........................................48 488

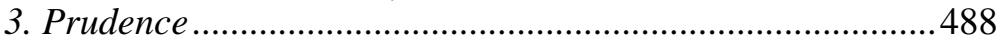

4. Subsidiary Duties: Prudent Diversification ..........................489

5. Subsidiary Duties: Prudent Exposure to Risky Assets..........494

6. Subsidiary Duties: Duty to Incur Only Reasonable Costs ..496

7. Subsidiary Duties: "Alpha Duties," aka Prudent Active

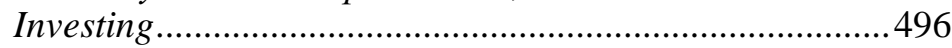

8. Some Answers to Practical Objections to Alpha Duties

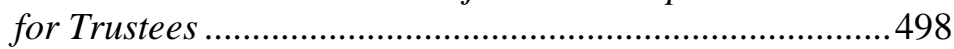
a. The Duties Require the Trustee to Gather Too Much

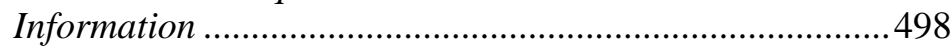
b. Reasonable Calculations Produce a Range of Offsetting Alphas, Rather than a Single Number................498

c. Imposing Alpha Duties Will Result in Too Many Suits..499

B. Registered Investment Advisers ............................................499

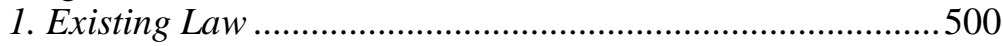

2. Incorporating Alpha Duties................................................500

3. Private Remedies Would Remain Limited Absent a

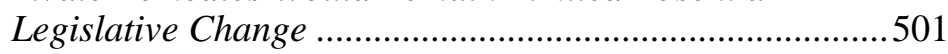

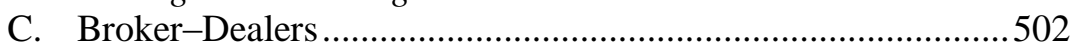

1. Existing Law ......................................................................504

a. Brokers' Suitability Obligations and the Duty of Care

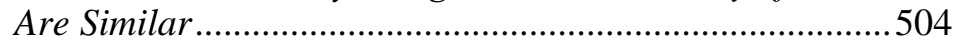

b. Regulation of Brokers' Potential Conflicts of Interest

Is Weaker than Advisers' Duty of Loyalty ..........................505

2. New Regulations Addressing Brokers' Conflicts of

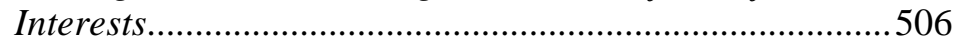

a. The DOL Fiduciary Rule …….....................................506

b. The SEC's Regulation Best Interest..............................507

3. Comparing the Two Rules and the Role of Alpha Duties ....508

4. Changing Licensing Testing ..............................................510

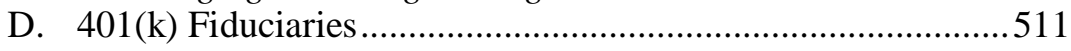

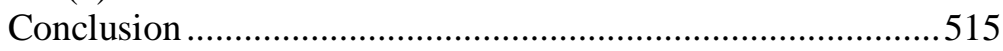




\section{Introduction}

Investment fiduciaries - like trustees, investment advisers, brokers, and 401(k) plan managers - help direct trillions of dollars of savings, including most of the nonhousing wealth of ordinary savers. ${ }^{1}$ Because these fiduciaries play a variety of roles in the investment process, no single body of law applies to all of them. Nevertheless, the fiduciary duties imposed by these different branches of law are aimed at a common problem: ensuring that savers' funds are invested prudently, with a level of risk appropriate for each investor's circumstances and earning the highest expected return given that level of risk. The question of how to invest prudently is often viewed by retail investors as daunting, but today's consensus is actually easily described: absent some opportunity to beat the market, one should invest in vehicles (such as mutual funds or ETFs) that are (1) well-diversified, (2) low-cost, and (3) expose one's portfolio to age-appropriate stock market risk. ${ }^{2}$ This consensus arose from decades of empirical and theoretical finance research. The laws governing investment fiduciaries have evolved to reflect this consensus and to push fiduciaries towards recommending (or executing) strategies consistent with it. There remains ample scope, however, for fiduciaries to recommend investing instead in specific assets that promise to deliver abovemarket returns. This is known in the argot of finance as "seeking alpha." Alpha investment opportunities often involve a tradeoff: investors gain expected excess returns but are required to sacrifice some of the benefits of diversification, low fees, or appropriate risk.

The laws governing fiduciaries have paid too little attention to identifying when seeking alpha is prudent, i.e., when the expected excess returns outweigh the costs of departing from the low-cost, diversified, appropriate-risk baseline. Indeed, we are not aware of any systematic attempts to provide estimates of how much alpha is needed to justify underdiversification costs or taking on the wrong level of market risk. Yet, these

1. As of 2014, approximately $\$ 4.4$ trillion was held in $401(\mathrm{k})$ accounts alone. EMP. BENEFITS SEC. AdMin., U.S. DEP'T LABOR, PRIVATE PENSION Plan Bulletin HistoricAl TABLeS AND GRAPHS 1975-2015, 31 tbl.E23 (2018). About 77\% of the nonhousing savings (and 63\% of total savings) of persons in the bottom $90 \%$ of the wealth distribution is held in some type of retirement account, the vast majority in accounts to which the fiduciary law contained in the Employee Retirement Income Security Act (ERISA) applies. See Thomas Piketty, Emmanuel Saez \& Gabriel Zucman, Distributional National Accounts: Methods and Estimates for the United States, 133 Q.J. ECON. 553, 579 fig. 2 \& app. II tbl.E2 (2018) (depicting the average pretax income of the bottom $90 \%$ and what types of assets compose the wealth of this group).

2. In fact, one of us has described it while standing on one leg. Ian Ayres, Concise Advice for Investing, While Standing on One Leg, FORBES (Jan. 30, 2016), https://www.forbes.com/sites /whynot/2016/01/30/hillel-investment-advice/\#60501a4b6b55 [https://perma.cc/9YCJ-GRSN]. It might be accomplished by simply investing your assets in a Vanguard target-date fund with the date you plan to retire.

3. The term "alpha" derives from the generic term for the intercept in the linear Capital Asset Pricing Model (CAPM) equation. See infra text accompanying note 29. 
estimates are necessary before one can rationally distinguish beneficial alpha seeking from the imprudent chasing of excess returns. Our first contribution in this Article is to provide a methodology for evaluating these costs and then to empirically estimate them. ${ }^{4}$

Our estimates of the required offsetting alpha are often substantial. For example, we calculate that an investor with average risk aversion would need to expect an annual alpha between $6 \%$ and $15 \%$ before being willing to entirely forego the benefits of diversification by holding only an individual stock. Moreover, during a period of market upheaval she would need to expect an alpha between $9 \%$ and $18 \%$. Alpha of this magnitude would easily more than double the risk premium normally paid on stock. ${ }^{5}$

Of course, most alpha opportunities are not so extreme as to necessitate investing solely in an individual stock. But some diversification is always sacrificed when investors adopt an alpha-seeking strategy. This is because the choice to concentrate one's investments in an alpha opportunity implies some movement away from the portfolio that would have best diversified risk. This results in the investor bearing some risk that is specific to the alpha investments - called "idiosyncratic risk"-which could otherwise have been diversified away. Even more modest departures from full diversification can, as we later show, impose substantial losses in alpha-seeking portfolios as large as 50 stocks.

In this Article, we identify two other benefits that alpha investors sometimes sacrifice in their attempts to achieve above-market returns. Besides sacrificing the benefits of diversification, investors also at times take on too much or too little exposure to stock market risk when pursuing alpha investment opportunities. While the diversification tradeoff involves bearing a nonoptimal amount of idiosyncratic risk in return for alpha, the exposure tradeoff involves taking on nonoptimal amounts of stock market risk, often called "systemic risk," to get alpha. Some alpha strategies involve both of these tradeoffs. For example, an investor who believes that her company will strongly outperform the market and chooses to invest all her savings in it might be exposed to nonoptimal amounts of both systemic and idiosyncratic risk. Finally, investors may be willing to pay large fees to fund managers whom they expect will deliver returns that more than offset the fee expense. Common sense tells us that a manager charging a large, supracompetitive fee must obtain alpha of at least the size of the excess fee to make it worth investing with her. But intuition provides no clear guideline for what

4. Our estimates depend in part on the assumptions we use, including, in some analyses, the CAPM. Qualitatively, we expect our results to continue under other reasonable assumptions about asset pricing and investors' preferences, but the precise size of the requisite offsetting alpha may change under other models or preferences. See infra text accompanying notes 39-41.

5. The "risk premium" on stock is typically measured by comparing the historical average performance of equity compared to that of (practically) risk-free Treasury bonds. This premium has averaged about $4 \%$ in the United States. See infra text accompanying Table 3. 
minimum alpha is required to justify sacrificing diversification or optimal market exposure. Our results suggest the offsetting alpha is frequently substantial in real-world settings.

Having empirically estimated the minimum compensating alphas needed to justify these diversification, market risk, and excess-fee tradeoffs, we explain how fiduciary duties should take into account these alpha tradeoffs. Our results have both general implications, which apply across a variety of contexts, and more specific applications for trustees, investment advisers, brokers, and 401(k) administrators, among others.

Our goal in this Article is to make retail alpha investing "safe, legal, and rare[r]." 6 We do not propose that fiduciaries eschew all alpha opportunities, by insisting, for example, that all retail portfolios be invested in low-cost, passively managed index funds. ${ }^{7}$ Rational investors, guided or unguided by fiduciaries, may sometimes identify credible alpha opportunities. We make no claim that such opportunities are fleetingly small. As a theoretical matter, there can be both Type I alpha errors (mistakenly pursuing alpha that will not pan out) and Type II alpha errors (mistakenly failing to pursue alpha that would deliver superior returns). And while some of our regulatory proposals might reduce Type II errors (for example, by enabling currently chilled trust fiduciaries to more easily trade off diversification for alpha), the bulk of our efforts here are to reduce existing Type I errors. Few retail investors, even when guided by investment fiduciaries, have sufficient information to justify the costs of seeking alpha. Indeed, the very magnitude of our estimates of required excess returns provides good reason for thinking that too many fiduciaries currently "seek alpha" on behalf of their clients.

Accordingly, we argue that fiduciaries who recommend or invest in alpha portfolios should be required to explicitly consider the costs of doing so. Specifically, fiduciaries should (1) estimate the costs of excessive fees, failing to diversify, and deviating from what otherwise would be optimal exposure, (2) separately estimate and justify the expected alpha from the investment decision, and (3) show that the expected alpha exceeds these costs. Fiduciaries who are recommending alpha-seeking portfolios should have a duty to explain the pertinent tradeoffs to their clients. Moreover, fiduciaries should have dynamic mechanisms in place to update their

6. Versions of the quoted phrase have been used by, among others, Bill Clinton. President Bill Clinton, Remarks Accepting the Presidential Nomination at the Democratic National Convention in Chicago (Aug. 29, 1996) (“[A]bortion should not only be safe and legal, it should be rare."). The suggestion that government should reduce the prevalence of abortion is contested, in part, because it threatens to impinge on a fundamental right to privacy. The idea that, in order to protect investors, the law should discourage fiduciaries from recommending (or executing) strategies that cut against a consensus among economists and financial professionals is far less controversial.

7. Cf. Peter Orszag \& Cass R. Sunstein, Give People Choices, Not Edicts, Minn. LaWYeR (Dec. 6, 2013), https://minnlawyer.com/2013/12/06/peter-orszag-cass-r-sunstein-give-peoplechoices-not-edicts/ [https://perma.cc/GM62-GEWH] (arguing that default rules like automatic enrollment in savings plans can provide benefits while still providing freedom of choice). 
recommendations based on evolving market conditions and to keep track of their success (across clients) in predicting alpha.

Beyond this general duty to explicitly consider and explain alpha tradeoffs, our results have a number of specific implications for various financial fiduciaries. For example, our estimates show that the value of diversification increases during periods of market upheaval. We therefore argue that the duty of trustees (of both personal trusts and defined benefit ERISA plans) to diversify should be stricter during these periods. Likewise, we argue that when idiosyncratic risk is high, trustees and the courts must be more sensitive to whether trusts waiving the duty of diversification-often these are trusts holding a family business - must nevertheless be diversified to protect the beneficiaries.

Trustees are subject to a strict duty of loyalty to consider only the best interests of the trust's beneficiaries. If trustees make bad decisions to seek alpha, therefore, those mistakes will usually arise from genuine errors concerning the costs and benefits of trying to get alpha. By contrast, there is widespread concern that due to conflicts of interest, brokers may recommend that retail clients imprudently seek alpha by buying high-fee mutual funds. These funds in turn pay the broker substantial commissions. Both the Department of Labor (the "Fiduciary Rule") and the Securities Exchange Commission ("Regulation Best Interest") have proposed or promulgated major regulations on this issue in the last couple of years. Because the Fiduciary Rule has been vacated, the SEC's proposed rule is the most likely candidate to significantly alter the status quo. To determine whether a broker's advice was unacceptably biased, the SEC's proposed new rule would look at both (1) the broker's conflict of interest and (2) how prudent the advice was. Our alpha analysis can help the agency refine that second question to more accurately decide when brokers are putting their own interests ahead of their clients'. In addition, to help assure that fiduciaries can perform a reasonable alpha cost-benefit assessment, we also recommend that Financial Industry Regulation Authority (FINRA) licensing tests for brokerdealers and registered investment advisers be enhanced to require would-be licensees to understand the three tradeoffs at the heart of our analysis.

We also suggest that ERISA be revamped to reduce the chance that savers in self-directed retirement accounts make ill-advised alpha investments. Specifically, we propose that the Department of Labor should issue new regulations interpreting $\S 404(\mathrm{c})$. These regulations would require that, in order to qualify for safe-harbor immunity, 401(k) plan sponsors periodically provide investors with an individualized portfolio analysis of potential diversification, exposure, and fee mistakes. This disclosure should include warnings about the alpha that would be required to justify the participant's portfolio choices and an estimate of how frequently retail investors with similar portfolios have achieved alphas of that size.

Our concerns about brokers and 401(k) plan managers reflect a desire to 
help prevent retail investors from mistakenly seeking alpha. Research suggests this is where the most serious alpha mistakes are made. ${ }^{8}$ Thus the gains from improving fiduciary conduct are likely to be greatest in these areas. Nevertheless, our results-e.g., the increasing importance of diversification during periods of upheaval-have important implications even for financially sophisticated parties because they are not yet widely appreciated. Moreover, our general proposal that fiduciaries should be required to weigh the costs and benefits of seeking alpha makes sense even when both the fiduciary and the beneficiary are sophisticated for the same reason that fiduciaries are held to an enforceable duty to act prudently along other dimensions in such contexts.

The costs of implementing these alpha duties is significantly lower today than it would have been in the past. With the advent of fintech like "robo-advisors," fiduciaries can usually make reasonable estimates of the alpha tradeoffs at quite low costs. In addition, while we are cognizant that our proposed duties could add to litigation expenses, we believe the existence of an effective safe-harbor when fiduciaries recommend a passive strategy limits this concern. Likewise, following existing trust law, any litigation arising out of these duties should be focused on the process used by the fiduciary rather than a substantive second guessing of the fiduciary's conclusion, to avoid incentivizing investors who lost money after receiving ex ante prudent advice to sue nevertheless.

Finally, we also consider the potential ramifications of our proposals for the broader economy rather than just investor protection. Our proposals aim in large part to reduce Type I errors: mistaken bets on alpha which will not pan out for the investor. Eliminating these bets will shift funds away from investment managers who try to find alpha by locating underpriced assets to passive funds which do not engage in price discovery. This in turn suggests that reducing Type I alpha errors may make asset prices less accurate. We conclude, however, that this effect is likely to be modest and self-limiting. The price discovery that would be lost is likely to be the most marginal (which is why it does not earn enough alpha to pay its costs). Moreover, if securities prices become less accurate that will make it easier to find alpha, drawing funds back into price discovery.

The remainder of this Article is divided into three Parts. Part II explains theoretically why alpha expectations might justify what otherwise would seem to be mistaken failures to diversify, minimize fees, or maintain ageappropriate exposure to equities. Part III presents our empirical estimates of the alpha required under a variety of conditions, levels of risk aversion, and different degrees of departure from optimal diversification, exposure to market risk, and competitive fees. Finally, Part IV draws out the normative implications of our analysis for three different sets of investment fiduciaries:

8. See, e.g., infra text accompanying notes 15 and 144 . 
trustees who might pursue alpha opportunities when investing trust assets, broker-dealers and investment advisers who might recommend or execute alpha opportunities for their clients, and ERISA fiduciaries who might offer alpha opportunities in 401(k) plan menus.

\section{Distinguishing Between Mistakes and Tradeoffs}

\section{A. $\quad$ The Three Central Investment Mistakes}

Retail investors often struggle to decide how best to invest nonprecautionary savings. ${ }^{9}$ Nevertheless, the consensus among economists and financial professionals is surprisingly straightforward: Absent an alpha opportunity, one should hold a portfolio which is (1) well-diversified, (2) low-cost, and (3) exposes you to age-appropriate stock market risk. The flip-side of this guidance is that there are three central investment mistakes: failing to diversify, paying high (supracompetitive) fees, and failing to expose one's portfolio to an appropriate amount of market risk.

Failing to diversify can be an investing mistake because diversification can reduce risk at very low cost. This means that diversification allows investors to reduce the volatility of returns without reducing expected returns. As a theoretical matter, full diversification would require portfolios holding some of every risky asset - including, for example, international equities, real estate investments, and all manner of fixed income securities. ${ }^{10}$ In practice, substantial benefits from diversification can be achieved by holding as few as ten well-selected large-cap stocks. ${ }^{11}$ While a portfolio of this size is far less risky than a single-stock portfolio, there remain very important benefits to further diversification, particularly during periods of high volatility.

We estimate that diversification during normal times can reduce the standard measure of volatility, the standard deviation of the annual return, by $14.3 \%$ - from $33.5 \%$ on an average individual U.S. equity to $19.2 \%$ on a fully diversified portfolio of U.S. stocks. ${ }^{12}$ What's more, the benefits of

9. Scholars often distinguish between precautionary and retirement savings. See, e.g., Anders Anderson et al., Precautionary Savings, Retirement Planning and Misperceptions of Financial Literacy 15-18 (Nat'l Bureau of Econ. Research, Working Paper No. 21356, 2015) (treating precautionary and retirement savings as distinct categories for financial-literacy analysis).

10. See generally HARRY M. MARKOWITZ, PORTFOlio SElection: EFFICIENT DIVERSIFICATION OF INVESTMENTS (6th ed. 1968) COWLES FOUNDATION MONOGRAPH\#16 (1959) (developing his earlier work on mean-variance analysis and portfolio theory).

11. See JonAthan R. MACEY, AN INTRODUCTION TO MODERN FinANCIAL THEORY 24-26 (2d ed. 1998) (citing studies suggesting a portfolio of 10 stocks may provide as much as $88 \%$ of total potential diversification advantages).

12. These figures are drawn from a "Monte Carlo simulation," which uses historical stock data to build a distribution of returns for both a diversified portfolio and the "average" individual stock. We split the sample into "normal" periods and "crisis" periods, by looking at the volatility of the market over the prior 30 days. If the annualized market volatility over the past 30 days was over 
diversification tend to be greater during periods of economic upheaval. In Figure 1, we plot the standard deviation of a diversified portfolio of CRSP stocks and the average volatility of individual stocks over time. During times of crisis, diversification reduces the standard deviation of return by $16.6 \%$ from $51.4 \%$ on an average individual stock to $34.8 \%$ on a diversified portfolio of U.S. stocks. Failures to diversify risk are generally not as stark as investing all of your savings in company stock, but lower-bound estimates on partial failures to diversify $401(\mathrm{k})$ savings have been estimated to be equivalent to paying excess fees of $0.71 \%$ annually. ${ }^{13}$

Paying excessive fees can be an investment mistake because these fees eat away at the net return. For example, paying an excess fee of $2 \%$ over time can halve your retirement savings. ${ }^{14}$ Overcharges on this order of magnitude have routinely occurred in the real world. One of us, in analyzing more than $3,500401(\mathrm{k})$ plans (with more than $\$ 120$ billion in assets), found that the top $5 \%$ had excess fees of $2.05 \%$ (with average excess fees of $0.63 \%$ ). ${ }^{15}$

$25 \%$, then we classified the month as a crisis period. For more information, see infra notes accompanying Table 1.

13. See Ian Ayres \& Quinn Curtis, Measuring Fiduciary and Investor Losses in 401( $k$ ) Plans 43 tbl.2 (7th Annual Conference on Empirical Legal Studies Working Paper, 2012), https://papers.ssrn.com/sol3/papers.cfm?abstract_id=2107796 [https://perma.cc/PE5A-8QHV] (mean menu diversification costs of $0.06 \%+$ mean investor diversification losses of $0.65 \%=$ $0.71 \%$ ); see also Ian Ayres \& Quinn Curtis, Beyond Diversification: The Pervasive Problem of Excessive Fees and "Dominated Funds" in 401(k) Plans, 124 YALE L.J. 1476, 1499-1500 (2015) [hereinafter Ayres \& Curtis, Beyond Diversification].

14. Ten-thousand dollars invested at a $6 \%$ annual return over 40 years will come to equal $\$ 102,857$, but a $4 \%$ return will yield only $\$ 48,010$. See Chris Arnold, When High Fees Stink Up Your 401(k), What Can You Do?, NPR (Oct. 30, 2015), http://www.npr.org/2015/10/30/453163154 /when-high-fees-stink-up-your-401-k-what-you-can-do [https://perma.cc/67TN-NLX8] (stating that a $2 \%$ annual fee "eats up half of your earnings over 35 years").

15. See Ayres \& Curtis, Beyond Diversification, supra note 13, at 1499-1500 tbl.1 (sum of "Plan additional fees" + "Plan Menu Additional Fund Fees" + "Investor Choice Additional Fund Fees"). Sixty-three basis points of excess fees would reduce the 40 -year nest-egg by more than $20 \%$ (from $\$ 102,857$ to $\$ 81,036$ ). See Arnold, supra note 14 (discussing the long-term impact of excess fees on 401(k) investment plans). 


\section{Figure 1}

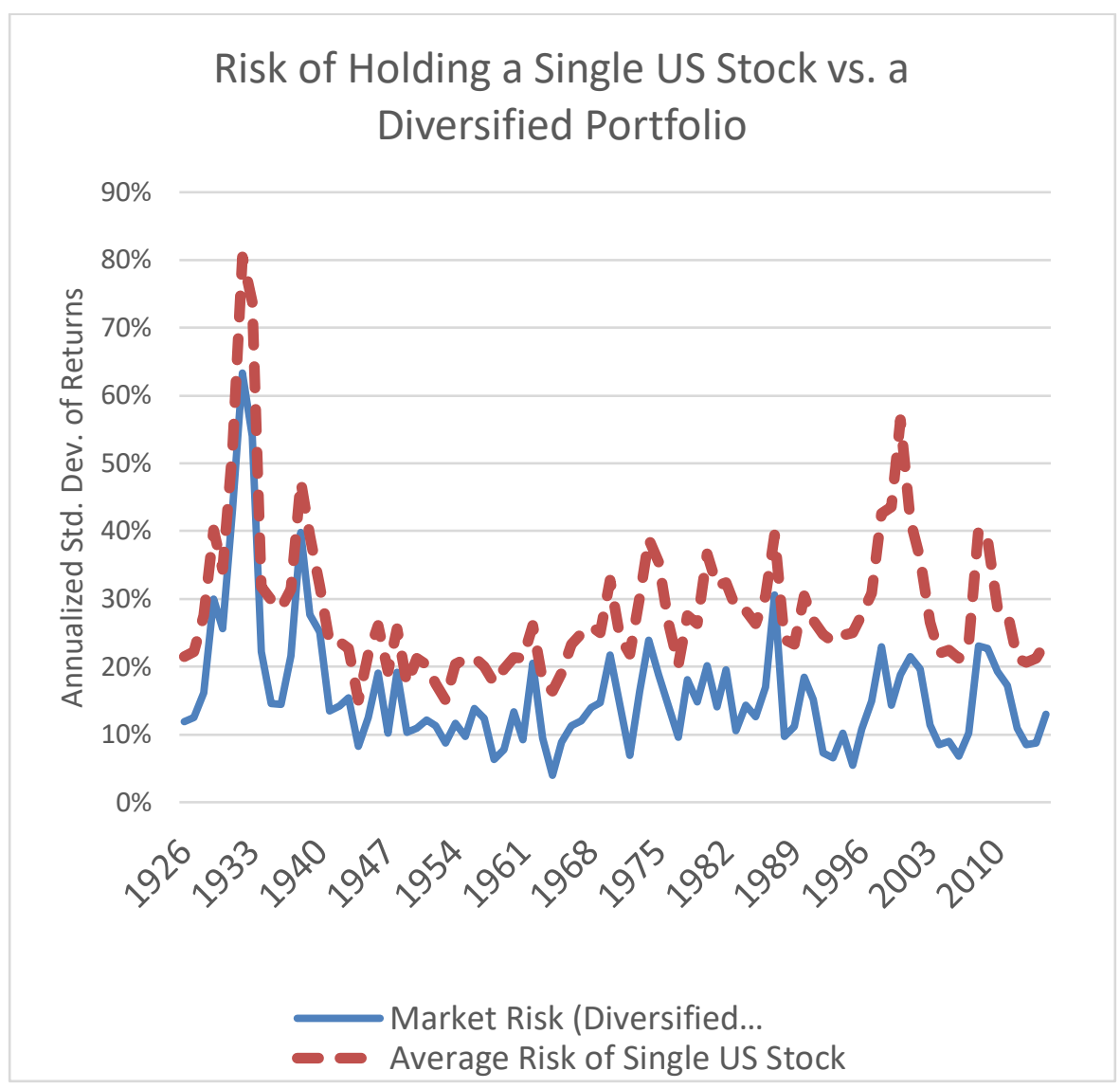

Exposing one's portfolio to the wrong amount of market risk is a mistake because investors who take on too much or too little stock market risk fail to optimally trade off risk and return. We will henceforth call this a "beta" mistake because in the Capital Asset Pricing Model (CAPM), beta is a numeric measure of how exposed a portfolio is to market risk. A portfolio with a beta of 0 is invested in risk-free assets, while a portfolio with a beta of 1 is invested $100 \%$ in equities. Investors can make beta mistakes by exposing their portfolio to either too much or too little stock market risk given their personal risk tolerance. The two types of beta mistakes are depicted in the following figure: 


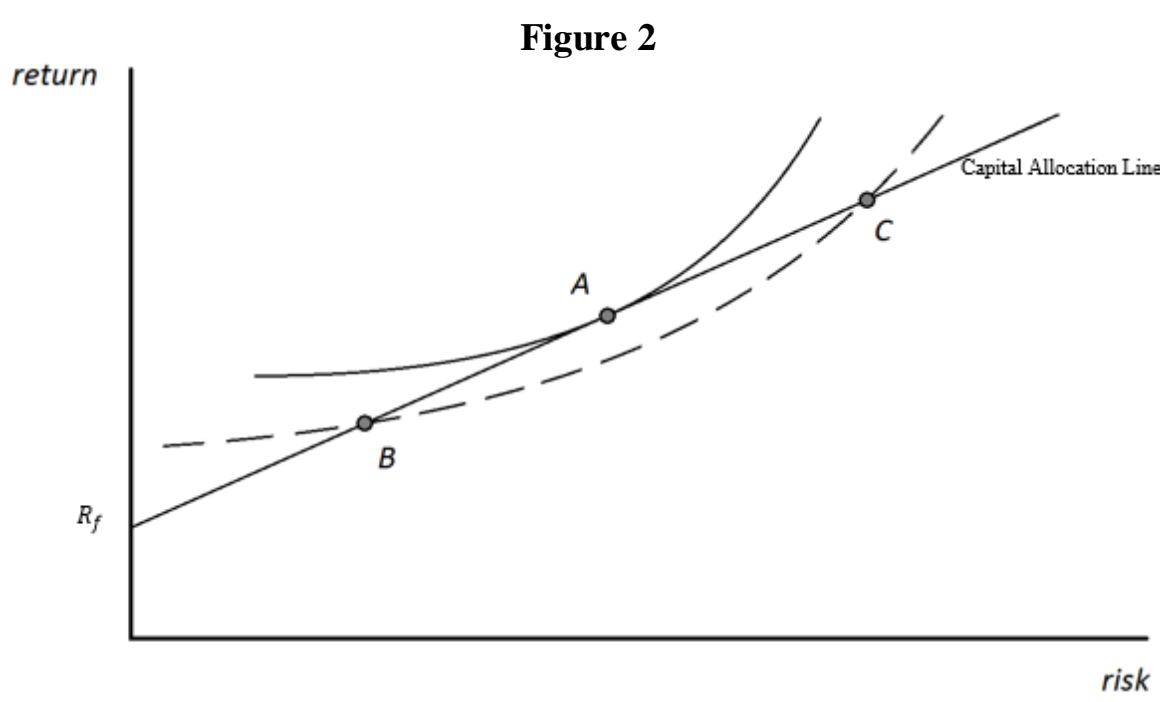

Point $A$ in Figure 2 depicts the expected return and risk (standard deviation of expected return) of a portfolio that optimally balances risk and return for a particular investor. In this Figure, the straight line is the "Capital Allocation Line," which represents the set of the best achievable investment portfolios. (These are the best portfolios because in a simple CAPM model like this, one cannot beat the market. ${ }^{16}$ ) Each point on the Capital Allocation Line (CAL) is uniquely associated with a particular beta-that is, the percentage of the portfolio exposed to market risk. At the far left (the $y$-axis), the portfolio is composed exclusively of risk-free assets, which earn the riskfree rate, $R_{f}$. Because it has no market exposure, this portfolio thus has a beta of 0 . The beta increases as one moves along the CAL to the northeast (say, from Point $B$ to $C$ ). The curved lines represent this investor's "iso-utilities," the set of returns and risks for which the investor's utility is constant. Higher iso-utility curves lie northwest because investors prefer higher expected returns and lower risk. Point $A$ is optimal because at that point the benefits to the investor of decreasing risk by moving down the CAL are exactly offset by the value she places on the associated decrease in expected return (and vice versa moving up the CAL). Points $B$ and $C$ depict exposure mistakes with portfolios that place the investor on a lower iso-utility curve. Point $B$ represents a portfolio that includes too few risky investments, given the

16. Under the standard CAPM model, there is a single fully diversified portfolio of risky assets - the market portfolio-which all investors will own. Investors, however, will vary what proportion of their wealth they hold in the market and the Capital Allocation Line represents the return and risk of different combinations of risk-free assets and the market portfolio.

The model does not account for frictions like transactions costs, taxes, the inability of investors to borrow at the risk-free rate, or the lack of full information available to all investors, and it assumes homogenous investor expectations. 
investor's risk preferences, while Point $C$ represents a portfolio that includes too much risky investment.

Robert Merton in 1969 offered a simple equation to estimate the optimal portfolio exposure as a function of just three variables ${ }^{17}$ :

$$
\beta_{M}=\frac{\text { Risk Premium }}{\sigma^{2} * \text { Risk Aversion }}
$$

where $\beta_{M}$ is the measure of optimal exposure to market risk, the Risk Premium is the amount by which the return on risky assets (say, a diversified portfolio of stocks) is expected to exceed the risk-free return (on say, government bonds), $\sigma^{2}$ is the expected volatility of returns (captured, say, by the variance of expected stock returns), and Risk Aversion is the investor's "relative risk aversion," which measures how sensitive she is to risk, with 0 indicating she is risk neutral and with larger numbers indicating an increasing unwillingness to bear additional risk to get a fixed increase in her expected returns. ${ }^{18}$ Like many economic models, Merton's assumes that investors exhibit "constant relative risk aversion" (CRRA), which much empirical work, though not all, suggests is a reasonable approximation of real behavior. ${ }^{19}$ We also adopt the assumption of CRRA in our empirical work below. ${ }^{20}$ Studies estimate that the relative risk aversion of average investors is in the range of 2 to $4 .{ }^{21}$ For

17. See Robert C. Merton, Lifetime Portfolio Selection Under Uncertainty: The ContinuousTime Case, 51 REV. ECON. \& STAT. 247, 253 (1969) (rewriting the "optimal proportion in the risky asset... in terms of Pratt's relative risk-aversion measure ..."); Paul A. Samuelson, Lifetime Portfolio Selection by Dynamic Stochastic Programming, 51 Rev. ECON. \& STAT. 239, 244-45 (1969) (applying Merton's “continuous-time case" analysis to the author's own model).

18. Returning to Figure 2, the investor's relative risk aversion is technically a measure of the curvature of her iso-utility curve.

19. See, e.g., Markus K. Brunnermeier \& Stefan Nagel, Do Wealth Fluctuations Generate Time-Varying Risk Aversion? Micro-Evidence on Individuals' Asset Allocation, 98 AM. ECON. REV. 713, 733 (2008) (finding that CRRA predicts investor behavior fairly well and better than other popular models); Pierre-André Chiappori \& Monica Paiella, Relative Risk Aversion Is Constant: Evidence from Panel Data, 9 J. EUR. ECON. ASS'N 1021, 1024 (2011) (finding that CRRA describes investor behavior relatively well).

20. CRRA is often used in conjunction with CAPM even though, under some assumptions, for CAPM to exactly predict prices in the model, investors must have quadratic utility. Our use of CAPM should therefore be thought of as a simple way to approximate how returns are generated. See P. Jean-Jacques Herings \& Felix Kubler, Approximate CAPM When Preferences Are CRRA, 29 COMPUTATIONAL ECON. 13, 14 (2007) (“[E]mpirical contradictions of CAPM might be explained by the fact that some agents do not have quadratic utility. . . . On the other hand[,] . . the CAPM pricing formula provides a very good prediction for actual equilibrium returns.").

21. See, e.g., Ian Ayres \& Barry Nalebuff, Diversification Across Time, J. PORTFOLIO MGMT., Winter 2013, at 73, 74-75, 82 (applying a risk-aversion parameter of 4); Robert B. Barsky et al., Preference Parameters and Behavioral Heterogeneity: An Experimental Approach in the Health and Retirement Study, 112 Q.J. ECON. 537, 548, 563 (1997) (finding mean "risk tolerance"-which is the inverse of relative risk aversion-in a representative survey is .24 , which corresponds to an average CRRA parameter of about 4); Néstor Gandelman \& Rubén Hernández-Murillo, Risk Aversion at the Country Level 2 (Research Div., Fed. Reserve Bank of St. Louis, Working Paper No. 2014-005B, 2014), http://research.stlouisfed.org/wp/2014/2014-005.pdf 
example, if the risk premium is $4 \%$, the standard deviation is $20 \%$, and risk aversion is 2 , then the optimal beta will be $50 \% .^{22}$

Merton's investment exposure equation makes intuitive sense: an investor should, all else equal, be willing to hold a portfolio that is more exposed to market risk when the expected premium of holding risky assets is larger, and be less willing to hold a portfolio that is more exposed to market risk when the expected volatility of risky assets is higher or if the investor is more averse to that risk.

Merton's exposure equation, however, excludes the age of the investor. If investors tend to become more risk averse as they age, then it would be natural that they would reduce their equity exposure as they grew closer to retirement. Target-date mutual funds tend to follow a variety of agecontingent strategies, such as the following "birthday rule":

$$
\beta_{B} \approx 110-\text { investor age }
$$

A target-date fund following the birthday rule would invest approximately $90 \%$ of its assets in equities when the investor is 20 and approximately $50 \%$ of its assets in equities when the investor is $60 .{ }^{23}$

To assess whether an investor is making a beta mistake, we must know what the right exposure to stock market risk would be. Reasonable people can differ over some range of exposures. However, some exposures are prima facie unreasonable judged by any of these standards. ${ }^{24}$ For example, one

[https://perma.cc/TJ8E-H3WP] (finding that most common estimates of average relative risk aversion are between 1 and 3 ).

22. $(.04) /(.2 * .2 * 2)=.5$.

23. While there is not a well-known term to capture the possibility of exposure or beta mistakes, the possibility is indirectly captured by ERISA regulations regarding default investment options when a 401(k) participant fails to provide investment instructions. One of the ways an investment product can qualify as a "Qualified Default Investment Alternative" (QDIA) in which those 401(k) funds can be invested is to have "a mix of investments that takes into account the individual's age or retirement date" such as a target date retirement fund. EMP. BENEFITS SEC. ADMIN., U.S. DEP'T of LABOR, FACT SHEET: REgUlation RELATING TO QUALIFIED DEFAUlt INVESTMENT ALTERNATIVES IN PARTICIPANT-DIRECTED INDIVIDUAL ACCOUNT PlANS 2 (2008). Sadly, while the QDIA requirements attend to beta and diversification mistakes, they are inattentive with regard to excessive-fee mistakes. Ian Ayres, 401(k) Reforms: What Should Be Done, FORBES (May 27, 2014), https://www.forbes.com/sites/whynot/2014/05/27/401k-reforms-what-should-bedone/\#3888ff3a223d [https://perma.cc/4D77-9Q6W] ("But the regulations don't stop plans from adopting default funds with excessive fees.").

24. Indeed, one of us argued for a third "leveraged lifecycle" approach:

$$
\beta_{L L}=\max \left[2, \frac{\beta_{M} * P V(\text { Lifetime Savings })}{\text { Present Savings }}\right]
$$

where $P V($ Lifetime Savings) is the risk-adjusted expected future and present savings and Present Savings is the amount that the investor has currently saved. See IAN AYRES \& BARRY NALEBUFF, LIFECYCLE INVESTING: A NEW, SAFE, AND AUDACIOUS WAY TO IMPROVE THE PERFORMANCE OF YOUR RETIREMENT PORTFOLIO 74-76 (2010) (arguing that investors "should start out fully leveraged" and stay that way until their "present savings are sufficient to meet [their] risk-adjusted target"). This leveraged-lifecycle equation that the authors offer does a better job of diversifying risk across time and reduces an investor's exposure to that of the Merton equation as the investor 
study found that in 2007, roughly half of 401(k) participants in their 20s had no exposure to equity. ${ }^{25}$ These investors are likely making exposure mistakes (akin to Point $B$ in Figure 2) by not capturing any of the substantial risk premium on equity. Such low beta portfolios fail both the Merton and birthday rule beta standards. ${ }^{26}$ Of course, with sufficiently high risk aversion or pessimistic market expectations, a low beta might be justified. But young people putting all their savings in money market accounts is a horrible way to save for retirement. The same study found that more than a fifth of older 401(k) participants (ages 56-65) had more than 90\% of their portfolio in equities. ${ }^{27}$ This is likely an example of the second type of exposure mistake (akin to Point $C$ in Figure 2), as these participants are arguably exposing too many of their assets to stock market risk. However, it is admittedly harder to empirically identify this second form of beta error. Oldsters who invest almost entirely in equities are inconsistent with the lifecycle dicta but not necessarily inconsistent with Merton's exposure equation, if, for example, the participants are not particularly risk averse and hold more sanguine views about the stock market. ${ }^{28}$

\section{B. Three Alpha Investing Tradeoffs}

While the last section explained how failing to diversify, economize on fees, or give one's portfolio appropriate exposure to equities can be mistakes, this section explains how each of these deviations might instead be justified by sufficient expectations that particular investment opportunities will deliver risk-adjusted returns superior to investing in the market as a whole. We will call such opportunities "alpha" investments following popular finance parlance. The term derives from how one might measure whether an investment generates excess returns: regressing the returns of that investment on the returns of a diversified portfolio of risky assets, which we will henceforth simply call the "market portfolio."

The regression (in simplified form ${ }^{29}$ ) is: $R_{i, t}=\alpha_{i}+\beta_{i}\left(R_{m, t}\right)$ where

approaches retirement (because $P V$ (Lifetime Savings) will equal current savings when there are no future saving increments).

25. Jack VanDerhei, What Will Happen to Retirement Income for 401( $k$ ) Participants After the Market Decline?, 22 J. AGING \& SOC. POL'Y 129, 134-35 (2010).

26. They are even more inconsistent with the Leverage Lifecycle standard proposed by Ian Ayres and Barry Nalebuff. See AYRES \& NALEBUFF, supra note 24 (emphasizing that investors should increase equity exposure early in the investment lifecycle).

27. VanDerhei, supra note 25, at 135.

28. In addition, investors who have saved far more than they will personally consume during their lives might rationally invest more aggressively because they wish to pass along as much as possible to their heirs.

29. In fact, both the returns on the investment and the market should be measured net of the risk-free rate, and there must be an error term that adjusts for the fact that the returns of any investment are not perfectly predicted by the market in every period. Thus, the full regression is 
$R_{i, t}$ is the return of the investment in question in period $t$ and $R_{m, t}$ is the return on the market portfolio in period $t$. If the investment outperforms the market, the regression will yield a positive intercept, $\alpha_{\mathrm{i}}$, hence the term "alpha." Note that by controlling for the investment's correlation with market returns, $\beta_{i}$, the regression adjusts for the investment's exposure to market risk. Thus, alpha will not automatically be generated by investments with high market exposure and high expected returns.

Graphically, the possibility of an alpha investment is depicted in Figure 3:

\section{Figure 3}

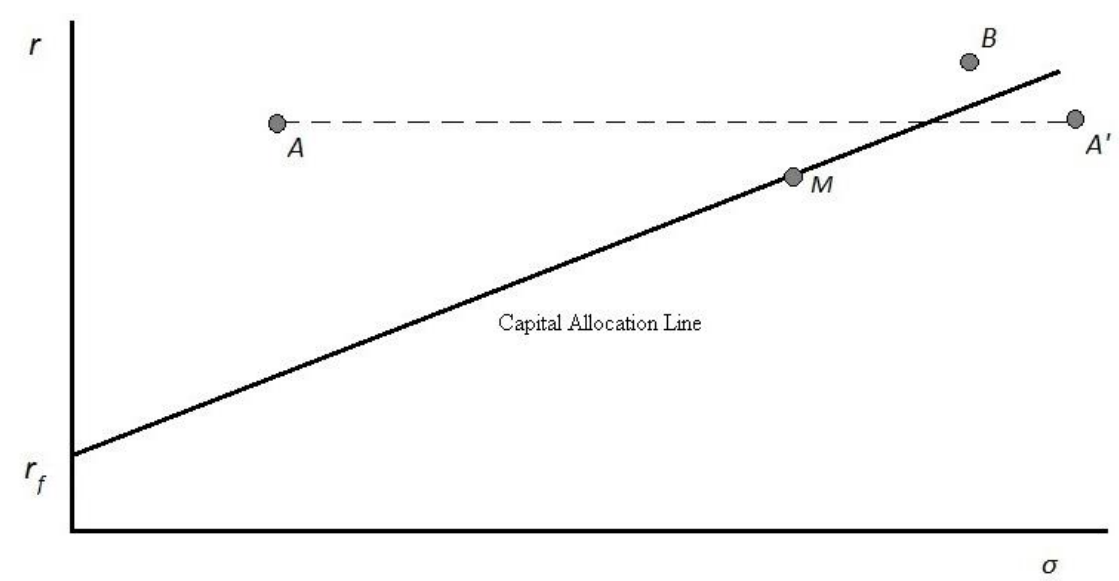

In Figure 2, we assumed away a number of real-world complexities, which meant that alpha opportunities were impossible. Recall that in that world, the CAL represents the set of the best achievable portfolios, which consists of (0 alpha) portfolios mixing risk-free assets and the market portfolio (Point $M$ ). If we now consider a world in which alpha opportunities can exist, alpha investments will lie above the CAL, like Points $A$ and $B$ in Figure $3{ }^{30}$ Since Point $A$ is to the left of Point $M$, it represents an investment with a $\beta<1$. In contrast, Point $B$ represents an alpha investment (again lying above the CAL) but with more heightened exposure to systemic risk with a

$R_{i, t}-R_{f}=\alpha_{i}+\beta_{i}\left(R_{m, t}-R_{f}\right)+\varepsilon_{i, t}$, where $R_{f}$ is the risk-free rate and $\varepsilon_{i, t}$ is the mean- 0 error term.

30. Alpha investments might also be based on a privately held belief that the systemic (beta) risk of a particular stock is lower than the market (and beta regressions) suggest. An alpha investor would in this case want to tilt toward larger portfolio holdings of the stock not because it lies "above" the CAL given its beta, but because it lives to the "left" of the CAL. But this alternative characterization would continue to produce the same type of increased exposure to idiosyncratic risk indicated by the movement from Point $A$ to $A^{\prime}$. 
$\beta>1$. Because the risk-adjusted expected returns of these two investments exceed the expected market return, one would rationally want to hold them as part of a diversified portfolio. Indeed, the excess returns could even cause one to be willing to overweight them in a portfolio-investing more than would be necessary to diversify.

Overweighting an alpha opportunity will come at a cost, however. The investor will bear some of the risk specific to the alpha investment-its "idiosyncratic risk" - which would have been diversified away if she did not overweight it. To make this more concrete, imagine that the alpha investment opportunity is "lumpy": the investor must invest all her savings in A or buy none at all. ${ }^{31}$ Say $\mathrm{A}$ is a startup with a minimum investment equal to the investor's savings. The additional idiosyncratic risk of investing only in $\mathrm{A}$ is shown in Figure 3 as Point $A^{\prime}$, which lies horizontally to the right of A. Given its level of systemic risk, A is a positive alpha opportunity lying above the CAL, but once we account for the loss of diversification, such a lumpy alpha opportunity need not make the investor better off. Indeed, as shown in Figure 3, Point $A^{\prime}$ lies below the CAL.

More generally, the additional expected return from investing in a lumpy alpha opportunity might or might not exceed the detrimental loss of diversification. For example, Figure 4 shows three possible outcomes of bearing the idiosyncratic risk of an alpha opportunity.

\section{Figure 4}

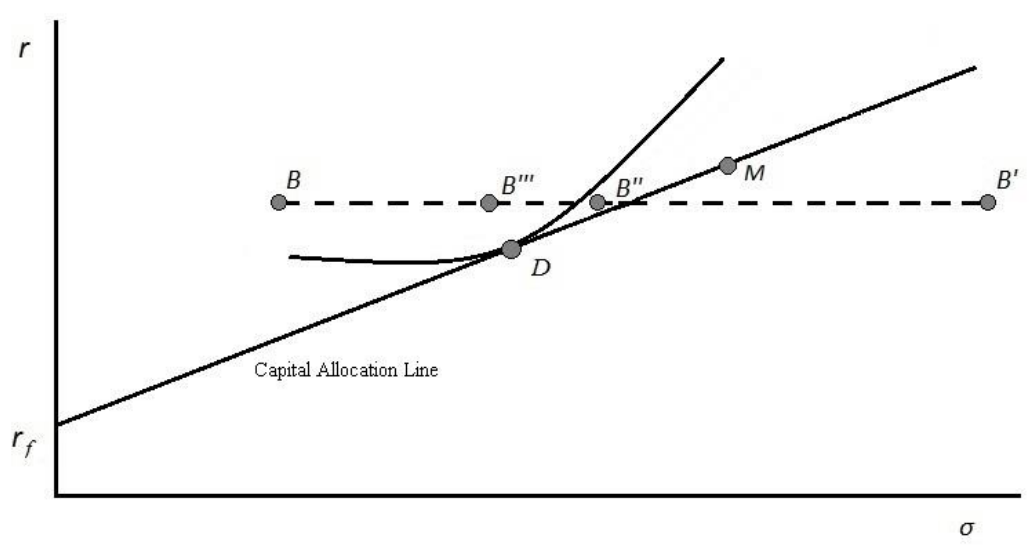

Point $B^{\prime}$ is, like Point $A^{\prime}$, an alpha opportunity that lies below the CAL once we account for idiosyncratic risk. Point $B^{\prime \prime}$ is an alpha opportunity that lies above the CAL once we account for idiosyncratic risk, but it still lies

31. We focus on lumpy investments in this subpart in part to build intuition. We consider the theoretical and empirical implications with non-lumpy investments at the end of this Part and in the next empirical Part. 
below the utility the investor could achieve by investing in a fully diversified portfolio at Point $D$. And Point $B^{\prime \prime \prime}$ is an alpha opportunity that lies above both the CAL and the investor's utility from holding a diversified portfolio. Only in the last case (Point $B^{\prime \prime \prime}$ ) would the investor be better off foregoing the benefits of diversification and placing all her savings in the alpha opportunity. Accordingly, it is not true that investors should always remain diversified. But the foregoing shows that sacrificing diversification requires a sufficient offsetting alpha.

A similar argument also applies to an investor trading off alpha for moving away from her ideal beta (exposure to market risk). A lumpy alpha opportunity might force an investor to be exposed to more or less market risk than she would have chosen from the zero-alpha alternatives on the CAL. As discussed above, this deviation in exposure would reduce the investor's expected utility. But, as before, expecting a sufficient alpha can outweigh the costs of departing from the ideal level of exposure. For example, in Figure 5, Point $D$ reflects the optimal portfolio for an investor, absent any alpha opportunities.

\section{Figure 5}

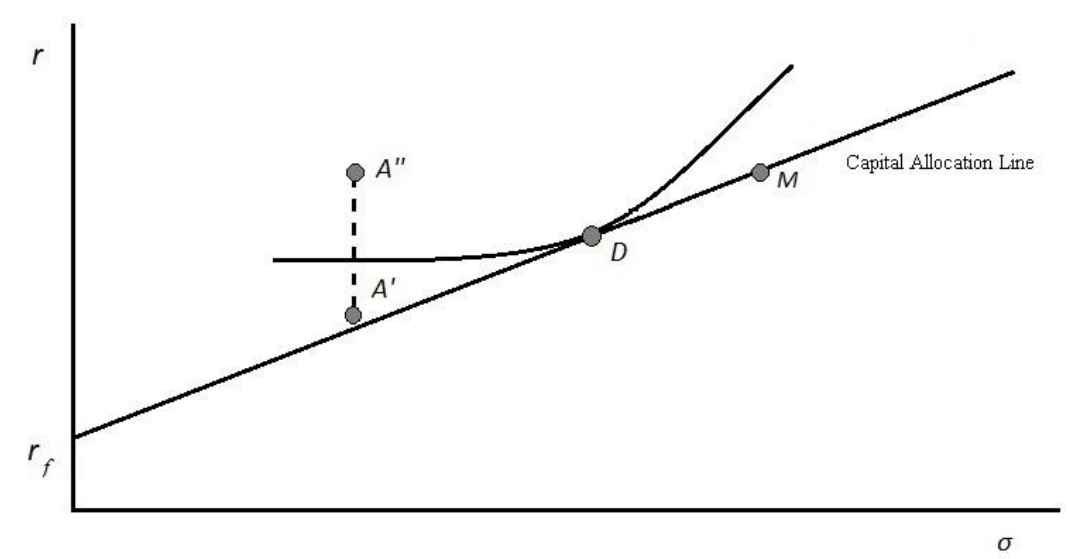

Now imagine that the investor is offered an alpha investment that exposes her to less systemic risk than at Point $D$, which means she will also obtain less of the risk premium. This positive alpha investment might either be utility-enhancing or not. In Figure 5, Point $A^{\prime}$ shows an alpha opportunity that lies above the CAL but not above the investor's iso-utility curve. Point $A^{\prime \prime}$, in contrast, shows an alpha opportunity that lies above both the CAL and the investor's iso-utility curve. Only in the latter case would the 
alpha benefit outweigh the cost of having a beta that is too low given the investor's risk preferences. ${ }^{32}$

Finally, the opportunity to obtain alpha might justify paying what otherwise would seem to be excessive fees. For example, imagine an investor is contemplating whether to invest in a well-diversified, actively managed mutual fund that charged $f$ basis points in fees more than competitive passive indexes, but which is expected to generate excess returns of $\alpha$ basis points. Here, the fee/alpha tradeoff is relatively straightforward. The key question is whether the excess expected returns justify the excess management fees:

$$
\alpha>f
$$

One should invest in the alpha opportunity only if expected alpha is greater than the excess fee. Graphically, this condition requires that the expected return of the opportunity net of the excess fee lies above the CAL.

As with the other examples examined above, our excess-fee hypothetical again isolates a single tradeoff-here the fee/alpha tradeoff. By assumption, the actively managed fund is well-diversified and non-lumpy so that the investor need not take on idiosyncratic risk and can adjust her equity exposure by mixing the fund to different degrees with government bonds. Real-world investments at times do only require considering the tradeoffs on one of these three dimensions. A mutual fund focused on one industry might sacrifice diversification without sacrificing fees or exposure. Or a high-fee target date fund (such as Fidelity Freedom Funds with expense ratios as high as 70 basis points annually ${ }^{33}$ ) might sacrifice competitive fees without diversification or exposure. Or a twenty-year-old's $100 \%$ money market portfolio investment might sacrifice exposure without sacrificing diversification or competitive fees. ${ }^{34}$ In each of these examples, an investor would need to have a sufficient alpha expectation to justify the isolated sacrifice of diversification, competitive fees, or optimal equity exposure.

But in many other contexts, the alpha investment opportunity will entail sacrificing some combination of diversification, competitive fees, or optimal market exposure. Actively managed funds, for example, usually both have higher fees and require some diversification sacrifices because the fund managers must pick a limited number of firms that they believe will

32. The analysis above implicitly assumes the investor is at least somewhat liquidity constrained. To the extent she can borrow at the risk-free rate to buy more risky assets, she can invest in the lumpy alpha opportunity without lowering the beta of her assets as a whole. Realistically, however, investors cannot borrow at the risk-free rate and do face other liquidity constraints.

33. Fidelity Freedom 2030 Fund, FIDELITY, https://fundresearch.fidelity.com/mutualfunds/summary/31617R704 [https://perma.cc/B45P-U2KF?type=image].

34. Investing one's entire portfolio in money market or government bonds might be considered an alpha opportunity — allowing one to beat the market—if one expected equity prices to fall. 
outperform the market. Lumpy, all-or-nothing investment opportunities are particularly prone to simultaneously requiring the sacrifice of both diversification and optimal equity exposure. Starting a family business, for example, might expose an investor to both idiosyncratic risk and too much (or too little) systemic risk. ${ }^{35}$ The key question in such situations would be whether the alpha expectation is sufficient to justify the total risk (systemic and idiosyncratic combined) that the investor has to take on. As shown graphically, this means not only that the expected return lies above the CAL when considering total risk, but the expected return lies above the iso-utility curve for the next-best market alternative.

Our theoretical analysis has focused on the CAPM and lumpy alpha opportunities, but it can easily be generalized. For example, Eugene Fama and Kenneth French have identified two attributes (or "factors") that empirically have been associated with excess returns, namely firms with small market capitalizations and those with a high-ratio book value to market value. ${ }^{36}$ From a CAPM perspective, the excess returns that tend to be garnered by small-cap stock or high book value stock can be interpreted as an "alpha," which would lead rational investors to want to overweight smallcap stocks in their portfolios. But as depicted in Figure 3, this overweighting will cause at least some diversification loss, pushing up the portfolio risk, possibly inside the CAL (as in Point $B^{\prime}$ ). Rational investors would not want, however, to overweight in ways that reduce utility below the iso-utility line. ${ }^{37}$

How much to overweight becomes a central concern when the alpha opportunity is not a lumpy, all-or-nothing investment choice, but can be chosen by an investor in various increments. An actively managed mutual fund with high management fees is a quintessential example of a non-lumpy investment because the investor can vary the proportion of her portfolio that she chooses to invest in the high-fee fund. An opportunity to start a family business, in contrast, is a much more lumpy investment as it might require committing a substantial proportion of an investor's portfolio. Minimum

35. Note that an investor would prefer a lumpy investment to have a lower beta than if she was investing in a diversified portfolio. Intuitively, this is because the addition of the lumpy investment's idiosyncratic risk makes the investor more sensitive to risk in the tradeoff between systemic risk and expected return. It is akin to the investor having become more risk averse, and this means she will prefer a lower beta when confronting an investment with idiosyncratic risk.

36. See Eugene F. Fama \& Kenneth R. French, Common Risk Factors in the Returns on Stocks and Bonds, 33 J. FIN. ECON. 3, 8 (1993); see generally, Richard Roll \& Stephen A. Ross, An Empirical Investigation of the Arbitrage Price Theory, 35 J. FIN. 1073 (1980) (laying out a theoretical multifactor model).

37. It would also be reasonable to think of offsetting alphas as being properly measured after controlling for the Fama-French factors or using another multifactor model. This is often how finance researchers measure mutual fund alphas. See infra note 44. In Figure 6, we estimate the offsetting alpha necessary to induce an average investor to bear de-diversification costs after controlling for the Fama-French factors. The results are barely different than using only the CAPM. 
investment requirements imposed by various types of funds (including hedge and private equity funds) also can make investment options a lumpy or discrete portion of a portfolio.

Theory tells us that when a non-lumpy alpha opportunity arises, rational investors would want to "tilt" or overweight their portfolios toward the investment. ${ }^{38}$ The extent of tilt will depend on the particular costs and benefits (and will be empirically estimated in the next section). When the alpha opportunity is lumpy, the optimal all-or-nothing investment choice will be "nothing" if the alpha is not sufficient to justify the incremental diversification, exposure, and fee losses.

\section{Empiricism}

The last Part explained as a theoretical matter why investment opportunities with expectations of sufficient above-market returns could justify reduced diversification, high fees, or non-optimal exposure to market risk. In this Part, we turn from theory to numbers - to estimate how much alpha is required to justify a failure to diversify, economize on fees, or obtain age-appropriate exposure to market risk. The estimates (and the ability to make such estimates) are important because, as we will argue in Part IV, fiduciaries who make one of the presumptive mistakes without considering whether they have the requisite alpha or who do not have a sufficient basis for believing that an investment opportunity has a sufficient alpha might, in a variety of contexts, be held liable.

The analyses below should be thought of as benchmarks, not the definitive estimates of the requisite alpha, because our results are dependent in part on our assumptions, including about the investor's other sources of income, the investor's preferences, and, in some analyses, the use of CAPM. An analysis by an actual fiduciary would need to be tailored to the investor's life circumstances including her sources of income other than investments, age, risk preferences, etc. In addition, as noted above, we make the common assumption that the investor's preferences can be represented by constant relative risk aversion. Financial economists, however, have suggested several other models of risk aversion, which help explain swings in asset prices during recessions and booms. These models typically posit larger increases in risk aversion (or something akin to that) during recessions than those implied by constant relative risk aversion. ${ }^{39}$ Using these models would

38. Intuitively, at the optimal beta, the investor is essentially indifferent between taking on marginally more risk and getting marginally more return by moving up the CAL. Purchasing a tiny amount of the alpha opportunity, however, provides a better tradeoff between risk and return than moving along the CAL, and hence, all investors will want to purchase at least a tiny amount of the alpha opportunity if possible.

39. See John H. Cochrane, Macro-Finance, 21 REv. FIN. 945, 948 (2017) (listing various prominent macro-finance theories). 
further increase the estimated alpha required to forego diversification during recessions and periods of market upheaval. ${ }^{40}$

With respect to trading off alpha for taking on non-optimal amounts of market exposure, we invoke CAPM's results to understand how increasing market exposure changes expected returns and overall risk. ${ }^{41}$ Although CAPM remains widely used, there is a broad literature arguing that it is incomplete and contending that multifactor models should be used instead. ${ }^{42}$

\section{A. Excess Fees}

The required alpha to justify a mutual fund's excess fees is the easiest to estimate. As mentioned in the last Part, the required alpha is simply the amount by which the fees exceed the competitive expense ratio charged by other funds offering well-diversified portfolios of similar investment classes. It would be a "nirvana fallacy" mistake to assume that the competitive market can offer diversified portfolios at zero cost. For domestic equities, there are a host of diversified funds and ETFs that annually charge less than 25 basis points. While for emerging markets, the competitive expense ratios are somewhat more, but many are offered with fees of less than 50 basis points. ${ }^{43}$ It is only the excess above the competitive price that needs to be traded off against alpha. When considering combination-fee tradeoffs, one can begin by simply subtracting the excess fees from the expected alpha and then asking whether the alpha net of excess fees is sufficient to justify the shortfall in diversification or exposure. Thus, in considering the required alphas

40. Our model also does not allow for the possibility that some investors might get some satisfaction from the act of seeking alpha itself. If such investors get pleasure out of trying to figure out which firms will outperform the market, they might rationally prefer to invest in alpha-seeking strategies even if those strategies would not otherwise be justified by the expected gains in portfolio wealth. Likewise, our model does not cover individuals who "view the stock market as a substitute for gambling" and who are, in economics terms, "risk loving." See Stephen J. Choi \& A.C. Pritchard, Behavioral Economics and the SEC, 56 STAN. L. REV. 1, 15 (2003) (noting the phenomenon of investors who prefer a remote chance to "strik[e] it rich").

41. The diversification results do not invoke CAPM. They simply ask how much we need to increase the expected return of a stock on average to make an investor with a given level of risk aversion indifferent to holding a single stock instead of a broad equity market index. This estimate should still be valid even if there are other sources of systemic risk other than stock market risk, as posited in multifactor models. See Fama \& French, supra note 36, at 6-10 (employing a multifactor model); Roll \& Ross, supra note 34, at 1074, 1076-78 (same). This argument is buttressed by Figure 6, which shows that explicitly controlling for the Fama-French factors makes little difference in the diversification analysis.

42. See Fama \& French, supra note 36, at 5 (arguing that multiple factors are necessary to explain expected returns); Roll \& Ross, supra note 36, at 1073-74 (noting potential flaws in CAPM's predictions and proposing an alternative approach)..

43. For a list of funds with expense ratios listed, see Diversified Emerging Mkts, U.S. NEWS \& WORLD REPORT, https://money.usnews.com/funds/etfs/rankings/diversified-emerging-mkts [https://perma.cc/76DR-X5X5]. 
estimated below, they should be construed as the net alphas that are required to take on deviations from optimal diversification or exposure.

Various studies have reported negative average mutual fund alphas (ranging between $-0.45 \%$ and $-0.60 \%$ per year). ${ }^{44}$ Nonetheless, some scholarship suggests that winning bets on actively managed higher-fee mutual funds do exist for a small percentage (less than $3 \%$ ) of funds. ${ }^{45}$ However, studies suggest that such alpha over-performance is not

44. Barras, Scaillet, and Wermers find that the average "unconditional estimated alphas for each category are negative, ranging from $-0.45 \%$ to $-0.60 \%$ per annum." Laurent Barras et al., False Discoveries in Mutual Fund Performance: Measuring Luck in Estimated Alphas, 65 J. Fin. 179, 195 (2010); see also Mark M. Carhart, On Persistence in Mutual Fund Performance, 52 J. Fin. 57, 64 tbl.3 (1997) (finding negative average alphas for mutual funds in a four-factor model); Edwin J. Elton et al., Efficiency with Costly Information: A Reinterpretation of Evidence from Managed Portfolios, 6 REV. FIN. STUD. 1, 11 (1993) (finding negative average alphas using two- or three-factor models); Michael C. Jensen, Problems in Selection of Security Portfolios: The Performance of Mutual Funds in the Period 1945-1964, 23 J. Fin. 389, 400 tbl.2 (1968) (finding negative average alphas for mutual funds in the 1940s-1960s); see generally Bruce N. Lehmann \& David M. Modest, Mutual Fund Performance Evaluation: A Comparison of Benchmarks and Benchmark Comparisons, 42 J. FIN. 233 (1987) (measuring alphas for 130 mutual funds over a fourteen-year period). Javier Gil-Bazo and Pablo Ruiz-Verdú also show that among actively managed equity funds, funds that are high-cost have worse "before-fee risk-adjusted" performance, meaning that high costs generally do not ensure better returns. Javier Gil-Bazo \& Pablo Ruiz-Verdú, The Relation Between Price and Performance in the Mutual Fund Industry, 64 J. Fin. 2153, 2154 (2009).

45. For instance, Barras, Scaillet, and Wermers find that $75.4 \%$ of the entire cross-section of mutual funds generate alphas equal to zero. Barras et al., supra note 41, at 196, 197 tbl.2. From the $24.6 \%$ remaining funds, $24.0 \%$ produce negative alphas and $.6 \%$ yield truly positive alphas. $I d$. at 197 tbl.2. Kosowski, Timmermann, Wermers, and White deploy a bootstrap strategy to detect that that the large positive alphas of the top $10 \%$ of funds, net of costs, are extremely unlikely to be solely due to luck and not managerial skill. Robert Kosowski et al., Can Mutual Fund "Stars" Really Pick Stocks? New Evidence from a Bootstrap Analysis, 61 J. FIN. 2551, 2580, 2593-94 (2006). Meanwhile, Baks, Metrick, and Wachter identify the gains from investing in actively managed funds by using a Bayesian method of performance evaluation that accounts for investors' prior beliefs about alphas that are consistent with intuition about managerial skill. Klaas P. Baks et al., Should Investors Avoid All Actively Managed Mutual Funds? A Study in Bayesian Performance Evaluation, 56 J. FIN. 45, 46-47 (2001). Other studies have estimated positive alphas using past returns, manager characteristics like age and education, and past fund inflows. See Mark M. Carhart, On Persistence in Mutual Fund Performance, 52 J. FIN. 57, 67 (1997) (associating portfolio characteristics like size and turnover with performance); Robert S. Carlson, Aggregate Performance of Mutual Funds, 1948-1967, 5 J. Fin. \& QUALITATIVE ANALYSIS 1, 20 (1970) (finding a positive relationship between portfolio performance and the availability of new funds); Judith Chevalier \& Glenn Ellison, Are Some Mutual Fund Managers Better Than Others? Cross-Sectional Patterns in Behavior and Performance, 54 J. FIN. 875, 876 (1999); Edwin J. Elton et al., The Persistence of Risk-Adjusted Mutual Fund Performance, 69 J. Bus. 133, 134 (1996); Joseph H. Golec, The Effects of Mutual Fund Managers' Characteristics on Their Portfolio Performance, Risk and Fees, 5 FIN. SERV. REV. 133, 136 (1996); Mark Grinblatt \& Sheridan Titman, The Persistence of Mutual Fund Performance, 47 J. FIN. 1977, 1983 (1992); Martin J. Gruber, Another Puzzle: The Growth in Actively Managed Mutual Funds, 51 J. FIN. 783, 793 (1996); Darryll Hendricks et al., Hot Hands in Mutual Funds: Short-Run Persistence of Relative Performance, 1974-1988, 48 J. FIN. 93, 102 (1993); Lehmann \& Modest, supra note 41, at 260; Lu Zheng, Is Money Smart? A Study of Mutual Fund Investors' Fund Selection Ability, 54 J. FIN. 901, 912 (1999). 
persistent. ${ }^{46}$ For example, a recent study found that of the top half of funds in 2010 , only $4.47 \%$ were able to stay in the top half for five years, and only $0.28 \%$ stayed in the top quarter. ${ }^{47}$

\section{B. Diversification Costs}

Estimating the required alpha to justify sacrificing diversification is the central empirical motivation for this Article. Imagine that you had a lumpy choice of either investing all your savings in a single stock representative of public U.S. companies (say, your company's) or in a fully diversified mutual fund of U.S. equities. How big would the expected alpha on the single stock have to be to justify the obvious loss in reduced idiosyncratic risk that could be achieved through diversification ${ }^{48}$

To answer this question, we examined historical data on U.S. stocks from the mid-1920s through 2015 . We calculated the utility of investors with various levels of risk aversion from holding either a diversified portfolio or a single stock over the course of one year. We then estimated how much alpha the individual stock must generate before an investor would prefer the individual stock with its higher alpha-boosted returns but higher risk to the diversified portfolio. We made separate calculations for periods of market upheaval because idiosyncratic risk rises during economic crises ${ }^{49}$ meaning that the required alpha will usually rise as well. We defined these

46. See Carhart, supra note 41 , at 74 (attributing persistent positive performance in managed portfolios to statistical noise rather than managerial skill); Barras et al., supra note 44, at 182 (finding that new, over-performing funds which attract high inflows of new investments are relatively likely to be estimated to have produced positive alpha (18\% of funds), but over the next five years only $2.4 \%$ of those funds are estimated to have produced positive alpha).

47. Aye M. Soe, S\&P Dow Jones Indices, Does Past Performance Matter? The PERSISTENCE SCORECARD 3 exhibit 2 (2014), http://www.spindices.com/documents/spiva /persistence-scorecard-june-2014.pdf [https://perma.cc/G85A-XVEK]. A recent paper provides a more comprehensive review of this extensive literature. See generally Jason P. Berkowitz et al., Characteristics of Mutual Funds with Extreme Performance, REV. FIN. ECON., Sept. 2017, at 50. It is plausible that high-fee funds are more likely to earn sufficient alpha to offset their costs to investors in less informationally efficient markets than U.S. equities, like real estate, U.S. bonds, or equities in developing countries, etc. But see Edwin J. Elton, Martin J. Gruber \& Christopher R. Blake, Fundamental Economic Variables, Expected Returns, and Bond Fund Performance, $50 \mathrm{~J}$. FIN. 1229, 1251 (1995) (finding average negative alphas in bond mutual funds).

48. This comparison is close to an analogous choice between investing costlessly in a single representative stock or investing in a fully diversified mutual fund with excess fees. And the analogous question is: How high would the excess fees have to be before you would prefer investing in the single stock? This question arises in real-world settings as some 401(k) plans offer company stock with no (or minimal) transaction or annual fees while offering mutual funds with annual expenses well above 100 basis points. See Ayres \& Curtis, Beyond Diversification, supra note 13, at $1502 \&$ n.93 (finding that $48 \%$ of plans offering company stock have such high fees that some investors would be wise to rationally sacrifice diversification by tilting their portfolio toward company stock investments).

49. Edward G. Fox, Merritt B. Fox \& Ronald J. Gilson, Economic Crisis and the Integration of Law and Finance: The Impact of Volatility Spikes, 116 COLUM. L. REV. 325, 329 (2016). 
Table 1

By How Much Must a Risk-Averse Person Outperform the Market to Make Holding a Single Stock Worthwhile?

\section{Additional Alpha}

\section{CRRA Coefficient $=1(\log$ Utility $)$}

\section{Required $^{50}$}

Regular Period

Crisis Period

$5.00 \%$

\section{CRRA Coefficient $=2$}

Regular Period

Crisis Period

\section{CRRA Coefficient $=3$}

Regular Period

Crisis Period

$14.80 \%$

\section{CRRA Coefficient $=4$}

Regular Period

Crisis Period

$19.10 \%$

Notes: The holding period is one year. The distribution of both the market and single-stock returns is constructed by randomly sampling from the historical returns of firms in the CRSP database from 1926-2015 (i.e., by Monte Carlo simulation). For the market, we use the market-cap-weighted average of all of the CRSP firms. We then calculate the real 1-year return for each month for this market portfolio during 1926-2015, and then randomly select (with replacement) 100,000 of the 1year returns to create a distribution. Similarly, we calculate a 1 -year real return for every firm for each month during the period and then randomly select 100,000 firm-years. The probability of selection is proportional to the firm's market cap as a percent of total market cap at the start of that month. "Crisis" periods are defined as any month in which the annualized standard deviation of market returns in the previous month was greater than $25 \%$.

\footnotetext{
${ }^{50}$ Note that our assumptions bias the estimated alphas downward because we assume the alpha is guaranteed. In reality, investors will not know with certainty whether a stock they believe will outperform the market will in fact do so. Accounting for this uncertainty increases the required alpha for risk-averse investors, sometimes substantially. For example, if the actual alpha is uniformly distributed between 0 and 2 times the expected alpha, the required alpha for investors with CRRA of $4 \%$ to $21 \%$ in normal periods and $45 \%$ in crisis periods. These estimates are presented in the Online Appendix to this Article. Ian Ayres \& Edward Fox, Appendix to Alpha Duties: The Search for Excess Returns and Appropriate Fiduciary Duties, fig.A1.3 (Jan. 28, 2019), https://ianayres.yale.edu/sites/default/files/files/AlphaDutiesAppendix.pdf [https://perma.cc/9BJE-3ADB].
} 
crisisperiods as those in which the annualized standard deviation of market returns over the previous month was $25 \%$ or more. (Further details on our calculations are included the following table.)

Table 1 teaches several important lessons. First, we can see that rational investors, even during regular periods, would require quite substantial alphas before foregoing the benefits of diversification. For investors with moderate risk aversion (measured by CRRAs between 2-4), the required excess annual returns by which an investment would need to be expected to beat the market ranges from $6.4 \%$ to $15.0 \% .^{51}$ Intuitively, investors with higher levels of risk aversion demand greater increases in expected return to bear the same increase in risk. Thus, they will require a higher alpha before they are willing to bear the same amount of additional idiosyncratic risk. ${ }^{52}$ As we discuss in detail, these large alphas are consistent with the increasing emphasis on the importance of diversification in fiduciary law, particularly in trusts, over the last 30 years.

51. As mentioned in note 48, supra, these estimates are very close to answers for the analogous choice between investing in a high-fee mutual fund versus a single (zero alpha) stock. In the latter case, the fees on the diversified mutual fund would need to exceed 500 basis points for many investors before they would prefer investing in a single stock to the high-fee fund. These extremely high fees probably exceed the risk premium that could be reasonably expected by investing in the mutual fund or the stock, however. Thus, these investors, if given the choice, would prefer to invest primarily in Treasury bonds rather than the 500-basis-point-fee fund or the single stock.

52. Note that we are assuming that the investors put their entire savings into either the market or a single stock and have no other source of income. If an investor has outside income like a salary from a safe job, her total wealth/consumption will be less variable, and therefore she will not demand quite as large alphas to bear additional idiosyncratic risk. The same is true if that outside income comes instead from the investor placing part of her portfolio in safe assets like inflationprotected government bonds. If an investor keeps $20 \%$ of her wealth in safe assets, that reduces the alphas by about $20 \%$ to $25 \%$ depending on her level of risk aversion. In the Online Appendix Table A1.2 we re-estimate Table 1 with varying levels of safe income. On the other hand, most of us actually bear additional risk through our human capital; our salaries are not safe but instead depend on how our firm, the industry in which we work, and the economy as a whole are performing. In such cases, risk-averse investors might rationally demand even higher alphas to bear additional idiosyncratic risk by owning, say, company stock. 
Second, we see from the table that the alpha required during crisis periods is substantially larger than during regular (non-crisis) periods. For investors with moderate risk aversion (again measured by CRRAs between $2-4$ ), the required alpha to forego diversification benefits ranges from $9.9 \%$ to a whopping $19.1 \%$, ballooning during these crisis times. This is primarily because idiosyncratic risk rises during crises. During ordinary periods, the idiosyncratic risk (measured as a standard deviation of return) is $27.4 \%$, while during crisis periods, the standard deviation is $37.8 \%$. As idiosyncratic risk increases, the benefits of diversification increase and therefore the alpha required to get investors to give up diversification increases as well. ${ }^{53}$

Table 2 estimates the required alpha that would be necessary to compensate for bearing different levels of idiosyncratic risk, given different levels of systemic risk.

53. In addition, crisis periods are defined by increases in systemic risk: during ordinary periods, the systemic market risk (measured as a standard deviation of expected return) is $19.2 \%$, while during crisis periods the standard deviation is $34.8 \%$. This rise in systemic risk increases risk-averse investors' sensitivity to taking on additional idiosyncratic risk. Put differently, a risk-averse investor loses more utility when his total risk (as measured by standard deviation) increases from $20 \%$ to $30 \%$ than going from $10 \%$ to $20 \%$. Thus, for the same increase in total risk brought on by idiosyncratic risk, investors will demand a higher alpha during periods of higher systemic risk.

Yet the rise in systemic risk can have offsetting effects. If idiosyncratic risk stays fixed and systemic risk increases, the marginal increase in total risk (as measured by standard deviation) from the fixed amount of idiosyncratic risk will fall. This is easier to see in an example. Assume idiosyncratic risk is $10 \%$, and systemic risk is $10 \%$. In that case, total risk-measured by the standard deviation of returns - will be the square root of the idiosyncratic risk squared plus the systemic risk squared $=\left(\sqrt{.1^{2}+.1^{2}}=14.1 \%\right)$, or $4.1 \%$ more than the systemic risk alone. If systemic risk now rises to $30 \%$, total risk is $\sqrt{.1^{2}+.3^{2}}=31.6 \%$, or just $1.6 \%$ more than systemic risk alone. The decreasing contribution of idiosyncratic risk to total risk can offset the investor's increasing sensitivity to additional risk, to the extent the investor's utility is affected by the standard deviation (rather than the variance) of total risk. In addition, increases in systemic risk can change the shape of the distribution of returns. For example, the rise in systemic risk may cause the distribution of total returns to become asymmetric, with more returns below the mean than above. This would change the "skew" of the distribution. These other effects on the shape of the distribution can in theory either increase or decrease the alpha demanded when systemic risk rises.

This complex relationship is reflected in Table 2 in which, for a given level of idiosyncratic risk, alpha usually rises but sometimes falls as systemic risk rises. 

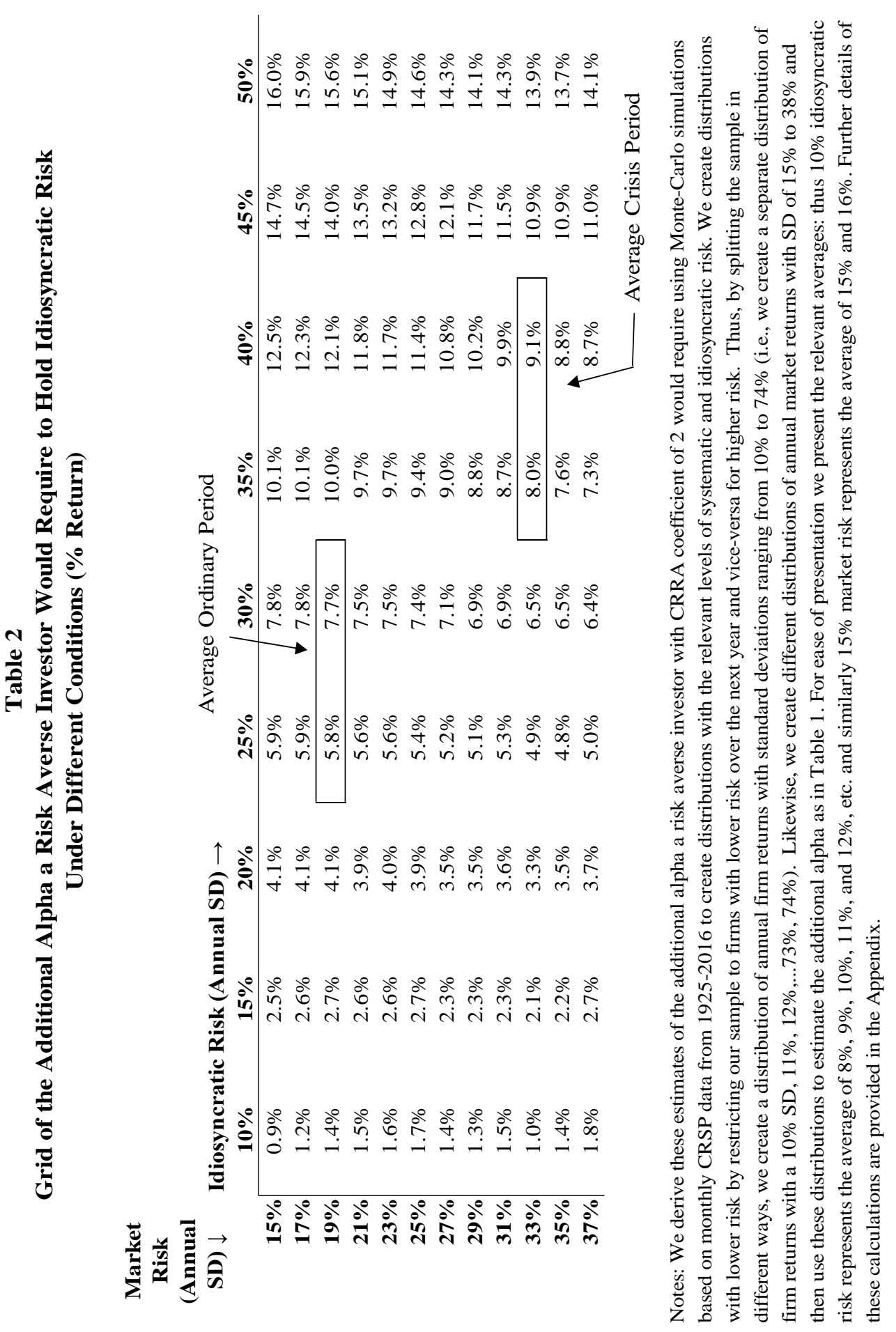
Table 2 helps us more clearly see why the required alpha rises during crises as both systemic and idiosyncratic risks rise, pushing southeast in the table. But the table is also useful in that it allows a more nuanced and specific assessment of how much annual alpha is required in particular circumstances. The market risk at any time can be estimated by viewing forward-looking market volatility measures (such as the VIX), and the idiosyncratic risk can be similarly estimated for any stock with traded options. ${ }^{54}$ Using these two inputs, one could assess what alpha was necessary for more particularized situations. Thus, for example, we estimate that an Enron employee with slightly below-average risk aversion $(\mathrm{CRRA}=2)$ who forewent diversification to invest her retirement savings entirely in company stock would need to expect at least an average alpha of $10.8 \% .{ }^{55}$ In fact, we have created an online widget that lets anyone plug in three variables (a level of CRRA risk aversion, a level of market risk, and a level of idiosyncratic risk for a particular stock) to determine the alpha required to take on the additional idiosyncratic risk. ${ }^{56}$

The results above barely budge if we instead use the FamaFrench three-factor model to measure the amount of uncompensated risk inherent in holding an average stock. As noted above, Eugene Fama and Kenneth French have shown that a stock's relative market capitalization and the ratio of its book value to market value also help predict its return, along with market exposure. They hypothesize that a stock's market exposure is an incomplete measure of the kinds of undiversifiable risk faced by its owners, and these other two factors proxy for these other risks, which help drive

54. A call (or put) option gives the owner the right to purchase (or sell) for a given price in the future. The value of these options depends in part on the expected volatility of the underlying stock from now until the option's expiration. Thus, when investors buy or sell options, they are, in part, placing an implicit bet on the volatility of the stock, and we can back out the market's prediction for a stock's future volatility from its option prices. Using this forward-looking measure of the stock's total volatility, we can capture the idiosyncratic part by regression or otherwise controlling for forward-looking measures of market volatility, like the VIX. See Fox, Fox \& Gilson, supra note 46, app. at 14 fig.A-8 (2015) (charting S\&P 100 firms' idiosyncratic risk derived from markettraded options' implied volatilities), https://sites.google.com/site/volatilityspikesappendix/ [https://perma.cc/PDQ5-RAFU].

55. To calculate this figure, we estimate an alpha for each day from January 1, 1999, to October 1, 2001, shortly before the Enron scandal finally broke, and then take the average. The calculation uses the implied volatility method discussed supra in note 50 to give forward-looking measures of systemic and implied volatility. Although we do not model it here, we emphasize that investing in company stock can be particularly risky because the employee's own human capital may be disproportionately exposed to idiosyncratic risk of her company. See Shlomo Benartzi, Excessive Extrapolation and the Allocation of 401(k) Accounts to Company Stock, 56 J. FIN. 1747, 1747-48 (2001) (explaining that "because employees select a stock that is presumably correlated with their human capital," they risk the loss of "both their retirement savings and their jobs if the company fails").

56. https://ianayres.yale.edu/sites/default/files/files/AlphaWidget.xlsx; Ian Ayres \& Edward Fox, By How Much Must a Risk-Averse Person Outperform the Market to Make Holding a Single Stock Worthwhile (2018) (Microsoft Excel spreadsheet) (on file with author). 
returns. ${ }^{57}$ Nevertheless, when we use the Fama-French model to measure how much alpha an investor would demand, the results are basically unchanged:

\section{Figure 6}

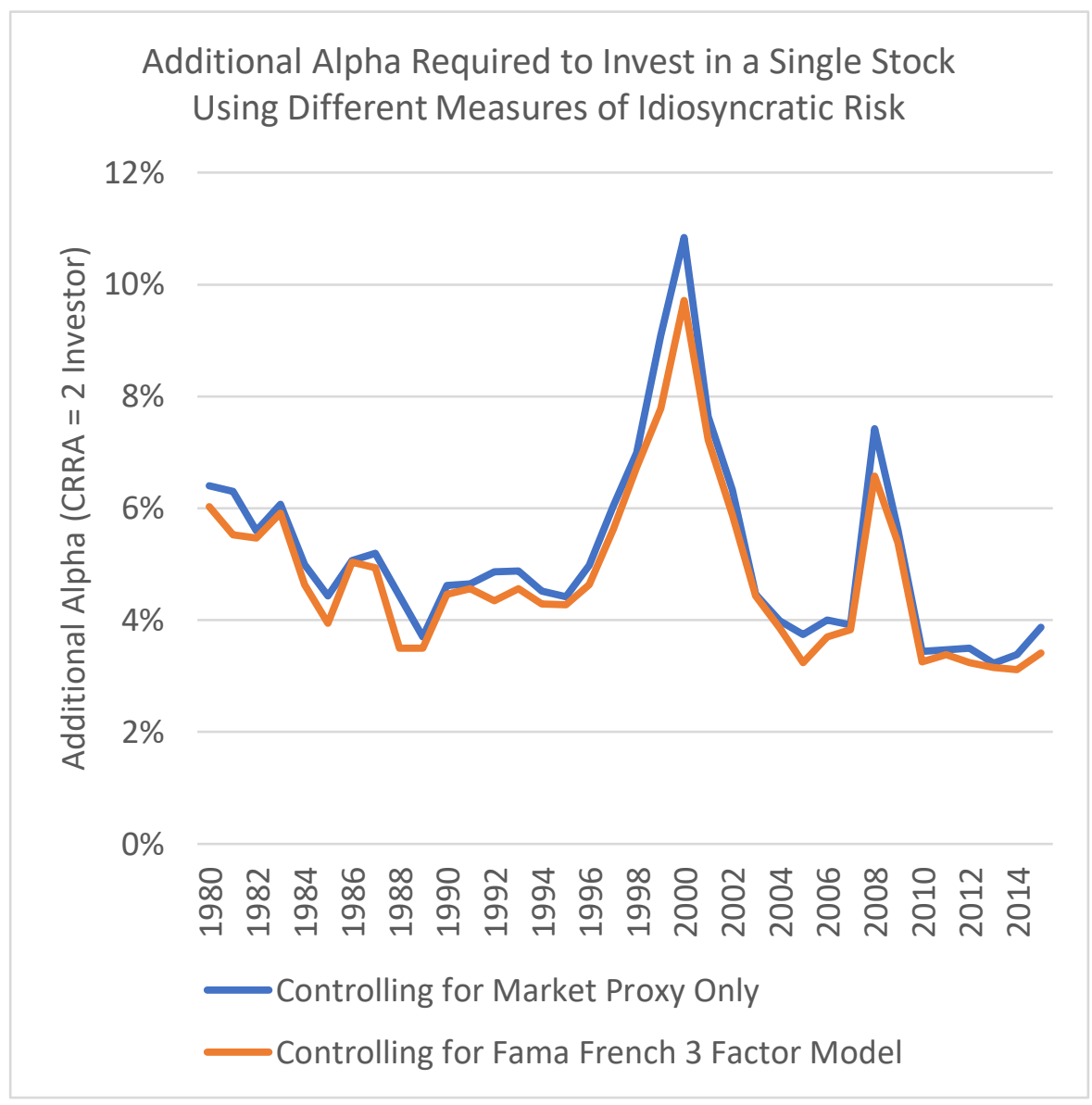

Of course, most alpha investment opportunities are not quite so extreme as to require investing in a single stock. While the previous tables have focused on all-or-nothing tradeoffs, in most real-world settings investors are only required to partially de-diversify in order to reap higher expected returns. For example, some investors may invest all their savings in an actively managed mutual or hedge fund that invests in several stocks that the fund's managers believe will outperform the stock market generally.

57. See Eugene F. Fama \& Kenneth R. French, The Capital Asset Pricing Model: Theory and Evidence, J. ECON. PERSP., Summer 2004, at 25, 38 (describing the effects of size and book-tomarket ratios on stock returns). 
Investing heavily in sector funds also sacrifices some potential diversification because the investor's portfolio bears the risk particular to that industry instead of diversifying it away by investing in the other sectors of the economy. These partially diversified positions also require offsetting alphas (but not as much as alpha opportunities that invest in a single stock).

To investigate how much alpha is required to compensate an investor for only partially diversifying, we perform another set of simulations based on historical data. In particular, in each year from 1926 to 2015, we randomly choose 1,000 representative portfolios with a given number of stocks (e.g., 20 stocks or 50 stocks). We then calculate how much idiosyncratic risk remains in these partially diversified portfolios and, using the figures underlying Table 2, convert this level of idiosyncratic risk into an alpha. ${ }^{58}$ We plot the results in Figure 7 for the 20- and 50-stock portfolios from 1960 to 2015:

58. The portfolios are representative in the sense that the probability of selecting a stock in the portfolio is proportional to the market capitalization of that firm over the course of the year.

Note that our method of calculating alpha for 20 or 50 firm portfolios using the data underlying Table 2 may in some cases overstate the alpha required. Using the data from Table 2 implicitly assumes that the 20 and 50 stock firm distributions look like individual firm distributions with the same level of total risk, but this may not be true. In particular, the 20 and 50 stock portfolios are likely less prone to extremely low (or high) returns than individual firms, even if the distributions have the same standard deviation. This would mean the 20 and 50 stock portfolios would have "thinner tails." In the Online Appendix, we present an alternate version of Figure 7 using the normal distribution instead of Monte-Carlo simulations to convert the additional risk imposed by the 20 and 50 stock portfolios into an alpha figure, which produces somewhat smaller-although still substantial—alphas. 


\section{Figure 7}

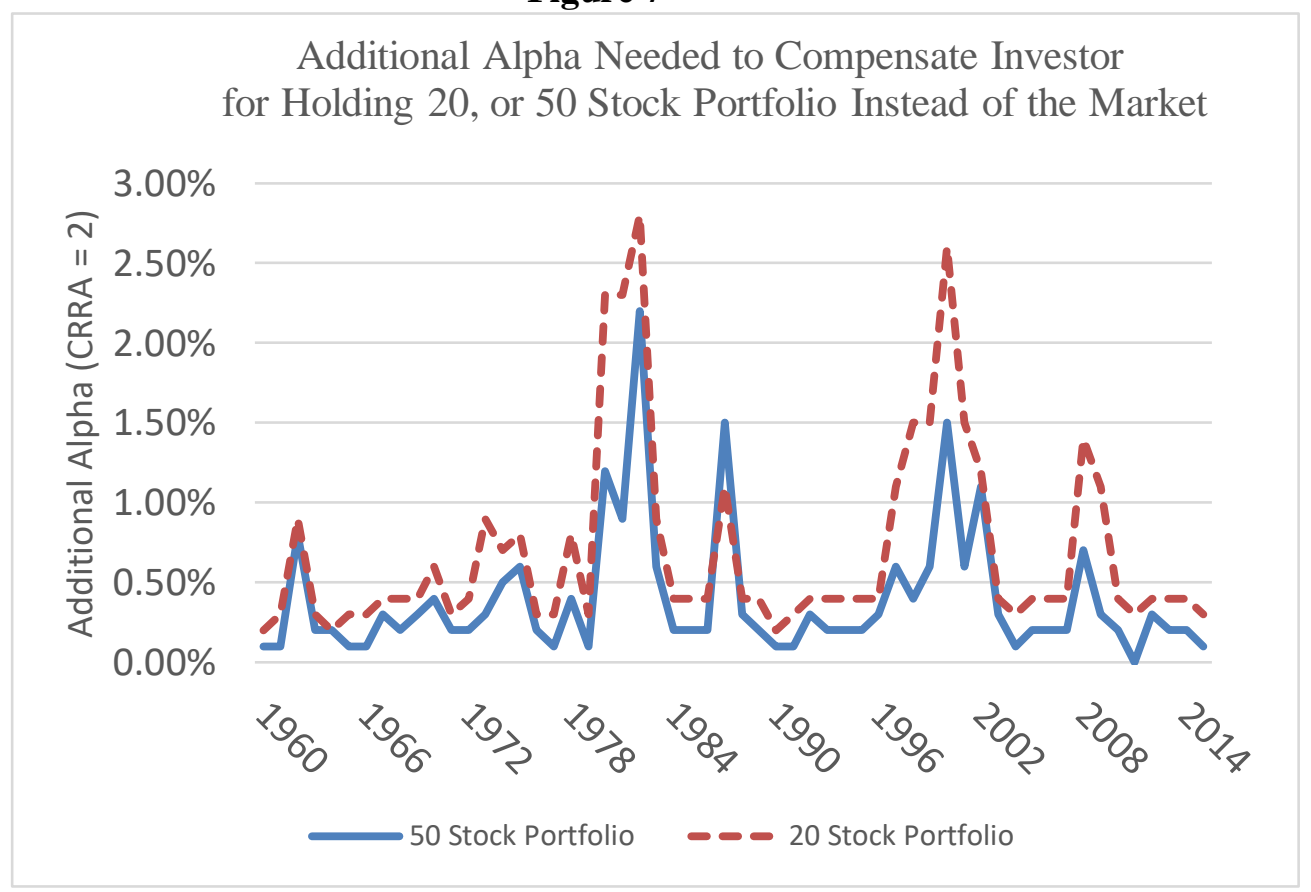

Notes: Each portfolio of 20 and 50 stocks for each year is created by drawing stocks randomly (without replacement), where the probability of selection is proportional to the stock's average market capitalization over the year. The portfolio return is also market capitalization weighted (i.e., the return of large firms has a larger effect on the portfolio returns than small firms). We draw 1,000 random portfolios of 20 and 50 stocks each year. We calculate the remaining idiosyncratic risk in each portfolio and take the average across the 1,000 portfolios and then calculate an alpha associated with that average idiosyncratic risk and the level of market risk in that year for an investor with a CRRA coefficient equal to 2 .

Figure 7 reveals that the required level of compensating alpha is, as theory would predict, substantially lower for partially diversified portfolios. While the average annual compensating alpha for a single stock over this time period is $5.71 \%$, we find that this drops to $0.70 \%$ when investing in 20 stocks and to $0.39 \%$ when investing in 50 stocks. But importantly, the figure shows that even with 50 stocks there are 5 separate years where the required offsetting alpha is at least $1 \%$. It is often suggested that investors can achieve the most important benefits of diversification by investing in just 10 or 20 different stocks ${ }^{59}$ but our estimates show substantial variation in the requisite

59. See, e.g., Robert H. SITKOFF \& JESSE DUKEMINIER, WILls, TRUSTS, AND EsTATES 640 (2017) (citing empirical evidence that investing in 10 or 20 different stocks achieves more than $88 \%$ of diversification's advantages). We are not in fact the first to observe the need, sometimes, to hold more than 20 stocks to eliminate the vast majority of idiosyncratic risk. See BURTON G. MALKIEL, A Random Walk Down Wall StReet: The Time-Tested StRategy for Successful INVESTING 207-08 (2011) (observing that in the years prior to 2011 one needed to hold 40-50 stocks 
alpha necessary to justify even relatively small departures from full diversification. During periods with relatively high systemic risk, then, adding even small amounts of potentially diversifiable idiosyncratic risk can necessitate substantial alphas. If the normal risk premium for holding nondiversifiable market risk is $4 \%$, then the alpha-adjusted risk premium required for adding on just the idiosyncratic risk of a 50-stock portfolio is frequently $25 \%$ higher. ${ }^{60}$ The takeaway here is that even partially diversified investment opportunities can at times require relatively substantial alpha to make such an investment utility-enhancing. As explained below, these results suggest that the usual rule of thumb about how much diversification is "enough" may be too loose.

\section{Exposure Costs}

Finally, we estimate the "beta" costs of being non-optimally exposed to the equity risk premium. As discussed above, beta costs can come in two forms: one can have too little equity exposure (as when a 23-year-old invests all her savings in money market funds), or one might have too much equity exposure (as when a risk-averse 70-year-old with a modest nest egg invests all her savings in stock). And while beta costs often also require sacrificing diversification when an alpha investment is lumpy, in this section we isolate the compensating alpha required to offset having to take on inefficiently high or low beta. (In other words, we assume that there are no diversification or excessive-fee losses entailed in the investment.)

to eliminate the vast majority of idiosyncratic risk). From 2013 to 2017, idiosyncratic risk fell again, making the environment closer to the one studied in the older papers which find smaller numbers of stocks sufficient. See generally Söhnke M. Bartram, Gregory W. Brown \& René M. Stulz, Why Has Idiosyncratic Risk Been Historically Low in Recent Years? (Nat'l Bureau of Econ. Research, Working Paper No. 24270, 2018), https://www.nber.org/papers/w24270 [https://perma.cc/XD5R8JVU] (finding idiosyncratic risk since 2013 has been low compared to historical averages and particularly compared to the late 1990s and early 2000s). The recent rise in systemic risk in the final quarter of 2018, however, suggests that idiosyncratic risk has risen again. These secular fluctuations and in particular their cyclicality, however, has largely escaped notice in the legal literature. But see Fox, Fox \& Gilson, supra note 46, at 336 fig.2, 397 (analyzing cyclical increases of idiosyncratic risk).

60. $5 \%=4 \%+1 \%$ is $25 \%$ higher than $4 \%$. 
As emphasized above, the notion of a beta error is only comprehensible if we have a background idea of what an optimal exposure to equities would be. That optimal level is intuitively a function of a particular investor's level of risk aversion, which might (or might not) increase as she ages. In the following table, we assume that the optimal equity exposure is determined by the Merton share described above $\left(\right.$ as $\beta_{M}$ ) so that investors with higher constant relative risk aversion would optimally choose to have lower exposures to equity. ${ }^{61}$ Applying a historical distribution of returns to the market portfolio and risk premiums, we can calculate the ideal $\beta$ for an investor with any level of risk aversion. Taking investors with ideal $\beta$ 's of $0.1,0.2, \ldots, 0.9$, and 1 as examples, we then estimate how much alpha they would require to depart from their ideal $\beta$ in Table 3 following. ${ }^{62}$

61. For example, an investor expecting a $4.15 \%$ risk premium, $21 \%$ equity return standard deviation, and with a CRRA of 2 would optimally invest $47 \%$ of her saving in equities, while an investor with the same expectation but a CRRA of 4 would optimally invest only $23 \%$ in equities.

62. Observe that the assumptions underlying Table 3 use the CAPM result that the equity premium is fully explained by market risk (as measured by $\beta$ ). In fact, tests have shown that while higher $\beta$ firms have higher expected returns, this does not usually explain the entire equity premium. E.g., Fama \& French, supra note 57, at $32 .$. 


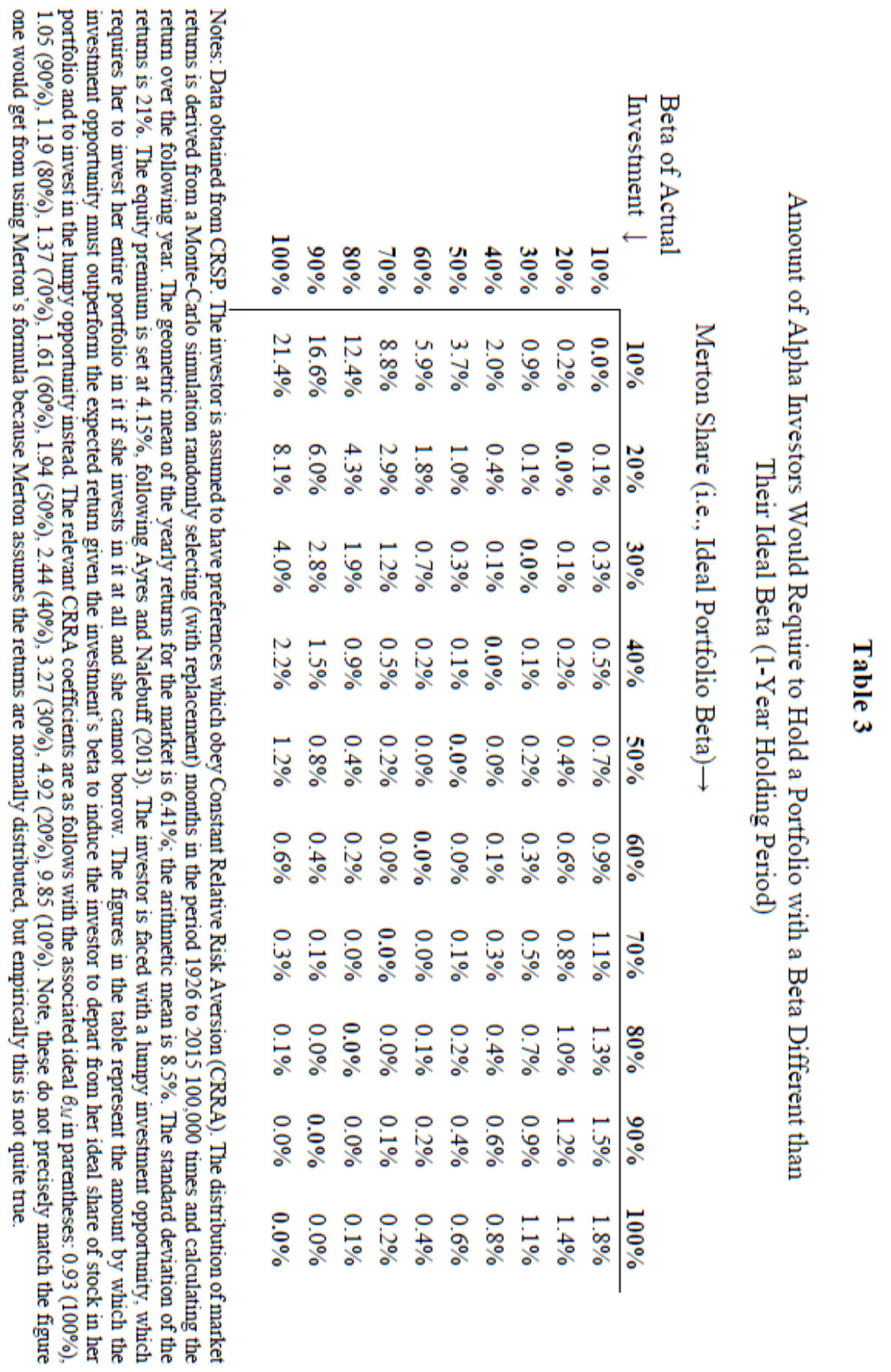


In Table 3, one can see the offsetting alphas from having too much or too little exposure to equities. ${ }^{63}$ The table shows that investors are more sensitive to beta deviations as they become more risk averse. For example, an investor with a $\beta_{M}=0.3$ would need an annual alpha of $0.3 \%$ before making a beta deviation of 0.2 , while an investor with a $\beta_{M}=0.7$ would only need an alpha of $0.1 \%$ for making that-sized beta deviation. More generally, the alpha required for putting risk-averse investors in high beta investments are substantially higher than the alphas required of relatively risk-neutral investors in low beta investments. Hence, we see in the diagonal corners of Table 3 that the alpha required for putting a $\beta_{M}=0.1$ investor into a $\beta=1$ portfolio is a whopping $21.4 \%$, while the alpha required for putting a $\beta_{M}=1$ investor in a $\beta=0.1$ portfolio is only $1.8 \%$. As we discuss below, this result accords with how fiduciary law has generally approached the question of beta mistakes: not investing aggressively enough is harmful, particularly over time, but the most damaging beta mistake in the short term is exposing a highly risk-averse client - a widow who is the sole beneficiary of a small trust set up for her maintenance - to too much risk.

In most real-world contexts, the estimates in Table 3 for lumpy investments should be seen as lower bounds on the required alphas for portfolio deviations from optimal betas. This is because the lumpiness of the investments usually entails some degree of diversification loss. The opportunity to invest a substantial portion of your portfolio in a friend's startup, for example, might force your portfolio above your optimal beta and expose your portfolio to idiosyncratic risk. Accordingly, in such circumstances it will be necessary in calculating the required alpha to account for (and offset) both types of losses. For example, if investing all of your savings in a friend's start-up caused you, a $\beta_{M}=0.5(\leftrightarrow \mathrm{CRRA} \approx 2)$ investor, to take on $\beta=1$ portfolio and expose your portfolio to average non-crisis idiosyncratic and market risk, then you would need at least an alpha of $7.6 \%$ : $6.4 \%$ to compensate for the diversification loss (as shown in Table 1) and an additional alpha of $1.2 \%$ to compensate for the beta loss (as shown in Table 3). ${ }^{64}$

63. For example, an investor who, ignoring the offsetting benefits of alpha opportunities would want to invest half of her savings in equities $\left(\beta_{M}=0.5\right)$, would need an offsetting annual alpha of $0.2 \%$ before wanting to invest her savings in a portfolio with a $\beta$ of 0.7 . Reading up and down individual columns, the table reveals substantial symmetry in the size of the offsetting alpha with regard to movements above or below the ideal beta. Thus, the same investor (with $\beta_{M}=0.5$ ) would also require an offsetting alpha of $0.2 \%$ before wanting to invest in a portfolio with a similarly sized beta deviation of 0.3 .

64. As discussed supra in note 35 , an investor's ideal $\beta$ for a lumpy investment with idiosyncratic risk will be lower than her ideal beta for investing in a diversified portfolio. Thus, in this case, the beta error is actually worse than it first appears, and the total alpha will be higher than one would calculate by adding the relevant numbers from Table 1 and Table 3 . 


\section{D. $\quad$ Tilting Mistakes}

While most of our foregoing estimates concern discrete investment opportunities, there are many real-world opportunities that give investors the option of varying the proportion of their portfolio that is invested. In such "non-lumpy" circumstances, theory suggests that an investor will want to "tilt" her portfolio toward alpha opportunities by overweighting the portfolio share of the alpha opportunity, even though this overweighting will expose the investor to some idiosyncratic risk. In this section, we investigate how much a person should invest in a non-lumpy alpha opportunity given two key variables: the size of the alpha and the total risk of alpha opportunity. ${ }^{65}$ As with beta mistakes, tilting mistakes can come in two varieties: (1) an investor can under-tilt by putting too small a proportion of her portfolio in the nonlumpy alpha opportunity or (2) the investor can over-tilt by putting too large a proportion of her portfolio in the alpha opportunity.

Table 4 estimates the optimal tilt for an investor with moderate risk aversion $($ CRRA $=2)$ depending on the size of the alpha and the riskiness of the alpha opportunity, fixing the riskiness of the market $(20 \%$ standard deviation), the $\beta$ of the alpha opportunity $(\beta=1)$, and the risk premium for holding the market portfolio instead of risk-free assets (5\%).

65. Here we measure total risk as the standard deviation of investing $100 \%$ of the portfolio in the alpha opportunity. In equilibrium, however, the total risk of the optimal portfolio will normally be reduced (toward the market risk), by investing only a portion of the portfolio in the alpha opportunity. 
Table 4

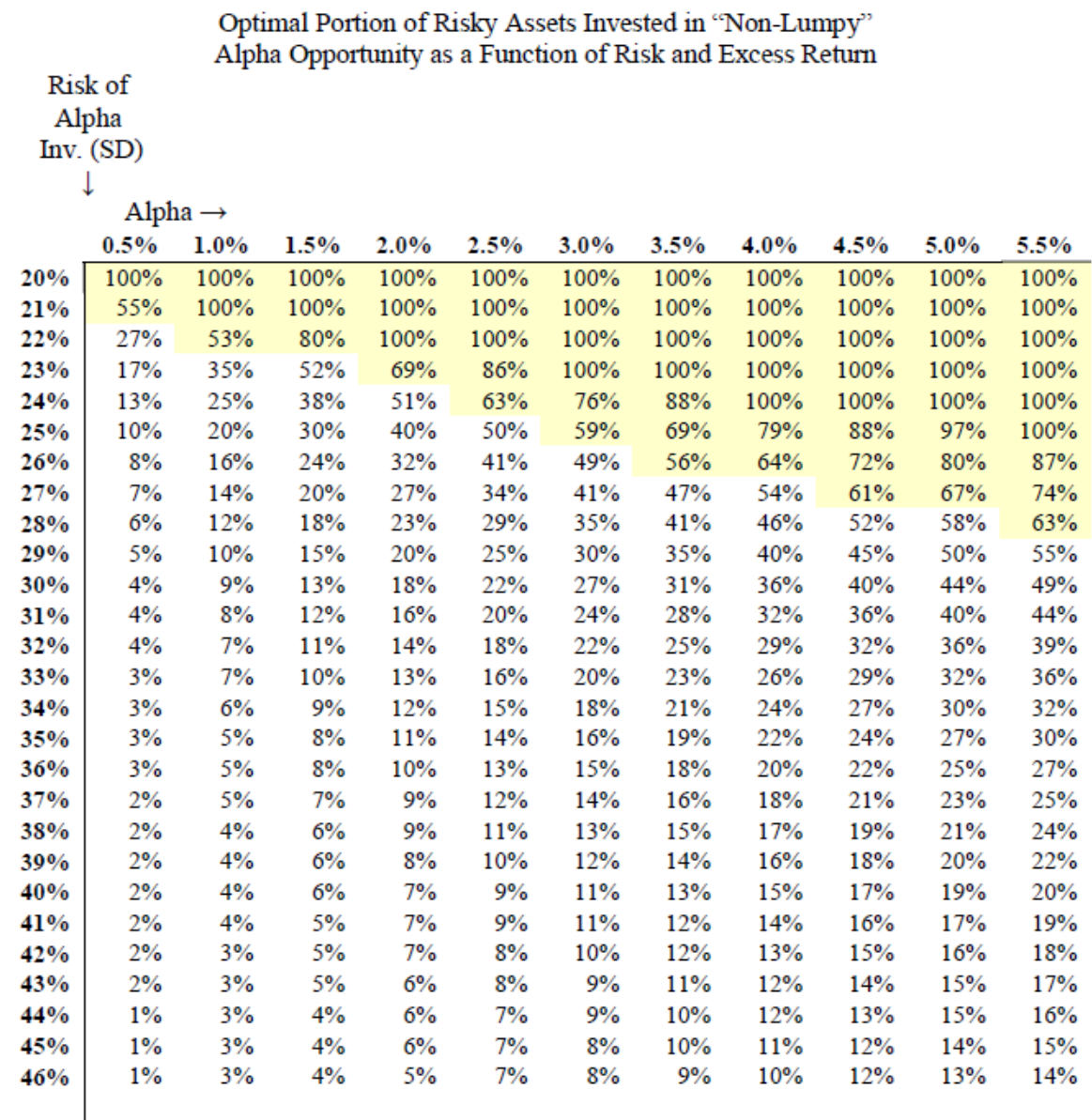

Notes: The investor's utility is assumed to obey Constant Relative Risk Aversion with a CRRA coefficient of 2 . We set the risk premium at $5 \%$, and use a $\beta$ of 1 for the alpha opportunity with the market risk of $20 \%$. The areas shaded in represent lumpy alpha opportunities an investor would choose if given the discrete choice to invest all or none of her portfolio in the alpha opportunity. Returns are assumed to be normally distributed.

Table 4 shows that when $100 \%$ tilting would expose the investor to relatively small additional idiosyncratic risk, that relatively small alpha is necessary to induce an investor to want to put all of her portfolio in the alpha opportunity. For example, if going full-tilt only increases the total risk standard deviation of return by 1 percentage point (from $20 \%$ to $21 \%$ ), then Table 4 shows that an alpha of just $1 \%$ would be sufficient to induce an investor to want to invest all of her portfolio in the alpha opportunity (even though she has the non-lumpy option to invest a lesser proportion).

But as the cost of tilting increases, investors will optimally invest a lower proportion of their portfolio in the alpha opportunity. Thus, we see if a $1 \%$ alpha opportunity has an associated total risk of $30 \%$, an optimal investor 
(with a CRRA risk aversion of 2) should want to invest only 9\% of her portfolio in the alpha opportunity. Under these circumstances, investing less than $9 \%$ of one's portfolio would represent an under-tilting error, while investing more than $9 \%$ would represent an over-tilting error. We conjecture in real-world settings that over-tilting is the more important error. Retail investors who are not aware of the size of the gains from diversification frequently hold only a few stocks, or even only stock in their company. Even if these investors believe the stocks will outperform the market, they are probably making a mistake by treating those stocks as though they require large minimum investments (as a share of the investor's portfolio). Although there are situations in which the alpha is so great that one would want to hold only the alpha investment even if it is "non-lumpy" - as in the northeast corner of Table 4-these situations will be relatively rare in the real world, because they require very large alphas (or very small idiosyncratic risk).

Stepping back, we have provided in this Part some of the first estimates of the minimum alphas that are required to offset diversification and beta losses, ${ }^{66}$ as well as excessive fees. But for a variety of reasons, these estimates should be viewed as ballpark measures. For example, our estimates on diversification losses assume that investors have a particular form of (constant relative) risk aversion. Other types of risk aversion are less mathematically tractable but might be more empirically relevant and give rise to alternative estimates. ${ }^{67}$ In addition, we have not modeled investors' exposure to the market through their human capital. ${ }^{68}$ Also, our estimates have assumed that investors "know" a variety of variables, including the alpha of particular investment opportunities and the levels of idiosyncratic and market risk. But in many situations, investors are likely to have varying

66. The importance of diversification, fees, and appropriate exposure to market risk has long been understood, but we are unaware of other work that has systematically converted the losses from sacrificing diversification or beta mistakes into an alpha required to justify them. Doing so is informative because most work simply treats failure to fully diversify or expose one's portfolio to the right level of market risk as an important mistake, but does not tell us when these costs are worth bearing.

67. Scholars have also at times analyzed constant absolute risk aversion (CARA) and hyperbolic absolute risk aversion (HARA). See Daniele Schiliró, Bounded Rationality and Perfect Rationality: Psychology into Economics, 3 THEORETICAL \& PRAC. RES. ECON. FIELDS 101, 107 (2012) (listing alternative utility functions). But see Brunnermeier \& Nagel, supra note 20, at 733 (suggesting that constant relative risk aversion is a reasonable way to approximate risk aversion); Chiappori \& Paiella, supra note 20, at 1024 (same).

68. See supra notes 52, 55. Our estimates of diversification losses may also be too high if investors are saving for retirement and have a lot of control over when they will retire and are relatively indifferent about this date. This option value - to work longer if the market does poorlymay effectively reduce investor's risk aversion. See generally Emmanuel Farhi \& Stavros Panageas, Saving and Investing for Early Retirement: A Theoretical Analysis, 83 J. FIN. ECON. 87 (2007) (exploring a model in which investors choose their retirement dates based in part on market performance and finding that this can cause investors to effectively exhibit less risk aversion when the market does well). 
degrees of confidence in their beliefs about alpha and these other variables. While the expected market volatility is derivable from options prices, ${ }^{69}$ investors' beliefs about idiosyncratic risk and alphas might be less precise. For risk-averse individuals, less precise beliefs about alpha should militate toward demanding even higher alphas because uncertainty about alpha is another form of risk. ${ }^{70}$

Even with these caveats, the take-home result of this section is that investors need to have reasonable expectations that an investment will substantially beat the market before being willing to take on diversification, beta, and excess-fees losses. Financial economists normally expect that stocks will beat government treasuries by somewhere between 3 and 6 percentage points. But an investor who puts all her savings in a single stock would need an additional alpha of at least twice this amount (6.4\% in Table 1) and during crisis periods an alpha of nearly $10 \%$ annually. Moreover, if the opportunity requires the investor to pay excessive fees, the alpha should be calculated net of this excess, and if the investment necessitated a beta deviation, an additional alpha to offset the exposure loss would be required. Investment opportunities with alphas of these magnitudes are not impossible, but they are likely to be sufficiently rare that the law should be quite concerned when fiduciaries advise clients to take on substantial diversification, beta, or excess-fees costs, or in the case of trustees, directly invest the beneficiaries' funds in that manner.

Our concern with the mistaken pursuit of alpha that is not cost justified (Type I errors) leads us to argue below for interpreting fiduciary law to more robustly deter these mistakes. Our goal is, of course, to protect investors. One might object, however, that more complex interests are also at stake. Investors who make alpha bets after seeking out new information or engaging in fundamental valuation of firms help align prices with the discounted cash-flow value of the businesses. This in turn, over the long run, allows the capital markets to allocate scarce capital to the most productive enterprises. Fiduciaries who guide investors to the low-cost, well-diversified baseline by investing in various passive mutual funds and ETFs, by contrast, are to a degree free-riders who do not contribute to price accuracy. Thus, arguably,

69. Faith in the VIX as an accurate measure of expected market volatility has, however, decreased in part because of the unexplainable decline under the Trump presidency during 2017 despite a number of seemingly relevant increases in risk-factors during that period. E.g., Dani Burger, The Mystery of the Stubbornly-Low Volatility Index Is Deepening, BLOOMBERG (May 3, 2017), https://www.bloomberg.com/news/articles/2017-05-03/do-volatility-trackingsecurities-keep-the-vix-artificially-low [https://perma.cc/884M-BDD]. As of late 2018, the VIX had in fact risen substantially, more than doubling from its low during 2017. CBOE Volatility Index $\left({ }^{\wedge} V I X\right)$, YAHOO! FIN. (Dec. 1, 2018), https://finance.yahoo.com/quote/\%5EVIX/ [https://perma.cc/6XK4-K86H].

70. See supra note 47. 
our proposed reforms could reduce price accuracy and, eventually, economic performance.

We take this concern seriously but believe it will have limited effect for a few reasons. First, to the extent our proposals are aimed at retail investors, we think such investors probably do relatively little in the way of price discovery. If we can reduce the number of people who use the broker window in their IRA or 401(k) plans to invest in individual stocks, this will have little effect on how closely market prices track fundamental value. Indeed, because most of these individuals are likely to be "noise traders," to stop investing in individual stocks might even improve price accuracy.

Reducing investment in high-fee, actively managed mutual funds, by contrast, might well marginally reduce price accuracy. It is worth distinguishing between two types of actively managed funds: (1) those which, after fees and de-diversification costs, break even compared with comparable passive indices and (2) those which, after fees and dediversification costs, perform worse than those indices. The funds in the latter category cost more than they contribute in price accuracy. ${ }^{72}$ Crimping investment in these funds will improve investor welfare while likely having a modest effect on price accuracy. Our proposal is not intended to limit investment in funds in the first category, which charge higher fees but obtain enough alpha to exactly offset those costs. These funds may do a significant amount of price discovery. ${ }^{73}$ To the extent fiduciaries eschew these breakeven funds under our proposals, say because recommending investing in passive funds is a clearer way to avoid potential liability, a meaningful amount of price discovery may be lost.

Nevertheless, if price accuracy does decline, the problem will be largely

71. Noise traders are investors who often follow fads or invest based on information that is already impounded in the stock price. See, e.g., J. Bradford De Long et al., The Size and Incidence of the Losses from Noise Trading, 44 J. FIN. 681, 683 (1989) (contrasting noise traders with rational investors).

72. There may be positive externalities from increasing price accuracy, such that high-fee, actively managed funds do not capture the full social gains of their price discovery as part of their trading profits (putting aside the fees they charge). In this case, the fact that the private costs to the funds exceed the trading profits they capture does not mean that it is economically inefficient for them to continue. Even assuming this is true, the current system is problematic if Type I errors for investors and fiduciaries are common. A rational system would not rely on ignorance and agency problems to induce investors to unwittingly subsidize price discovery by high-fee funds. Instead, we would subsidize all forms of socially valuable price discovery.

73. It may seem unrealistic to think many funds are in this knife-edge case, but in fact, as Jonathan Berk and Richard Green have observed, if there is a competitive market for talented investment managers who can generate alpha (at least when managing small portfolios) and one makes some other assumptions, we will find many of these knife-edge funds. The intuition is, partly, that the investment managers will simply end up keeping the alpha they are able to produce, leading to funds whose after-fee performance matches the passive indices. See Jonathan B. Berk \& Richard C. Green, Mutual Fund Flows and Performance in Rational Markets, 112 J. POL. ECON. 1269, 1269-72 (2004) (laying out a model which produces only these knife-edge funds). 
self-correcting. As price accuracy falls, the expected gains from making alpha bets through fundamental valuation or information discovery will increase. This will induce direct investors, and fiduciaries under our rules, to direct more clients into funds making alpha bets based on fundamental valuation or information discovery. Finally, in an era when the financial sector has earned as much as $40 \%$ of total corporate profits, ${ }^{74}$ many people are reasonably concerned that we have devoted too many resources to finance and that many of the activities that are profitable for financial-sector firms do not have commensurate social gains. Reducing the investment in funds that do not earn enough alpha to outweigh their excess fees and the costs of failing to diversify might then be thought of as a salutary reduction in excessive resources devoted to finance.

\section{Legal Implications}

The last two Parts analyzed the theoretical and empirical tradeoffs that often arise when investors pursue alpha investment opportunities. This Part develops the legal implications of these tradeoffs. More particularly, we describe what we call "alpha duties," the legal duties that investment fiduciaries should have before recommending alpha investments or investing in such opportunities on their clients' behalf.

This Part is organized around three types of fiduciaries: (a) trustees, (b) broker-dealers and investor advisers, and (c) 401(k) plan managers. The next section on trustees lays out the core limitations concerning recommendation and actual investment in alpha opportunities, while the subsequent sections explore specialized questions regarding upgraded licensing requirements of broker-dealers and investment advisers as well as "alpha-tized" 401(k) menu selections and fintech warnings.

\section{A. Trustees}

Trust law is typically thought of in the context of personal gratuitous transfers. ${ }^{75}$ These kinds of trusts are important: U.S. banks and trust companies held more than $\$ 600$ billion in assets as trustees of personal trusts in $2017 .^{76}$ This figure understates the true size of personal trusts because it

74. See Jordan Weissmann, How Wall Street Devoured Corporate America, ATLANTIC (Mar. 5, 2013), https://www.theatlantic.com/business/archive/2013/03/how-wall-street-devoured-corporate -america/273732/ [https://perma.cc/9KEK-GTPG] (attributing 40\% of corporate profits in the early 2000s to Wall Street).

75. See John H. Langbein, The Secret Life of the Trust: The Trust as an Instrument of Commerce, 107 YALE L.J. 165, 165 (1997) (observing that this view of trust law dominates how trust law is taught, where it is codified in statutes, etc.).

76. See Fed. Deposit Ins. CorP., Statistics on Depository Institutions: Standard REPORT \#3 (2017), https://www5.fdic.gov/sdi/main.asp?formname=standard [https://perma.cc/D9FG-N2NN] (reporting over $\$ 600$ billion in total fiduciary and related assets in 
does not include those with trustees who are individuals (rather than entities), and other commentators have estimated that personal trusts have at least $\$ 1$ trillion in assets. ${ }^{77}$

In addition, much of what we say here applies to retirement accounts governed by ERISA. As the Supreme Court recently observed in Tibble v.

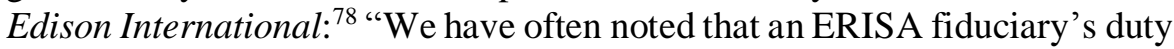
is 'derived from the common law of trusts.' In determining the contours of an ERISA fiduciary's duty, courts often must look to the law of trusts." ${ }^{79}$ As of 2014 there were about $\$ 5.3$ trillion invested in defined contribution ERISA plans (mostly 401(k) plans) and $\$ 3.0$ trillion in defined benefit plans (traditional pension plans in which the employer promises a fixed payout schedule). ${ }^{80}$ Again, these accounts constitute the majority of ordinary Americans' savings not invested in housing. We discuss some issues peculiar to $401(\mathrm{k}) \mathrm{s}$ in the final section of this Part.

In the rest of this subpart, we discuss the basics of trust law, including the trustee's fiduciary duties of loyalty and prudence. The duty of prudence is in turn broken down into many subsidiary duties when applied to trust investing. We address the implications of our results for three of these subsidiary duties, which are well-recognized under current law: (1) the duty to diversify, (2) the duty to take on only risk appropriate for the beneficiary's circumstances, and (3) the duty to incur only reasonable costs. The law regarding the first two of these duties has evolved substantially over the last thirty years. In their modern form, these three duties restrain trustees from making the three central investment mistakes when there is no justification for doing so. The development of the law has been less complete, however, in using these duties to ensure alpha seeking is worth the cost, and we show how our work can help trustees and courts make better decisions on this question.

We then argue that taken together these three duties impose what we have called "alpha duties" on trustees. Under these duties, trustees should calculate the cost of a given alpha-seeking strategy in terms of underdiversification, excess fees and costs, and non-optimal exposure, and

personal trust and agency accounts for 2017).

77. See James R. Hines Jr., Efficient and Impartial Trust Investing 1 (August 2016) (unpublished manuscript) (on file with the University of California, Berkeley School of Law Scholarship Repository), https://scholarship.law.berkeley.edu/cgi/viewcontent.cgi?article $=1091$ \&context=law_econ [https://perma.cc/597M-U4PM] (estimating that U.S. trusts have "aggregate assets that comfortably exceed one trillion dollars").

78. 135 S. Ct. 1823 (2015).

79. Id. at 1828 (citation omitted).

80. EMP. Benefits SEC. AdMin., U.S. DeP'T OF LABOR, PRIVATE PENSION Plan Bulletin HISTORICAL TABLES AND GRAPHS: 1975-2015, 13 tbl.E10 (2018), https://www.dol.gov/sites /default/files/ebsa/researchers/statistics/retirement-bulletins/private-pension-plan-bulletinhistorical-tables-and-graphs.pdf [https://perma.cc/92YC-AT6W]. 
compare that to a reasonable estimate of the expected alpha to decide whether a strategy is prudent. These alpha duties accord with the Third Restatement's approach to prudent active investment. ${ }^{81}$ The duties also serve as a model for what we would propose for fiduciaries in other situations.

1. Trust Basics.-A trust separates the legal and beneficial ownership of property. The trustee is by default given all the powers over the property of an owner to manage and invest it for the advantage of the beneficiaries. ${ }^{82}$ It should also be noted that most trust law is default law-i.e., the person creating the trust (the settlor) can usually opt out if she chooses-but the default is nevertheless highly influential. ${ }^{83}$

2. The Trustee's Fiduciary Duties. - A trustee has two main duties: (1) loyalty and (2) prudence, as well as a variety of subsidiary obligations, which are "applications of prudence and loyalty." 84 Trust law has long contained a stringent duty of loyalty that requires the trustee to manage the trust solely in the interest of the beneficiaries. ${ }^{85}$ While there have been incremental changes, the scope of the duty of loyalty has been largely stable for over a century.

3. Prudence.-By contrast, the duty of prudence, as it applies to trust investments, has undergone substantial changes over the last thirty or so years. Prior to the $1980 \mathrm{~s}$, most states limited the types of property a trustee could invest in either through formal lists or the "constrained prudent man rule." Both doctrines channeled trust property into bonds or real property and banned investment in some or all equities. ${ }^{86}$ The rules frequently prevented

81. See Restatement (ThIRD) OF Trusts $\S 90 \mathrm{cmt}$. (h)(2) (AM. LAW InSt. 2007).

82. UNIF. TRUST CODE $\S 815$ (UNIF. LAW COMM'N 2000) [hereinafter UTC]; UNIFORM PRUDENT INVESTOR ACT § 2(e) (UNIF. LAW COMM’N 1994).

83. See Max M. Schanzenbach \& Robert H. Sitkoff, Did Reform of Prudent Trust Investment Laws Change Trust Portfolio Allocation?, 50 J.L. \& ECON. 681, 682 (2007) (finding that after states adopted new prudent-investor rules, institutional trustees held about $1.5-4.5$ percentage points more equities and less "safe" investments).

84. John H. Langbein, Rise of the Management Trust, TR. \& EST., Oct. 2004, at 52, 54. Fiduciary duties are not the only possible disciplining forces for trustees. Market forces provide some check on commercial trustees who can garner new clients by showing superior investment returns. See Jeffrey N. Gordon, The Puzzling Persistence of the Constrained Prudent Man Rule, 62 N.Y.U. L. REV. 52, 83-84 (1987) (acknowledging that "demonstrably superior performance of a common trust fund helps attract new assets to manage"). This seems likely to be insufficient on its own given the difficulty of separating skill and luck, particularly by trust settlors and others who are usually not investment professionals.

85. See, e.g., In re Will of Gleeson, 124 N.E.2d 624, 627-28 (Ill. App. Ct. 1954) (holding the trustee liable under the "no further inquiry rule" where the trustee benefited from a transaction with trust property, even though the transaction was arguably in the best interest of the beneficiaries).

86. See John H. Langbein, The Uniform Prudent Investor Act and the Future of Trust Investing, 81 IOWA L. REV. 641, 644-45 (1996). 
trustees from giving beneficiaries enough exposure to equities - i.e., the rules forced trustees to make beta mistakes by investing with too low betas-and during the high inflation periods in the 1970s and 1980s, bond-heavy trust portfolios floundered. In addition, it was unclear in some states whether there was a duty to diversify. ${ }^{87}$ These rules ran counter to the finance research and practice, discussed above. ${ }^{88}$

Observing these failures, trust-law reformers succeeded during the 1990s in breaking down the previous constrained approach. The 1994 Uniform Prudent Investor Act (UPIA), eventually adopted in 45 states, abrogated bans on investing in categories of risky assets and instead requires the trustee simply to "invest and manage trust assets as a prudent investor would, by considering the purposes... [and] circumstances of the trust." 89 The remaining states adopted similar measures, although not based on the UPIA language.

Although the prudent investor standard provides useful flexibility, some commentators have complained that it fails to prevent trustees from investing in portfolios that are too risky for the beneficiaries. ${ }^{90}$ Likewise, while the UPIA clarified the importance of the duty to diversify, it provides relatively little guidance as to how much diversification is enough or when circumstances make a relatively undiversified portfolio prudent. Our results can help to address these problems by fleshing out the meaning of appropriate risk and the duty to diversify under the Act.

4. Subsidiary Duties: Prudent Diversification.--Under the UPIA (and the Restatement), the trustee has a duty to diversify the trust portfolio "unless the trustee reasonably determines that, because of special circumstances, the purposes of the trust are better served without diversifying." 91 The official

87. Stewart E. Sterk, Rethinking Trust Law Reform: How Prudent Is Modern Prudent Investor Doctrine?, 95 CORNELl L. REV. 851, 864 n.71 (2010).

88. The Uniform Prudent Investor Act's prefatory note observes:

Over the quarter century from the late 1960's the investment practices of fiduciaries experienced significant change. The Uniform Prudent Investor Act (UPIA) undertakes to update trust investment law in recognition of the alterations that have occurred in investment practice. These changes have occurred under the influence of a large and broadly accepted body of empirical and theoretical knowledge about the behavior of capital markets, often described as "modern portfolio theory."

UNIFORM PRUDENT INVESTOR ACT intro. note (UNIF. LAW COMM'N 1994).

89. Id. § 2; John H. Langbein, Burn the Rembrandt? Trust Law's Limits on the Settlor's Power to Direct Investments, 90 B.U. L. REV. 375, 390 n.113 (2010).

90. See Sterk, supra note 82, at 892 (arguing that the reformers "inadvertently . . . incentivized trustees to overemphasize potential returns even at the cost of excessive risk").

91. UNIFORM PRUDENT INVESTOR ACT $\S 3$; see also RESTATEMENT (THIRD) OF TRUSTS $\S 90$ (b) (AM. LAW INST. 2007) ("[T] he trustee has a duty to diversify the investments of the trust unless, under the circumstances, it is prudent not to do so."). There is a robust debate about whether the duty to diversify is simply a default that can be waived for nearly any reason or is mandatory 
comment lists two common circumstances in which not diversifying might be prudent: (1) if the trust consists in part of property with a low tax basis or (2) if the trust contains a family business. In addition, trust law permits prudent active management of trust assets, ${ }^{92}$ which entails not fully diversifying.

Although the UPIA does not necessarily set up a formal shifting of the burden of persuasion or of going forward, the text of the rule, at a minimum, makes it incumbent on the trustee to make a showing that her decision was reasonable, if she fails to diversify.$^{33}$ But that begs the question: how much concentration of the trust portfolio must a complaining beneficiary show before the trustee owes an explanation? The leading textbook in trusts and estates notes the received wisdom:

In light of the studies showing that diversifying into 20 to 30 unrelated large capitalization stocks removes most of the diversifiable risk from a stock portfolio, a good rule of thumb is that a concentration in a single security of more than 5 percent requires explanation. ${ }^{94}$

Our work shows that during volatile periods when idiosyncratic risk is high, this rule of thumb is probably too loose. A random, market-weighted, portfolio of 50 stocks will have few or no stocks with concentrations above $5 \%$, but will still impose high costs during volatile periods. These underdiversification costs have been up to 150 basis points per year for moderately risk-averse beneficiaries during unsettled periods. ${ }^{95}$ By comparison, during calm periods like 2003-2007 and 2011-2015, a random market-weighted

unless the settlor has a sensible reason to waive it. John Langbein argues that a trust instrument that waives the duty of diversification and directs the trustee to hold only one publicly traded stock, for example, would be so likely to impair the value of the trust that courts should strike the requirement because it runs afoul of the rule that trusts must benefit the beneficiaries. John H. Langbein, Mandatory Rules in the Law of Trusts, 98 Nw. U. L. REV. 1105, 1112-15 (2004). But see Jeffrey A. Cooper, Empty Promises: Settlor's Intent, the Uniform Trust Code, and the Future of Trust Investment Law, 88 B.U. L. REV. 1165, 1166-71 (2008) (arguing the benefit-the-beneficiaries standard does not impede terms that are likely foolish, like requiring the retention of only one stock, but not illegal, immoral, or against public policy).

92. RESTATEMENT (THIRD) OF TRUSTS $\S 90 \mathrm{cmt} . \mathrm{h}(2)$.

93. See, e.g., In re HSBC Bank USA, N.A., 947 N.Y.S.2d 292, 301 (N.Y. App. Div. 2012) ("[T]he prudent investor rule puts diversification at the forefront of the fiduciary's obligations, but allows leeway for the fiduciary to opt out if the beneficiaries require otherwise ...."). The official comments to the UPIA note that "[t]here is no automatic rule for identifying how much diversification is enough." UNIFORM PRUDENT INVESTOR ACT $\S 3 \mathrm{cmt}$.

94. SitKOFF \& DUKEMINIER, supra note 55, at 640. The Restatement (Third) of Trusts $\S 90$ comment $\mathrm{h}(2)$ also observes that in a hypothetical example, 20 stocks selected to provide diversification likely met the duty to diversify. RESTATEMENT (THIRD) OF TRUSTS $\S 90 \mathrm{cmt} . \mathrm{h}(2)$, illus. 14. Our results do not necessarily contradict this but do show that holding 20 stocks selected without considering diversification should usually not be found to meet the duty to diversify during periods of high idiosyncratic risk like periods of market upheaval.

95. See supra Figure 6 (additional alpha required to hold random 50-stock portfolio for CRRA = 2 investor instead of market index). 
portfolio of 10 stocks would have imposed much smaller-although still important - average costs of about 60 basis points for the same investor. This is true despite the 10 -stock portfolio raising serious red flags under the $5 \%$ concentration rule of thumb, while the 50 -stock portfolio would not. ${ }^{96}$ During volatile periods, concentrations of the trust corpus in individual stocks of more than about 3 percentage points over the firm's share of the market as a whole ${ }^{97}$ should usually be considered not diversified, triggering an explanation from the trustee. ${ }^{98}$ If a trustee cannot always quickly shift the portfolio from active management to broad diversification as soon as idiosyncratic risk rises, this suggests the trustee should be more concerned about potential diversification costs even during calm periods than our results above would otherwise indicate.

The arguments above apply with equal force to trustees of defined benefit employee retirement plans under ERISA. These trustees are under a statutory duty to diversify, like the trustees of personal trusts under the UPIA and the Restatement. ${ }^{99}$ For these ERISA fiduciaries, the duty of diversification should likewise be stricter during periods of upheaval when the value of diversification increases. ${ }^{100}$

To give a concrete sense of how our work can provide guidance for courts evaluating whether trustees have fulfilled their duty to diversify, consider a private trust that has invested all of the trust's assets in a single stock. ${ }^{101}$ Assume the trustee justifies the failure to diversify because selling

96. Tightening the rule of thumb has real costs in potentially increasing the number of fiduciary suits and forcing the trustee to spend more time recording her reasons for holding a concentrated position. Still, rearranging the rule of thumb to slide depending on whether it is a relatively calm or relatively volatile period could improve the trustee's incentives without raising total costs.

97. The same is true if the trustee indirectly holds an equivalent position through actively managed mutual funds or some other mechanism.

98. Note that the rule of thumb works only one way. A portfolio that passes the "test" is not necessarily prudently diversified. For example, a portfolio holding only U.S. stocks with no exposure to other risky assets like real estate, international equities, or bonds may not be appropriately diversified.

99. 29 U.S.C. $§ 1104(a)(1)(C)$ (2006); see also Tibble v. Edison Int'l, 135 S. Ct. 1823, 1828 (2015) (citing the UPIA and the Restatement (Third) of Trusts in determining an ERISA fiduciary's duties); James Kwak, Improving Retirement Savings Options for Employees, 15 U. PA. J. BUS. L. 483, 507-08, 513-16 (2013) (examining the relationship between ERISA, the Restatement (Third) of Trusts, and the prudent investor rule).

100. There is some evidence that alpha may be easier to obtain during periods of upheaval. See, e.g., Robert Kosowski, Do Mutual Funds Perform When It Matters Most to Investors? US Mutual Fund Performance and Risk in Recessions and Expansions, 1 Q.J. FIN. 607 (2011) (finding that actively managed mutual funds tend to overperform during recessions even though they underperform on average). This would have a countervailing effect on the desirability of diversification during crisis periods: offsetting alphas rise during these periods but the probability of obtaining a given-size alpha may increase. If the latter effect is real, these two effects would need to be weighed against each other.

101. We provide simplified examples in this subsection and address below complicating issues like how the trustee is supposed to determine the beneficiary's level of risk aversion, how her other 
the stock would trigger a capital gains tax realization. In this case, the alpha the trustee hopes to obtain is from the tax savings and is readily calculable. For simplicity, imagine the stock has a 0 tax basis, average idiosyncratic risk, and a single beneficiary with moderate risk aversion (with a CRRA coefficient of 2) during a relatively calm period. We calculated (in Table 1, supra) the benefit of diversifying would be equivalent to adding $6.3 \%$ to the return to the stock for the year. Ignoring the potential step-up basis at death, ${ }^{102}$ triggering the tax this year rather than postponing it until next year would cost the trust:

$$
\alpha=\left(\tau *(\text { Gains }) * r_{f}\right) *(1-\tau)
$$

where $\tau$ is the tax rate and $r_{f}$ is the risk-free rate. The first part of this equation $\left(\tau *(\right.$ Gains $\left.) * r_{f}\right)$ represents the lost time value of money in failing to delay recognizing the untaxed gains, while the second part $(1-\tau)$, represents the fact that investors only capture the after-tax portion of these gains. This expression represents the excess, alpha-like return the trust can expect from postponing realization. Even taking the risk-free rate as high as $5 \%$, and if $\tau=20 \%$ is the long-term capital gains rate, then the tax benefit to not diversifying is $0.8 \%$ of the value of the untaxed gain and it would be imprudent not to diversify. The alpha benefit from not diversifying $(0.8 \%)$ is outweighed by the cost of failing to diversify $(6.3 \%)$.

With a portfolio that is not as extremely under-diversified, the tax benefits might justify remaining undiversified. For example, if the trust instead held a portfolio of 10 stocks with 0 basis, whether it would be prudent to fully diversify might depend on the volatility of the market. ${ }^{103}$ During volatile periods, the benefits of diversification increase, but the tax benefits are roughly fixed. Thus, during calm periods when the diversification benefits are only around $0.5 \%$, it might be prudent to not fully diversify, thus saving the tax costs of $0.8 \%$. During more volatile times, however, it would be imprudent not to diversify. For example, the average benefit of diversifying during 1999-2001 or 2008-2009 was 2.2\%, well in excess of the $0.8 \%$ tax costs. ${ }^{104}$

Under other circumstances the gains from concentrating the trust portfolio may be harder to calculate, but it can still be important to estimate

assets are invested, etc. See infra note 126 and accompanying text.

102. Under I.R.C. $\S 1014(\mathrm{a})$, a person taking most kinds of property from a decedent receives tax basis equal to the current fair market value, regardless of the decedent's original basis, and accrued capital gains at the time of death will escape income taxation. I.R.C. $\S 1014($ a) (2012). Many trust arrangements, however, particularly those that are irrevocable by the settlor and in which she retains no interest, will not entitle the trust to such a step-up basis at the settlor's death.

103. For purposes of this calculation, we assume the 10 stocks were selected without regard to how well they would diversify the portfolio.

104. Even during the calm periods, it would likely be prudent to sell off part of the low-basis portfolio and diversify that portion. 
the costs of having a concentrated portfolio. For example, trusts are often used to perpetuate family businesses. In these businesses, the benefits of not diversifying are diffuse and difficult to quantify. These benefits include the potential for obtaining returns higher than the market, employment at the firm for family members, perquisites, family sentiment and pride of ownership, etc. Still the trustee can estimate the cost of failing to diversify - that is, the offsetting alpha required to make concentrating the trust assets in the family firm prudent - by using the average of small publicly traded firms in the same sector. ${ }^{105}$ This provides a benchmark against which the benefits of control can be weighed. Moreover, these costs of not being diversified are likely to change significantly over time, with costs rising during volatile periods. Thus, all else equal, a prudent trustee will be more likely to seek or accede to a bid for the family firm in the midst of an unsettled market than in calm periods. ${ }^{106}$ This is true even if the mean expected return for the firm was the same in both periods.

Frequently, the trustee is not only permitted to retain the concentrated position in a family firm but also required to do so by the settlor in the trust instrument. In such cases, the firm's prospects or level of idiosyncratic risk may change in ways not anticipated by the settlor. Increases in risk may force the trustee to petition the court to allow her to sell the firm to avoid serious harm to the beneficiaries. ${ }^{107}$ This is known as an "equitable deviation." Our results demonstrate that courts should be most amenable to these petitions during periods when idiosyncratic risk is high. This is consistent with the most famous equitable deviation case, In re Pulitzer's Estate. ${ }^{108}$

The Pulitzer case arose from the potential sale of the New York World newspaper during the throes of the Great Depression. In 1931, the trustees of Joseph Pulitzer's testamentary trust petitioned the court to allow the sale of the New York World, which the trust was required to hold. At that time, the

105. Thus, the method applied in Table 1 to all stocks could be applied just to publicly traded firms in the same industry. For example, when we do this for the newspaper and periodical field, we estimate an offsetting required alpha of $4.9 \%$ for investors with moderate risk aversion $($ CRRA $=2)$.

106. If, by contrast, the offer is discounted as a result of the poor market conditions, a prudent trustee will not necessarily be more likely to accept it, relative to a better offer during a period with lower idiosyncratic risk. Likewise, individual trustees will often have information about particular downside risks - like the likelihood of losing an important IP suit, etc.- to the family company that may dominate in importance economy-wide changes in idiosyncratic risk when considering bids. Nevertheless, our results suggest that the risk borne by beneficiaries during periods of economic upheaval may increase more than trustees directly anticipate through easily viewed mechanisms like IP suits, etc.

107. The trustee has a duty to petition the court if she knows or should know of changed circumstances that have "the potential ... to cause substantial harm to the trust or its beneficiaries" and can be avoided by changing the terms of the trust. RESTATEMENT (THIRD) OF TRUSTS $\S 66(1-$ 2) (AM. LAW INST. 2003).

108. 249 N.Y.S. 87 (N.Y. Surr. 1931). 
paper was foundering, and the early years of the Great Depression were a period of enormous market upheaval and spikes in idiosyncratic risk. ${ }^{109} \mathrm{~A}$ moderately risk-averse person would have needed to receive a staggering $162 \%$ expected alpha to make her willing to hold only one of the publicly traded newspapers during the period, instead of a diversified portfolio of U.S. stocks, as compared with $19 \%$ from 1926 to September 1929. ${ }^{110}$ Although the court did not use the language of risk, it wisely concluded that changed circumstances unforeseen by Pulitzer required the trustees to be allowed to sell the paper. ${ }^{111}$

Our results also militate toward the possible creation of a new duty, or at least best practice, for the drafter of the trust to warn settlors who are interested in setting up a trust that would depart from the diversified, lowfee, appropriate-risk benchmark about the offsetting alpha that would be required to justify that departure. Courts might even establish a cautionary "altering rule," mandating that to be effective, a trust instrument opting out of the default duty to diversify must indicate that the settlor has been apprised of and understands the alpha tradeoff relevant to the investment restriction that the settlor wishes to put in place.

5. Subsidiary Duties: Prudent Exposure to Risky Assets.-The drafters of the UPIA recognized that no assets are categorically imprudent for all beneficiaries. This allows today's trustees to avoid being forced to make beta mistakes by having too little exposure to equities, unlike the old constrained prudent man approach. The drafters also realized, however, that creating a portfolio with high systemic risk is usually imprudent for trusts meant for highly risk-averse beneficiaries, i.e., "widows and orphans" trusts. ${ }^{112}$ Subpart III(C), infra, quantifies this intuition, showing that, unsurprisingly, the trustee should expect very large alphas before it would be prudent to invest the portfolio of highly risk-averse beneficiaries with full market exposure. A risk-averse investor who but-for the alpha opportunity would

109. See Fox, Fox \& Gilson, supra note 46, at 336 fig. 2 (charting extreme levels of idiosyncratic risk during the Great Depression); see also supra Figure 1.

110. There were six newspaper companies traded on the NYSE or American Stock Exchange during the relevant period. The average (not weighted by market cap) idiosyncratic risk for these firms during 1931 was $6.2 \%$ per day. The alpha calculation is made using the normal distributiondue to the fact that there are not enough firms to use a Monte Carlo simulation - for an investor with a CRRA coefficient of 2 and assuming the worst possible outcome is for the investor to lose $99.9 \%$ of her investment.

111. See Pulitzer, 249 N.Y.S. at 93 (concluding that, in emergencies, a testator has impliedly given the trustee the power to protect the beneficiaries of a trust by selling distressed assets).

112. See UNIFORM PRUDENT INVESTOR ACT $\S 2 \mathrm{cmt}$. (UNIF. LAW COMM'N 1994) (noting that risk tolerance "varies greatly with . . . the purposes of the trust and the relevant circumstances of the beneficiaries," i.e., a trust for a widow should bear less risk than a trust for a young wealthy individual). 
only rationally invest $10 \%$ of her portfolio in equities would need an offsetting annual alpha of $21.4 \%$ before investing in a well-diversified allequity portfolio with a beta of $1 .{ }^{113}$ Opportunities with so much alpha are, of course, rare. By contrast, relatively risk-tolerant individuals $($ CRRA $=1)$ would happily take very low exposure to risky assets if they could obtain alphas one-tenth that size.

Our calculations can serve as benchmarks to help courts understand whether a trustee has taken too much risk in the portfolio. Some scholars have argued that by eliminating the legal list and constrained prudent man approach to trust investing, the UPIA eliminated the main checks on trustees' incentives to take on too much risk without imposing an effective replacement. ${ }^{114}$ They argue that trust settlors choose trustees in part based on the trustees' past investment returns but will not fully account for risk, leading to trustees taking excess risk to try to boost returns and thus attract new customers. ${ }^{115}$ Our results cannot give an exact answer to the appropriate level of risk, but they confirm the intuition that it is likely to be imprudent to invest in portfolios with $\beta$ of .5 or more for highly risk-averse beneficiaries, even when presented with alpha opportunities as large as 360 basis points. By contrast, the trustee of "a trust to accumulate for a young scion of great wealth" ${ }^{116}$ (who is presumably relatively risk-tolerant) can reasonably choose to invest in less risky assets with a $\beta$ that is lower than ideal, say of .5 , if she believes there is an opportunity to gain alpha as little as 50 basis points.

Excessive exposure to market risk becomes more costly during crisis periods, because even with full diversification, the systemic risk of equities tends to be higher during crisis periods. Hence (if the risk premium is assumed to have been unchanged) the cost of taking on inefficiently high market exposure will be particularly high during crises. For example, during the most recent financial crisis market risk more than doubled, leading to the ideal Merton share for investors falling by half, if the risk premium is assumed to be unchanged. This means that a trustee who was taking on only a bit too much systemic risk in the period before the crisis would have been making a much larger mistake during the crisis if she did not scale back the trust's exposure to stocks.

In addition, in both the low-tax basis and family-firm scenarios discussed above, a prudent trustee must consider not only the costs of the failure to diversify, but also the potential mismatch between the ideal

113. See supra Table 3.

114. See Sterk, supra note 82 , at 882,887 (cautioning that market forces alone are unlikely to constrain trustees' risky investment behavior as well as the liability under the old constrained prudent man rule did).

115. Id. at 881-82.

116. UNIFORM PRUDENT INVESTOR ACT $§ 2 \mathrm{cmt}$. (“Risk and return”). 
exposure to risky assets for the beneficiaries and the exposure provided by the concentrated portfolio. ${ }^{117}$

6. Subsidiary Duties: Duty to Incur Only Reasonable Costs.-Trust law recognizes that prudent investment requires the trustee to "incur only costs that are reasonable ...."118 Indeed, the Ninth Circuit recently found that " cost-conscious management is fundamental to prudence in the investment' . . a and should be applied 'not only in making investments but also in monitoring and reviewing investments." "119 Because our empirical analysis of fees is limited, we contain our discussion here to observing that trust law includes a duty to economize on fees, preventing trustees from making one of the fundamental investing mistakes discussed above.

7. Subsidiary Duties: "Alpha Duties," aka Prudent Active Investing.The three subsidiary duties discussed above - the duty to diversify, to take only an appropriate amount of risk, and to incur only reasonable costsshould be thought of together when a trustee is considering an investment program that would likely require significant costs. ${ }^{120} \mathrm{We}$ believe that in such a situation, the three duties, collectively, should be viewed as creating what we call "alpha duties" for the trustee. Under these duties, a trustee must separately calculate the costs of the strategy in terms of excess fees, underdiversification, and exposure and compare it to a reasonable calculation of the expected alpha before investing. Our empirical work shows how trustees could fulfill these duties at a low cost.

Our proposed alpha duties align with the Third Restatement's approach to active investment. The official comment states:

If the extra costs and risks of an [active] investment program are substantial, these added costs and risks must be justified by

117. For concentrated portfolios with relatively low exposure to risky assets, this can lead to counterintuitive results. A prudent trustee given a low beta (e.g., $\beta=.5$ ), low tax basis portfolio of 50 stocks might conclude that she should sell the portfolio if the beneficiaries are highly risk averse or only slightly so but should hold it if the beneficiary is in the middle in terms of risk aversion. For the highly risk averse, the diversification benefits outweigh the tax costs, and for the relatively risktolerant beneficiaries, the costs of having too little exposure to the market may exceed the tax costs. For moderately risk-averse beneficiaries, however, the portfolio provides close to the optimal beta, and the diversification benefits are smaller than for more risk-averse beneficiaries and can thus be less than the tax costs.

118. RESTATEMENT (THIRD) OF TRUSTS $\S 90(c)$ (AM. LAW INST. 2007).

119. Tibble v. Edison Int'1, 843 F.3d 1187, 1197-98 (9th Cir. 2016) (en banc) (quoting RESTATEMENT (THIRD) OF TRUSTS $\S \S 90 \mathrm{cmt}$. b, $88 \mathrm{cmt}$. a).

120. We have analyzed the three duties in separate sections to highlight the implications of our work for each duty, but ultimately, they must be viewed together. If a strategy provides a gross alpha of $2 \%$, but has excess fees of $1.5 \%$ and also imposes under-diversification costs with an offsetting alpha of $1 \%$, it is not prudent, even though the alpha is sufficient to justify either the fees or the departure from diversification. 
realistically evaluated return expectations .... [The] gains from the course of action ... [must] reasonably be expected to compensate for its additional costs and risks. ${ }^{121}$

Moreover, the trustee's duty to keep adequate records includes contemporaneously recording the reason for major investment decisions, like taking on "substantial" costs through an active investment strategy. Under this duty, the trustee's reasoning and calculation of costs and expected alpha should thus be contemporaneously recorded. ${ }^{122}$

Although the Restatement's view-that the duty of prudence requires trustees to only invest actively if the expected alpha is reasonably expected to exceed the costs - makes perfect sense, its influence has been limited thus far. In fact, no court appears to have quoted or cited this comment since it was published in 1992. Perhaps this is not surprising: before our work there have been few attempts to systematically estimate the size of offsetting alphas, and these figures are needed to make the calculations that the Restatement seems to call for. Our analysis therefore has the potential to make applying the Restatement's approach practical and thereby close a hole in the regulation of trust investments.

As with other aspects of the duty to invest prudently, the trustee's alpha duties would be ongoing. "[T]he trustee must systematically consider all the investments of the trust at regular intervals to ensure that they are [still] appropriate." ${ }^{123}$ As discussed above, the duty to revisit portfolio choices is particularly important for strategies that are poorly diversified because our work shows that the costs of such a strategy will often change significantly over time and tend to rise during periods of market upheaval. ${ }^{124}$

The alpha duties we propose for trustees could serve as a model for other areas of fiduciary law. As discussed above, trust law is highly influential on ERISA law, and the arguments we made above largely apply to trustees of defined benefit plans. These kinds of alpha duties would also make sense for

121. RESTATEMENT (THIRD) OF TRUSTS $\S 90 \mathrm{cmt} . \mathrm{h}(2)$. This section was initially published in 1992, before much of the rest of the Third Restatement.

122. As discussed below, many professional fiduciaries already have investment protocols that require this kind of alpha justification for under-diversified portfolios with single holdings making up more than 10 or $20 \%$ of the trust's assets. See infra note 127 and accompanying text. An exception would be made for time-sensitive alpha opportunities, although care must be taken that this exception not be abused.

123. Tibble, 843 F.3d at 1197 (citations omitted) (quoting AMY M. HESS, GEORGE G. BOGERT \& GeORge T. Bogert, THE LAW OF TRUSTS AND TRUSTEES $§ 684$, at 147-48 (3d ed. 2009)) (internal quotation marks omitted).

124. A prudent strategy will often therefore include a VIX contingent trigger that would presumptively trigger a rebalancing of an alpha portfolio toward a more diversified set of investments if market risk became too high. See Alan Moreira \& Tyler Muir, Volatility-Managed Portfolios, 72 J. FIN. 1611, 1611 (2017) ("Managed portfolios that take less risk when volatility is high produce large alphas ...."). 
investments by charitable trusts, as well as guardians, conservators, and executors.

Trustees should also monitor over time and across clients how often their alpha investments actually beat the market. While alpha opportunities are not expected to uniformly produce returns above the market's return, keeping track of return of outcomes compared to the trustee's ex ante alpha assessments can provide valuable feedback that can allow trustees (as well as settlors, beneficiaries, and courts) to update their beliefs about the trustee's ability to identify true alpha opportunities. ${ }^{125}$

\section{Some Answers to Practical Objections to Alpha Duties for Trustees}

a. The Duties Require the Trustee to Gather Too Much Information.As noted above, our analyses serve as benchmarks but cannot be directly applied to the question of whether a particular trust investment strategy is prudent without being adapted to the facts and circumstances concerning the beneficiary of a trust, including among other things, how other savings of the beneficiary are invested, her age, job, etc. A trustee, however, is already under a duty to gather this kind of information. ${ }^{126}$

b. Reasonable Calculations Produce a Range of Offsetting Alphas, Rather than a Single Number.-Of course, some of the information gathered by the trustee may be difficult to quantify exactly, for example, the beneficiary's level of risk aversion. Information of this kind is likely better thought of as falling into some range. Using a range of values for the beneficiary's risk aversion or other parameters will likewise result in a range of offsetting alphas. Similarly, our results depend in part on assumptions like CRRA and, for some calculations, CAPM. Trustees could reasonably use different assumptions and arrive at different estimates, again producing a range of offsetting alphas.

If the strategy at issue could have been reasonably expected to produce alpha exceeding the lower bound of a range that the trustee sensibly calculated, there should be no violation of the trustee's alpha duties.

125. The value of updating decision-maker beliefs based on interim outcomes is central to many areas of evidence-based policy making. See IAN AYRES, SUPER CRUNCHERS: WHY THINKING-BYNuMBERS IS THE NEW WAY TO BE SMART 118, 122-24 (2007) (arguing that parole boards should particularly pay attention to recidivism rates when overriding statistical algorithms and paroling prisoners they deem to be low risk).

126. See RESTATEMENT (THIRD) OF TRUSTS $\S 90 \mathrm{cmt}$. d ("Ordinarily this involves [the trustee] obtaining relevant information about such matters as the circumstances and requirements of the trust and its beneficiaries ...."). Because trustees of employee retirement plans often have thousands of beneficiaries, they would need to use a few representative beneficiaries to make these calculations. On problems created by beneficiaries with conflicting preferences, see Hines, supra note 72, at 10 12 (illustrating such problems through an example of a trust benefiting a widow and her children). 
Reasonable calculations, however, will still rule out many imprudent alphaseeking strategies falling below the lower threshold of the range.

c. Imposing Alpha Duties Will Result in Too Many Suits.-As with other areas of the trustee's duty to invest prudently, there is a temptation for a beneficiary to sue the trustee when things go badly, for example, if the market declines, even when the trustee has acted prudently in implementing an alpha-seeking portfolio. We believe that in order to combat hindsight bias, it is particularly important for courts to focus on the process the trustee used to decide on an alpha-seeking strategy. Courts already place significant emphasis on the trustee's process when confronting claims that the trustee made one kind of potential alpha-seeking mistake: a failure to properly diversify. As a result, most professional trustees already have investment protocols in place that document the reasons for choosing to maintain any relatively concentrated positions (over $10 \%$ or $20 \%$ ) in certain securities. ${ }^{127}$ Courts often find the failure to set up an investment plan in a timely manner or adhere to an internal protocol as strongly probative of whether the trustee has acted imprudently. ${ }^{128}$

In addition, to the extent our proposals create any new duties for trustees (or other fiduciaries discussed below), choosing a passive strategy will be a safe harbor from such duties. ${ }^{129}$ When fiduciaries avail themselves of this safe harbor it will curtail opportunistic suits.

\section{B. Registered Investment Advisers}

Registered investment advisers (hereinafter simply "advisers") provide advice to a substantial slice of retail investors. They help manage approximately $\$ 9$ trillion of individuals' assets. ${ }^{130}$ Unlike a trustee, who holds ultimate investment authority, advisers generally make investment

127. See SitKofF \& DUKEMINIER, supra note 59, at 640 (noting that bank trust departments usually require review and special documentation of portfolios within these parameters).

128. See In re Estate of Janes, 681 N.E.2d 332, 338-39 (N.Y. 1997) (holding that the coexecutor acted imprudently, in part, by failing to adhere to the internal trustee review protocol); In re Hunter, 955 N.Y.S.2d 163, 165 (N.Y. App. Div. 2012) (affirming that the executor violated the prudent person rule by failing to diversify in a timely manner). As one commentator noted, "Trustees who understand both the power of hindsight bias and the weakness of uncorroborated testimony will document every potentially important decision clearly, completely, and contemporaneously." Randall W. Roth, Hindsight Bias and the Curse of Knowledge: Forewarned Is Forearmed, ABA TR. \& INV., Jan.-Feb. 2011, at 30, 33.

129. A passive strategy, of course, is not always prudent regardless of the circumstances. As under current law, it would still be imprudent for a trustee to invest $100 \%$ of trust assets in a lowcost S\&P 500 ETF when the beneficiary is highly risk averse.

130. INV. AdVISER Ass'N, 2017 Evolution REVOLUTION: A PROFILE OF THE INVESTMENT ADVISER PROFESSION 5, 16 (2017), http://www.investmentnews.com/assets/docs /CI111329731.PDF [https://perma.cc/9TLA-39FU] (using data reported to the SEC). 
recommendations, which the client is empowered to reject. As a result, advisers are subject to somewhat less comprehensive fiduciary duties than trustees. Nevertheless, the alpha duties outlined above could be readily incorporated into advisers' existing duties, likely even without additional agency or congressional action.

1. Existing Law.-Advisers are regulated as fiduciaries under the Investment Adviser Act of 1940. The Supreme Court in SEC v. Capital Gains Research Bureau, Inc. ${ }^{131}$ found that the Act imposes on advisers "an affirmative duty of utmost good faith, and full and fair disclosure of all material facts, as well as an affirmative obligation to employ reasonable care to avoid misleading his clients." 132 Therefore, like trustees, advisers must fulfill duties of care and loyalty to their clients. ${ }^{133}$ As part of the duty of care, advisers have a duty to learn their client's needs and to recommend only prudent transactions in light of that, as well as to monitor the client's portfolio. ${ }^{134}$

2. Incorporating Alpha Duties.-Advisers' duty of care can easily be adapted to respond to the analysis of this paper. A recommendation from an adviser that exposes a client's portfolio to significant diversification, beta, or excess-fee losses should only be deemed prudent if the fiduciary meets the alpha duties discussed in the previous section, calculating the costs and the expected alpha. The adviser should also explain this tradeoff to the client. And, as before, advisers should have mechanisms in place to update their recommendations based on evolving market conditions and to keep track of their success across clients with regard to predicting alpha.

As with trustees, investment advisers (and broker-dealers, who are

131. 375 U.S. 180 (1963).

132. Id. at 194 (footnotes omitted) (internal quotation marks omitted). This opinion remains highly influential in defining the scope of advisers' duties. See, e.g., Arthur B. Laby, Fiduciary Obligations of Broker-Dealers and Investment Advisers, 55 VILL. L. REV. 701, 708 (2010) (remarking on the long-lasting influence of Capital Gains).

133. See Donald C. Langevoort, Brokers as Fiduciaries, 71 U. PITT. L. REV. 439, 440 (2010) (concluding that the Supreme Court's decision in Capital Gains "deemed [investment advisers] fiduciaries vis-à-vis their clients, owing them duties of loyalty and care"). These duties are enforceable by private parties or the SEC through the Investment Adviser Act's anti-fraud provision in $\S 206(2)$. Investment Advisers Act of 1940 § 206(2), 15 U.S.C. § 80b-6 (2012). As discussed below, however, private parties' remedies are limited in a suit under the Act.

134. See MLC Ltd., SEC No-Action Letter, 1997 WL 408759, at*1 (July 21, 1997) (providing that an investment adviser "must make suitable recommendations to its clients in light of their needs, financial circumstances[,] and investment objectives"); Suitability of Investment Advice Provided by Investment Advisers; Custodial Account Statements for Certain Advisory Clients, 59 Fed. Reg. 13,464-67 (Mar. 22, 1994) (to be codified at 17 C.F.R. pt. 275) (laying out "suitability obligations under the Advisers Act" and "expressly prohibit[ing] investment advisers from making unsuitable recommendations to clients"); Laby, supra note 124, at 719 (acknowledging the duty of "undertak[ing] a suitability analysis"). 
discussed below) have been criticized for beta mistakes - with courts finding recommendations that expose clients to risks that are excessive given the client's level of risk aversion unsuitable. ${ }^{135}$ But courts have not been sufficiently attentive to what level of alpha could justify beta deviations. Accordingly, suitability inquiries informed by our analysis can lead to more nuanced imposition of liability that simultaneously corrects Type I and Type II errors under the current jurisprudence.

Our alpha duties could be incorporated by the SEC using its regulatory authority to issue rules "defin[ing], and prescrib[ing] means reasonably designed to prevent... deceptive" practices. ${ }^{136}$ Moreover, even without additional action by the SEC, courts could absorb alpha duties into the doctrine by fleshing out the meaning of "full and fair disclosure" and "reasonable care" as used in Capital Gains in light of current best practices in the investment world.

3. Private Remedies Would Remain Limited Absent a Legislative Change.-Even if our alpha duties were incorporated into the obligations of advisers, private remedies for violations of these duties would be somewhat limited. Under the Investment Advisers Act, private parties' relief may only take the form of rescission or restitution, which in practice often means that only the adviser's fees are recoverable after she breaches her duties. ${ }^{137}$ The SEC has a much broader set of remedies at its disposal, including barring the adviser from the industry in the most serious cases.

Full damages are available to a private party against an adviser if Rule 10b-5 has been violated. Rule 10b-5 violations, however, are a subset of potential breaches of the duty of care. This is because a 10b-5 violation requires both a material misstatement (or omission of information necessary to make a statement not misleading) and scienter. ${ }^{138}$ An investment adviser

135. See Thomas P. Lemke \& Gerald T. Lins, Regulation of InVESTMEnt AdVisers $\S 2: 162$ (2018) (stating that advisers should likely not recommend risky assets to clients near retirement); Charles R. Mills et al., Customer Transactions: Suitability, Unauthorized Trading, and Churning ("A recommended securities transaction must comport with the customer's risk tolerance. The mere fact that a customer may be wealthy does not provide a basis for recommending risky investments, if the customer is risk averse."), in BROKER-DEALER REGULATION § 6:1.2, at 6-7 (Clifford E. Kirsch ed., 2011); Jonathan Macey et al., Helping Law Catch Up to Markets: Applying Broker-Dealer Law to Subprime Mortgages, 34 J. CORP. L. 789, 818 (2009) (listing cases where the court found brokers to have given unsuitable recommendations to clients).

136. 15 U.S.C. $\$ 80 b-6(4)$.

137. See, e.g., Morris v. Wachovia Sec., Inc., 277 F. Supp. 2d 622, 643 (E.D. Va. 2003) (explaining that the Investment Advisers Act "creates no private right of action for damages").

138. To recover in a Rule 10b-5 action:

A plaintiff must prove (1) that the securities purchased were unsuited to the buyer's needs; (2) that the defendant knew or reasonably believed the securities were unsuited to the buyer's needs; (3) that the defendant recommended or purchased the unsuitable securities for the buyer anyway; (4) that, with scienter, the defendant made material 
can make an imprudent recommendation without making a misleading statement or without the requisite mens rea. In such cases, 10b-5 claims will fail.

These limitations on private parties' remedies are a mixed bag from a policy point of view. On the one hand, these constraints tend to ameliorate the problems associated with parties simply suing when their investments decline, regardless of the ex ante quality of the fiduciary's decision-making and disclosure. Moreover, unlike with trusts, primary enforcement will then be in the hands of an agency with substantial technical expertise and the ability to shape a coherent enforcement strategy. On the other hand, the SEC may not have the resources or incentives to pursue cases against many violators, leading to undercompliance. In addition, even a successful agency action resulting in a bad actor losing her license may be cold comfort to the victims of imprudent advice who have lost their investments.

\section{Broker-Dealers}

Like advisers, broker-dealers frequently provide investment recommendations to retail clients. At the end of 2009, broker-dealers held over 100 million retail and institutional accounts. ${ }^{139}$ Broker-dealers and advisers therefore often play quite similar roles in providing advice to retail investors. Indeed, retail investors are unsure what distinguishes them. ${ }^{140}$ Nevertheless, they are regulated somewhat differently. Broker-dealers have not traditionally been considered fiduciaries. ${ }^{141}$ As a result, the law today

misrepresentations (or, owing a duty to the buyer, failed to disclose material information) relating to the suitability of the securities; and (5) that the buyer justifiably relied to its detriment on the defendant's fraudulent conduct.

Brown v. E.F. Hutton Grp., Inc., 991 F.2d 1020, 1031 (2d Cir. 1993). To be held liable, an investment fiduciary must have scienter, but some courts have interpreted each of these elements broadly - for example, by finding that mere "recklessness" by brokers is sufficient. See O'Connor v. R.F. Lafferty \& Co., 965 F.2d 893, 899 (10th Cir. 1992) ("Therefore, in our test for unsuitability a plaintiff must show the broker purchased the securities with an intent to defraud or with reckless disregard for the investor's interests."). But see 2 NORMAN S. POSER \& JAMES A. FANTO, BROKERDEALER LAW AND REGULATION $\S \S 17.01,19.03$ (4th ed. 2007) (noting that it is unsettled whether recklessness suffices).

139. U.S. SEC. \& EXCH. COMM'N, STUDY ON INVESTMENT ADVISERS AND BROKERDEALERS, at iii (2011), https://www.sec.gov/news/studies/2011/913studyfinal.pdf [https://perma.cc /U24V-BY28] [hereinafter SEC STUDY].

140. See id. at 98 (reporting that focus-group participants could not distinguish between brokerdealers and investment advisers).

141. See Langevoort, supra note 133, at 440 (noting that broker-dealers have traditionally offered advice in the context of selling, which "is not a fiduciary occupation"). Our Article focuses on the federal regulatory structure, but a minority of states do regulate brokers as fiduciaries. Mark Miller, U.S. States Eye Protections for Investors if Federal Regulation Falters, REUTERS (Apr. 12, 2018), https://www.reuters.com/article/us-column-miller-fiduciary/u-s-states-eye-protections-forinvestors-if-federal-regulation-falters-idUSKBN1HJ1NT [https://perma.cc/C79Q-GR2K]. Brokerdealers are sometimes entrusted with what is called a "discretionary account" that they can invest 
tolerates conflicts of interest in broker-customer relationships that would not be acceptable for advisers under the duty of loyalty.

A significant portion of brokers' compensation for advice comes from commissions paid by mutual funds that the broker receives when she invests a client's assets in the fund. ${ }^{142}$ This arrangement has the potential to bias brokers' recommendations, consciously or unconsciously, toward higher commission funds. Empirical evidence strongly suggests that broker-sold mutual funds underperform the market. Moreover, the greater the commissions paid by the fund, the greater the degree of underperformance, and yet the more assets that are invested in that fund through brokerage accounts. ${ }^{143}$ The Council of Economic Advisers in 2015, for example, estimated that conflicted retirement advice leads to investments that underperform low-cost indices by 100 basis points per year, imposing an estimated $\$ 17$ billion annual cost for savers in IRAs who rely on conflicted advice. ${ }^{144}$ Thus, millions of ordinary savers have been unsuccessfully (and many probably unwittingly) chasing alpha through high-fee, actively managed mutual funds due to conflicted advice.

As a result, two major regulations have been proposed over the last couple of years that aim to curb conflicted advice from brokers. In 2016, the Department of Labor promulgated the "Fiduciary Rule" pursuant to ERISA, which would have substantially changed how brokers provided advice to retirement savers, ${ }^{145}$ but the Fifth Circuit vacated the rule in 2018. ${ }^{146}$ (Although the Fiduciary Rule was promulgated under ERISA, it was aimed

without the client approving each transaction. In such a case, broker-dealers act as fiduciaries, and what we have said regarding investment advisers generally applies. See Langevoort, supra note 133, at 443 (concluding that brokers have fiduciary duties when they control accounts). Broker-dealers may also act as fiduciaries in other circumstances but are not categorically fiduciaries like advisers. Id.

142. A portion of these third-party commissions are " $12 \mathrm{~b}-1$ " fees, which alone totaled $\$ 9.5$ billion in 2009. (Note that not all 12b-1 fees, though, are paid to brokers.) Karen Damato, What Exactly Are 12b-1 Fees, Anyway?, WALL ST. J. (July 6, 2010), https://www.wsj.com/articles /SB10001424052748704009804575309011863641700rs [https://perma.cc/ZBD6-R22V]. One study estimated that "sales loads," which are commissions going to brokers for selling mutual funds totaled another \$6.4 billion in 2002. See Daniel Bergstresser, John M.R. Chalmers \& Peter Tufano, Assessing the Costs and Benefits of Brokers in the Mutual Fund Industry, 22 REV. FIN. STUD. 4129, 4129-30 (2009).

143. See COUNCIL of ECON. AdVISERS, THE EFFECTS OF CONFLICTED INVESTMENT ADVICE ON RETIREMENT SAVINGS 10-11, 13 tbl.4 (2015) (citing academic studies showing that funds sold primarily on commission tend to underperform low cost index funds, and that all else equal, funds with higher commissions receive more fund inflows but underperform by more than funds with lower commissions).

144. Id. at 2.

145. Definition of the Term "Fiduciary"; Conflict of Interest Rule-Retirement Investment Advice, 81 Fed. Reg. 20946, 20950 (Apr. 8, 2016) (to be codified at 29 C.F.R. pts. 2509, 2510, 2550).

146. Chamber of Commerce of the U.S. v. U.S. Dep't of Labor, 885 F.3d 360, 363 (5th Cir. 2018). 
primarily at changing broker-dealers' behavior, and for that reason we discuss it here and not in our ERISA section below.) In April 2018, the SEC proposed "Regulation Best Interest," which, if finalized, would alter the obligations of all broker-dealers regardless of whether their clients are saving for retirement or not. ${ }^{147}$

The SEC's approach is more flexible but arguably weaker than the DOL rule. It relies less on banning certain types of conflicts than the Fiduciary Rule. Instead, the SEC rule uses a standard. It assesses whether a recommendation is in the client's "best interest" by looking at both duty of loyalty-like elements ("How conflicted is the broker?") and duty of care-like elements ("How prudent does the recommendation seem, aside from the conflict?"). Thus, under the SEC rule, the prudence of a recommendation will often play a key role in deciding whether the advice is unacceptably biased toward the broker's self-interest.

Alpha analysis of the type we have done above can help narrow the range of prudent portfolio choices compared to a more basic examination. This in turn can prevent the SEC's rule from permitting some types of conflicted advice that would otherwise meet the rule's requirements if a more limited prudence analysis were done.

\section{Existing Law}

a. Brokers' Suitability Obligations and the Duty of Care Are Similar.Broker-dealers are subject to a FINRA Rule to recommend only "suitable" transactions, which mimics the duty of care of trustees and advisers:

A member or an associated person must have a reasonable basis to believe that a recommended transaction or investment strategy involving a security or securities is suitable for the customer, based on the information obtained through the reasonable diligence of the member or associated person to ascertain the customer's investment profile. ${ }^{148}$

The rule requires broker-dealers to seek to obtain information about "the customer's age, other investments, financial situation and needs, tax status, investment objectives, investment experience, investment time horizon, liquidity needs, [and] risk tolerance ...."149 They must also do

147. See infra subsection $\operatorname{IV}(C)(2)(b)$.

148. FIN. INDUS. REGULATORY AUTH., FINRA MANUAL $\$ 2111$ (2014). A related rule requires members to "know thy customer." Id. § 2090 ("Every member shall use reasonable diligence . . . to know (and retain) the essential facts concerning every customer . . .."); see Macey et al., supra note 127 , at 814 (explaining the "suitability rule" for broker-dealers).

149. Fin. InDUS. REgUlatory AUTH., FINRA MANUAL $\$ 2111$ (2014); see Macey et al., supra note 127 , at 815 (positing that "broker-dealers only recommend to their clients those financial transactions that are suitable"); see also Mills et al., supra note 127, § 6:1.2[A], at 6-6 (emphasizing 
reasonable diligence to understand the security that they are recommending. ${ }^{150}$ This all is quite similar to the duty of care of advisers and trustees.

b. Regulation of Brokers' Potential Conflicts of Interest Is Weaker than Advisers' Duty of Loyalty. - Although not formally constrained by the duty of loyalty, broker-dealers are prohibited from engaging in a variety of selfserving and unethical conduct under both case law and FINRA rules. ${ }^{151}$ Still, as Donald Langevoort has observed:

An adviser is presumably expected to recommend the best available securities for the desired portfolio, taking costs into account. By contrast, a broker has no well-defined obligation to offer the best available securities - just suitable ones with no hidden risks or fees. Within these norms, the broker is free to push what is in inventory, or what is otherwise most profitable to sell, even if there may be other, less costly investments that would satisfy the customers['] risk/return preferences just as well or better. ${ }^{152}$

One might quibble with whether the broker's freedom to push otherwise suitable products that generate higher fees for her is quite so unfettered. Suitability does have a little bit of duty of loyalty-like bite, with the SEC glossing the rule as requiring recommendations be "consistent with [the] customer's best interests." 153 And there are cases finding against brokers for pushing a high-fee mutual fund, which generates higher commissions for the

the importance of "[u]nderstanding a customer's investment objective").

Potentially excessive trading of portfolio investments (possible "churning") is a species of excess fees that should be alpha justified. Under FINRA "quantitative suitability" regulations, broker-dealers are required "to have a reasonable basis for believing that a series of recommended transactions, even if suitable when viewed in isolation, are not excessive and unsuitable for the customer when taken together in light of the customer's investment profile, as delineated in Rule 2111(a)." Fin. IndUS. RegulatORY AUTH., FINRA MANUAL § 2111.05(c) (2014). The regulation's list of factors defining excessive trading activity should include alpha evidence related to the possibility that purchases or sales will yield excess returns. FINRA also regulates excessive fees by prohibiting "breakpoint sale" transactions when a regulated member sells mutual fund shares in dollar amounts just below the point at which the sales commission is reduced on high quantity transactions, so the member can obtain higher compensation. FIN. INDUS. REGULATORY AUTH., FINRA MANUAL $\S 2342$ (2014).

150. See, e.g., Hanly v. SEC, 415 F.2d 589, 595-96 (2d Cir. 1969) (asserting that brokers are "under a duty to investigate").

151. See Langevoort, supra note 133, at 444 \& n.20 (citing cases under the "shingle theory" under which brokers always make an implied representation of fair dealing).

152. Id. at 445.

153. Faber, Exchange Act Release No. 49216, 57 S.E.C. 297, 310 (Feb. 10, 2004); see also FIN. Indus. Regulatory Auth., Regulatory NOTICE 11-02: KNOW YOUR CUSTOMER AND SUITABILITY $7 \mathrm{n} .11$ (2011) ("[I]t is well-settled that a 'broker's recommendations must be consistent with his customer's best interests' and are 'not suitable merely because the customer acquiesces in [them].'”) (citations omitted). 
broker, over an identical fund without the fees and with lower commissions. ${ }^{154}$ Nevertheless, it seems fair to say the law tolerates moreprobably significantly more-potential conflicts of interest for brokers than advisers. This is underscored by the important role played in brokerages of third-party commissions and transactions in which the broker-dealer is on the other side of the deal from the client. This is not true of advisers. ${ }^{155}$

\section{New Regulations Addressing Brokers' Conflicts of Interests}

a. The DOL Fiduciary Rule.-The Department of Labor promulgated its final Fiduciary Rule in April 2016. ${ }^{156}$ The rule was eventually vacated by the Fifth Circuit in 2018, and the Trump administration declined to appeal this ruling, all but sealing its fate. ${ }^{157}$ The rule would have significantly broadened the definition of who becomes a fiduciary by rendering advice regarding retirement plan investments. The old regulation allowed most brokers "comfortably to conclude that they were not acting as ERISA fiduciaries when making most investment recommendations to retail retirement clients." 158

The Fiduciary Rule, by contrast, would have pulled into its ambit most financial professionals, including brokers, making investment recommendations to retail retirement clients. If a broker became a fiduciary, she would be prohibited under ERISA from accepting commissions and other common forms of third-party compensation unless she qualified for an exception like the rule's "Best Interest Contract" exemption. ${ }^{159}$ To qualify for that exemption, brokers would have to, among other things, accept no more than reasonable third-party commissions and commit to acting impartially and in the customer's best interest without regard for their own financial

154. See, e.g., Belden, Exchange Act Release No. 47859, 2003 WL 21088079, at*4 (May 14, 2003) (concluding that a broker put his own interest before that of his client in recommending shares that would provide a "significantly greater commission[]"); FINRA Rule 2111 (Suitability) FAQ, FIN. INDUS. REGULATORY AUTH., http://www.finra.org/industry/faq-finra-rule-2111-suitabilityfaq [https://perma.cc/MDD7-AGR8] (providing examples of unsuitable broker behavior like recommending products based on higher commissions). Note that the words "best interest" do not appear in the FINRA suitability rule, and it is rather a gloss that FINRA and the SEC have put on the rule.

155. See SEC STUDY, supra note 131, at 7 (explaining that "[f]ew investment advisers report[] receiving commission-based compensation").

156. Definition of the Term "Fiduciary"; Conflict of Interest Rule-Retirement Investment Advice, 81 Fed. Reg. 20946 (Apr. 8, 2016) (to be codified at 29 C.F.R. pts. 2509, 2510, 2550).

157. Chamber of Commerce of U.S. v. U.S. Dep't of Labor, 885 F.3d 360, 363 (5th Cir. 2018).

158. Kenneth J. Laverierre \& Matthew H. Behrens, The U.S. Department of Labor's Final "Fiduciary" Rule Incorporates Concessions to Financial Service Industry but Still Poses Key Challenges, 17 J. INV. COMPLIANCE, no. 4, 2016, at 1, 2 (2016). 2017).

159. Id.; Chamber of Commerce of U.S. v. Hugler, 231 F. Supp. 3d 152, 164-65 (N.D. Tex. 
interests. ${ }^{160}$ In addition, brokers becoming ERISA fiduciaries would have other duties of prudence and exclusive benefit, whose violation could expose them to liability. ${ }^{161}$

b. The SEC's Regulation Best Interest.-The SEC proposed its Regulation Best Interest pursuant to $\S 913$ of the Dodd-Frank Act, which required the Commission to study whether the obligations of advisers and broker-dealers should be harmonized, and empowered it to "commence a rulemaking... to address the legal or regulatory standards of care for brokers, dealers, [and] investment advisers ...."162 The provision cautioned, however, that the receipt of "standard" commissions by broker-dealers would not by itself violate any standard the SEC decided to implement. ${ }^{163}$ The SEC's staff report under $\S 913$ recommended bringing the regulations governing broker-dealers fully into line with the fiduciary duties applicable to advisers. ${ }^{164}$

Notwithstanding the report's recommendation, the proposed Regulation Best Interest does not explicitly make brokers into fiduciaries. ${ }^{165}$ The regulation instead seeks to walk a tightrope of permitting broker-dealers to retain a largely commission-based compensation model, while managing the conflicts of interest inherent in that scheme. The SEC expressed concern that too stringent an approach to conflicts would all but eliminate the commission-based advice model, reducing "investor choice" and freezing some investors out of the market for advice. ${ }^{166}$

The actual regulation requires that brokers make recommendations that are in the client's "best interest . . . at the time the recommendation is made, without placing the financial or other interest of the broker ... ahead of the

160. See Hugler, 231 F. Supp. $3 d$ at 165 . The Hugler court noted that advisers may only qualify for the best-interest contract exemption if they take certain steps:

enter into a written contract with the retirement investor, agreeing to: (1) acknowledge their fiduciary status, (2) commit to complying with standards of impartial conduct and to act in the customer's "best interest," (3) receive no more than "reasonable compensation," (4) adopt policies and procedures reasonably designed to minimize the effect of conflicts of interest, and (5) disclose basic information about conflicts of interest and the cost of their advice.

Id.

161. Laverierre \& Behrens, supra note 150 , at 6.

162. Dodd-Frank Wall Street Reform and Consumer Protection Act, Pub. L. No. 111-203, § 913(f), 124 Stat. 1376, 1827 (2010) (codified at 15 U.S.C. § 78o).

163. Id. $\S 913(\mathrm{~g})$.

164. SEC STUDY, supra note 131.

165. See Regulation Best Interest, Exchange Act Release No. 34-83062, 2018 WL 1911162, at *141 (Apr. 18, 2018), https://www.sec.gov/rules/proposed/2018/34-83062.pdf [https://perma.cc/3TG2-ZM9V] (noting that the SEC could extend a fiduciary duty to brokers, implying that it has not).

166. Id. at *11-12. 
interest of the retail customer." 167 It also includes a safe harbor if brokers (1) disclose material conflicts in plain English; (2) comply with the "care obligation"; and (3) maintain policies and procedures to disclose, manage, and eliminate conflicts of interest. ${ }^{168}$ The SEC rule does not ban any practices, though it suggests some are particularly problematic (e.g., sales contests), and states that for some practices, disclosure alone may not meet the third prong of the safe harbor.

The "care obligation" is perhaps a bit of a misnomer because it appears to contain elements of both the duty of loyalty as well as the duty of care. ${ }^{169}$ The obligation tracks the FINRA suitability rule, except with explicit emphasis on the customer's best interest rather than suitability. The SEC has suggested that when a broker recommends products that are more expensive or more remunerative for her, the broker's actions will be scrutinized more heavily as part of the care obligation. ${ }^{170}$

3. Comparing the Two Rules and the Role of Alpha Duties.-At a high level, one can think of the Fiduciary Rule as substantially strengthening brokers' duty of loyalty by banning most sources of conflict unless the broker complies with relatively onerous safeguards. The proposed SEC rule enhances brokers' duty of loyalty-like obligations, but does so less than the Fiduciary Rule and relies more on disclosure. It will not per se ban many conflicts that would violate the Fiduciary Rule. Instead, it will bar those conflicts only on a case-by-case basis if the arrangement fails a combined test using factors including both the duty of care and the duty of loyalty.

The advantage of the SEC's proposal is that it is more flexible and preserves a wider space for investor choice. The SEC is right to worry about freezing savers out of the market for advice. Research shows that retail investors badly need financial advice due to their limited understanding of financial markets. ${ }^{171}$ It seems probable that brokers' somewhat conflicted advice will often result in better portfolios on average than having these investors choose without any professional advice. How important this consideration is, however, depends on how many investors would have been frozen out under the Fiduciary Rule. It is not obvious this number would be

167. Id. at $* 176$.

168. Id.

169. $I d$. at $* 53$.

170. Id. at *55-58; Hillel T. Cohn et al., SEC Proposes a New Standard of Care for BrokerDealers: Regulation Best Interest, MORRISON FOERSTER (Apr. 24, 2018), https://www.mofo.com/resources/publications/180424-sec-regulation-best-interest.html [https://perma.cc/YZ6U-LZVR].

171. See, e.g., Jill E. Fisch et al., The Knowledge Gap in Workplace Retirement Investing and the Role of Professional Advisors, 66 DUKE L.J. 633, 647 \& n.81 (2016) (summarizing the criticisms of the Fiduciary Rule and presenting a survey that shows an important potential role for financial professionals in preventing investors from making a variety of investment mistakes). 
large given that the consensus advice for retail savers is simple and should not be expensive to provide: invest in low-cost, well-diversified funds which provide age-appropriate market risk. Nevertheless, some investors may rationally prefer some of the commission-based advice models, which would not pass muster under the Fiduciary Rule.

The danger of the SEC's proposed course is that its regulation may be too weak and too indirect. The problem giving rise to both regulations is a duty of loyalty issue: brokers' conflicts of interest. By not categorically banning many problematic conflicts using the duty of loyalty, the proposed rule puts more pressure on the duty of care to reveal where conflicts have caused a broker to recommend an imprudent choice. As noted above, this will often take the form of recommending chasing alpha through a high-fee, under-diversified, actively managed fund that pays high compensation to the broker.

Our alpha analysis thus complements the SEC's proposed rule by helping make the duty of care analysis more accurate. Making alpha analysis part of the standard "care obligation" can narrow the range of potentially prudent portfolios. This in turn will help the SEC identify places where brokers are pushing (among other things) high-fee, under-diversified, actively managed funds due to conflicts of interest.

Moreover, the SEC's proposed rule relies more on disclosure than did the Fiduciary Rule. Requiring clear, concise, and salient estimates of the alpha needed to justify investing in high-fee funds - and how infrequently such funds deliver that alpha-might make investors more likely to reject conflicted advice to buy a high-fee or under-diversified fund. These alpha estimates can be provided at relatively low cost, as we discuss below in relation to "robo-advising."

We do not view adding alpha analysis to the "care obligation" and disclosures required under the proposed SEC rule as a panacea, however. The fee structures of the funds recommended by brokers are not secret today, and all that clear disclosure can do is to tell investors that investing in most highfee, under-diversified funds will not pay off. When investors with relatively limited financial sophistication are confronted with (conflicted) advice from an expert to buy a fund, however, it is unclear how much even very obvious disclosures about high fees and alpha can do. ${ }^{172}$ Likewise, enhancing the "care obligations" with alpha duties can only go so far as a substitute for problems brought on by duty of loyalty-like conflicts. Even with alpha

172. See id. at 634-35 (positing improving disclosure as a solution to problems facing investors but concluding that it is "unclear whether disclosure is useful to investors who do not understand the task at hand or the material they must evaluate"); see also Daylian M. Cain et al., The Dirt on Coming Clean: Perverse Effects of Disclosing Conflicts of Interest, 34 J. LEGAL STUD. 1, 5-6, 20 (2005) (arguing that, psychologically, disclosure can sometimes have perverse effects allowing the discloser to engage in greater opportunism while the recipient becomes more trusting). 
analysis, the range of prudent portfolios will still often be fairly wide. If brokers are free under the SEC rule to recommend, within that range, the portfolio that pays them the most, many investors will continue to lose. ${ }^{173}$

4. Changing Licensing Testing.--In addition, the licensing tests for both broker-dealers and advisers should be enhanced to assure that they are cognizant of the three tradeoffs at the heart of our analysis. FINRA currently requires both broker-dealers and advisers to pass exams that include sections covering the suitability requirement. ${ }^{174}$ But the questions on these exams fail to test applicants on whether failures to diversify or take appropriate levels of risk or to minimize investment fees can be justified by expectations of excess returns. ${ }^{175}$ Enhanced testing should assure that broker-dealers and advisers have both a theoretical and empirical understanding about the central alpha tradeoffs. For example, they should not only know theoretically that some alpha is required before sacrificing the benefits of diversification (and that it tends to increase during crisis periods), but they should also know empirically what order of magnitude this alpha must be for clients of different levels of risk aversion. They should be tested on what alpha is required before taking on too much or too little risk for their clients. And, most simply, they should know that any superficially excessive fees on a mutual fund must be alpha justified by even higher alpha expectations. Assuring ex ante that licensed fiduciaries have this kind of knowledge will better position them to follow through on the enhanced alphatized suitability requirements laid out above and hence make more suitable investment recommendations for their clients.

173. Note that like the existing suitability requirements, the proposed Regulation Best Interest would likely not imply a private right of action. See Regulation Best Interest, supra note 157, at 2018 WL $1911162 * 13$ ("Furthermore, we do not believe proposed Regulation Best Interest would create any new private right of action or right of rescission, nor do we intend such a result."). Our comments about limited private remedies with respect to advisers, supra note 137 and accompanying text, thus apply here as well.

174. Before recommending transactions involving stocks, bonds, and a variety of other securities, broker-dealers must, inter alia, pass a 6-hour Series 7 exam. Series 7: General Securities Representative Exam, FIN. INDUS. REGULATORY AUTH., http://www.finra.org/industry/series7 [https://perma.cc/8D5H-XFEM]. Conversely, investment adviser representatives must pass a 3-hour Series 65 exam. Series 65: Uniform Investment Adviser Law Exam, FIN. INDUS. REGULATORY AUTH., http://www.finra.org/industry/series65 [https://perma.cc/J5WL-39N8]. See Michael Kitces, Are the Licensing and Other Requirements to Become a Financial Advisor Too Easy?, KITCES (Aug. 24, 2015), https://www.kitces.com/blog/are-the-licensing-and-other-requirements-tobecome-a-financial-advisor-too-easy/ [https://perma.cc/2PKF-5CPX] for the License Requirements.

175. Test questions do presuppose a knowledge of beta. For example, one question imagines that a client's $\$ 1,000,000$ portfolio has an "aggressive bias towards growth stocks" and says that the portfolio's "beta is 1.4" before asking how many S\&P 500 index puts would be required to hedge the downside risk if the index is "currently at \$2000.00." SERIES 7 PRACTICE EXAM 1, http://www.series7practiceexam.com/series-7-practice-exam-1/ [https://perma.cc/PPC9-RYTN]. 


\section{D. $401(k)$ Fiduciaries}

Finally, we take on the implications of our analysis for 401(k) fiduciaries. Under the Employee Retirement Income Security Act of 1974 (ERISA), sponsors of 401(k) retirement plans who manage the plan or exercise discretionary authority over the plan's assets are fiduciaries and are required to exercise control solely in the interest of plan participants. ${ }^{176}$ But the "safe harbor" provision of the statute- $\$ 404(\mathrm{c})$ - immunizes plan sponsors from fiduciary liability "for any loss, or by reason of any breach, which results from such participant's or beneficiary's exercise of control." 177 To qualify for this safe-harbor protection, plans must satisfy three prerequisites:

First, the participant must have the right to exercise independent control over the assets in his or her account and must in fact exercise such control. Next, the participant must be able to choose from a broad range of investment alternatives, which requires at least three investment options and the plan must permit the participant to give instructions to the plan with respect to those options once every three months. Third, the participant must be given or have the opportunity to obtain sufficient information to make informed decisions with regard to investment alternatives available under the plan. ${ }^{178}$

This third "sufficient information" requirement is particularly relevant.

The Department of Labor should issue new regulations mandating periodic disclosure of individualized participant portfolio analysis as a prerequisite for this safe harbor immunity. While individualized analysis might have been costly in the past, the advent of fintech robo-advisors show that the marginal cost of providing such information is essentially zero. A host of firms including SigFig, Betterment, FutureAdvisors, and Wealthfront currently provide portfolio analysis for free. ${ }^{179}$ The essence of this portfolio review would be to assess potential losses from diversification, beta, or excessive-fees mistakes. The disclosures would include estimates of how much the portfolio would have to be expected to beat the market in order to justify the diversification and other failures. The disclosures should provide

176. 29 U.S.C. $\S 1002(21)(A)(i)$ (2012). These fiduciaries are required to exercise the same degree of care and diligence that a prudent man would demonstrate under similar circumstances. 29 U.S.C. § 1104(a)(1) (2012); see Ayres \& Curtis, Beyond Diversification, supra note 13, at 1489 (explaining the fiduciary duties of plan sponsors under ERISA).

177. Employee Retirement Income Security Act of 1974, Pub. L. No. 93-406, § 404(c)(2), 88 Stat. 829, 877-78 (codified at 29 U.S.C. \$ 1104(c)(ii) (2012)).

178. Tibble v. Edison Int'l, 639 F. Supp. 2d 1074, 1120 (C.D. Cal. 2009) (citations omitted); see also Ayres \& Curtis, Beyond Diversification, supra note 13, at 1490-91 (elaborating on the "safe harbor requirements").

179. The providers often will also manage your portfolio for a fee. Maxime Rieman, Which Online Advisor Is the Best Fit for You?, NERDWALLET, https://www.nerdwallet.com/blog/investing /online-advisor-comparison/ [https://perma.cc/C5JQ-LMFQ]. 
information on specific transactions that would reduce the diversification, exposure, and fee losses. Some additional regulations would likely be necessary to ensure the quality and lack of bias of these disclosures, ${ }^{180}$ but the demonstrated success of SigFig and other fintech companies underscore the feasibility of providing such information. These "alpha-tized" warnings should let participants know how often portfolios with this level of alpha deviation ended up beating the plan's default investment portfolio. ${ }^{181}$ This personalized information fits well with the existing requirements to give participants "the opportunity to obtain sufficient information to make informed decisions." 182

Providing individualized participant portfolio analysis would also enhance disclosure of potential participant investment mistakes on the Form 5500, which plan sponsors are required to file annually with the Department of Labor. The second safe harbor requirement that the "participant must be able to choose from a broad range of investment alternatives" has been found to require a compliant plan to give participants the opportunity to diversify away most idiosyncratic risk. ${ }^{183}$ But the current

180. Critics have argued that existing robo-advisors have a number of problems, including not offering sufficiently personalized advice and being subject to various conflicts of interest. See generally Melanie Fein, Robo-Advisors: A Closer Look, BANKING \& INS. EJOURNAL (Sept. 23, 2015), https://papers.ssrn.com/sol3/papers.cfm?abstract_id=2658701 [https://perma.cc/ H9VN-Y6XG] (explaining the issues associated with robo-advisors). For our scheme to work, the DOL would need to promulgate new regulations to ensure that the robo-advisors solicit enough information about the investor's outside assets and investment horizon to make the loss calculations reasonably reliable and recommendations suitable, as well as free from conflicts of interest.

181. ERISA allows plans to establish default investments, so-called QDIAs (Qualified Default Investment Alternatives) — which must be tailored to avoid two of the three central investment mistakes (lack of diversification and non-optimal exposure to equities). Ayres \& Curtis, Beyond Diversification, supra note 13, at 1516, have argued for an Enhanced QDIA that would also mandate non-excessive fees. Ideally, the alpha-tized warnings would reveal how often plan participants with alpha deviations of various magnitudes end up beating the Enhanced QDIA - and that plans without a default investment announce a qualifying comparator portfolio for these disclosure purposes.

182. Tibble, 639 F. Supp. $2 \mathrm{~d}$ at 1120 . Another low-cost opportunity for improved personalized disclosure concerns "mapping": the default reinvestment of participant savings into a sponsorchosen fund when a pre-existing menu option is discontinued. At the moment, plan sponsors send participants warnings that, absent participant objection, investments will be mapped into the new fund - regardless of whether participants have invested in the discontinued fund. As a result of this untailored disclosure, most mapping disclosures have no relevance to most participants who learn over time to ignore them. See Ian Ayres, The Problem of 401(k) Mapping to Dominated Funds, FORBES (Mar. 29, 2014), https://www.forbes.com/sites/whynot/2014/03/29/the-problem-of-401kmapping-to-dominated-funds/\#7d66d0e96974 [https://perma.cc/4J8W-HQTP] (stating that "many employees don't pay attention to plan notices"). Instead, mapping warnings should only go to participants who are currently invested in the fund that is to be discontinued. The warnings should disclose the expense ratio of both the discontinued and default funds to which the investments will be mapped, and whether the mapping will increase the offsetting alpha necessary to justify diversification, exposure, or excess-fee losses.

183. See Ayres \& Curtis, Beyond Diversification, supra note 13, at 1490, 1501 (estimating that menu diversification failures are equivalent to just 5 basis points of lower return). 
Form 5500 disclosure does not give regulators or sponsors any way to tell whether individual participants are taking undiversified positions. ${ }^{184}$ Fintech algorithms could be easily programmed to provide aggregate information about the extent of diversification, exposure, or excess-fee losses and how often these losses are in fact offset by market-beating returns. ${ }^{185}$

The foregoing 401(k) proposals fit comfortably within the current $\S 404$ (c) safe harbor regime and the definition of fiduciary under the Act and could be implemented by enlightened DOL regulation. However, our analysis also has potential implications for more far-reaching reforms to reduce the likelihood of investment error. To begin, plan sponsors might be required to assess whether their menu offerings are alpha justified. For example, the choice to offer corporate stock is likely to harm participants (whose human capital is often already overexposed to their employer's fate) by needlessly increasing idiosyncratic risk if participants invest too large a percentage of their savings portfolio in this single equity. Offering undiversified menu offerings is problematic if the plan sponsor has not considered the offsetting alpha necessary to justify the probable failures of participant diversification. Similarly, plan sponsors should be asked whether menu offerings are alpha justified given the tendency of participants to naively diversify by putting some of their savings in every menu offering. ${ }^{186}$ Sponsors should consider whether their menus include funds that are "dominated" by other menu options, and if so whether the fund's presumptive losses might plausibly be justified by offsetting expected alpha. ${ }^{187}$

In addition to providing participants with enhanced, individualized information about their portfolios, ERISA might go further and require participants to pass a "Retirement Plan Investment Sophistication" test before investing in portfolios that need an offsetting alpha of over $1 \%$ annually. This testing requirement is an example of an altering rule that "reduces the likelihood of error by requiring individuals to demonstrate actual knowledge of the issues related to opt out before they can deviate from the status quo." 188

184. The form requires disclosure of aggregate plan investments, which might substantially mask diversification problems (for example, if some participants are solely invested in bonds while others are solely invested in equities).

185. It might also be advisable to analogously require that broker-dealers report the extent to which their clients' portfolios are not fully diversified.

186. See generally Shlomo Benartzi \& Richard H. Thaler, Naive Diversification Strategies in Defined Contribution Saving Plans, 91 AM. ECON. REV. 79 (2001) (analyzing why participants divide their contributions evenly among the options offered).

187. As defined by Ayres and Curtis, a menu offering is dominated if no rational investor would invest funds in this option given the other option available on the menu. Ayres \& Curtis, Beyond Diversification, supra note 13, at 1504-05. A high-cost S\&P index option would be an example of a dominated fund if a lower-cost S\&P index were also available. Ayres and Curtis found that nearly half of 401(k) plans that they analyzed included dominated funds in their menus and that these dominated funds garnered $11.5 \%$ of plan assets. Id. at 1506 .

188. Ayres \& Curtis, supra note 24 , at 1525. 
Train and test altering has been deployed in other high-stakes settings (such as student loans and human-subjects approval ${ }^{189}$ ) and has been recommended for testing securities sophistication. ${ }^{190}$ Participants who demonstrate by passing the test that they are aware of the kinds of tradeoffs at the core of our analysis would be free to seek alpha in ways that exposed them to some mixture of diversification, exposure, or excess-fee losses. But the vast majority of shareholders would be restricted from pursuing nonstandard investment strategies. ${ }^{191}$

Returning briefly here to the issue of brokers giving retirement savers conflicted advice, requiring such retirement investors to pass a test concerning alpha tradeoffs before putting their savings in high-fee, underdiversified funds would be more effective in combatting conflicted investment advice than simple disclosure. A policy based on testing-while defensible both as consumer protection and conserving the taxpayer subsidy implicit in IRAs - might well be politically infeasible, however. As with the Fiduciary Rule and (to a lesser extent) Regulation Best-Interest, it would engender strong opposition from parties who benefit from the current system. Moreover, it might prove far more unpopular with the public than either of those regulations because it would deem a significant portion of the population not informed enough to pass the test.

Our finding that the size of offsetting alpha can vary substantially over time also suggests that plans might institute an automatic remapping of participant portfolios. A portfolio that, for example, starts bearing more costly idiosyncratic risk during a period of market upheaval might by default be mapped into a portfolio that requires less of an offsetting alpha unless the participant owner either passes the sophistication test (and thereby gains the right to make alpha-opportunity bets) or, before the mapping, the participant self-directs the investments to a portfolio with sufficiently lower diversification, exposure, and excess-fee losses.

189. The 2008 Higher Education Opportunity Act encourages institutions administering student loan programs to use "interactive programs that test the borrower's understanding of the terms and conditions of the borrower's loans ... using simple and understandable language and clear formatting." 20 U.S.C. $§ 1092(l)(1)(B)$ (2012) (emphasis added). Health Insurance Portability and Accountability Act (HIPAA) regulations require researchers to train and test on the requisite privacy protection before they can access personal health information. 45 C.F.R. $\S 164.530$ (b) (2017).

190. A 2009 Forbes article suggested that sophisticated investors "should be required to meet minimum qualifications, attend a few educational classes[,] and pass a basic test of knowledge of the markets." John E. Girouard, The Sophisticated Investor Farce, FORBES (Mar. 24, 2009), http://www.forbes.com/2009/03/24/accredited-investor-sec-personal-finance-financial-advisornetwork-net-worth.html [https://perma.cc/QG86-AHXU].

191. The possibility of a sophistication test is also explored by Ayres and Curtis in Beyond Diversification, supra note 13 , at 1525 , albeit without testing participants' knowledge of alpha tradeoffs. 


\section{Conclusion}

Instead of prohibiting investment fiduciaries from recommending or allowing clients to "seek alpha," we have proposed making sure that the fiduciaries understand how much alpha is required to offset specific kinds of losses. Failures to minimize fees, to fully diversify, or to get the right amount of market exposure can be justified by sufficient expectations that a portfolio will generate above-market returns. This Article has estimated how much alpha is necessary to offset these particular kinds of portfolio losses which arise from departing from the low-fee, well-diversified, appropriate market exposure baseline. Requiring that fiduciaries understand and explicitly weigh these alpha tradeoffs might reduce both Type I and Type II errors. Some fiduciaries will refrain from pursuing alpha investment opportunities when they learn that the benefit of the expected alpha is outweighed by the expected losses. ${ }^{192}$ Other fiduciaries who are now deterred from alpha opportunities may discover that the expected benefits of some of these investments outweigh their costs.

It is not necessarily stupid to put all of your retirement eggs in one basket. But most people who do so are making a grave mistake. This Article integrates both of these maxims by acknowledging that alpha opportunities can render nonstandard investment strategies rational and showing that the required offsetting alpha to justify diversification, exposure, and excess-fee losses are often surprisingly large.

192. Reducing Type II errors might exacerbate the problem of "common ownership" if firms that compete in product or service markets become increasingly owned by very diversified shareholders. See Einer Elhauge, Horizontal Shareholding, 129 HARV. L. REV. 1267, 1303-04 (2016) (arguing that the common ownership of companies whose outputs are in the same product market can lead to anticompetitive effects); see generally David Gilo et al., Partial Cross Ownership and Tacit Collusion, 37 RAND J. ECON. 81 (2006); Erik P. Gilje et al., The Rise of Common Ownership 2 (June 6, 2017) (unpublished manuscript) (on file with author). However, the potential anticompetitive effect of inducing increased diversification can be remedied by other government interventions. See, e.g., Eric A. Posner et al., A Proposal to Limit the Anticompetitive Power of Institutional Investors, 81 ANTITRUST L.J. 669 (2017) (arguing that passive funds should be allowed to hold a large stake in only one firm in a given oligopolistic industry, which would lead to only relatively small diversification losses and significantly lessen anticompetitive effects). See generally Ian Ayres \& Stephen F. Ross, "Pro-competitive Executive Compensation" as a Condition for Approval of Mergers that Simultaneously Exploit Consumers and Enhance Efficiency, CANADIAN COMPETITION REC., Spring 1998 (proposing that mergers be conditioned on "pro-competitive compensation packages"). 